RONNIE CHTCOT BRITO

Acelerogramas artificiais de sismos aplicados a edificações 
RONNIE CHTCOT BRITO

\section{Acelerogramas artificiais de sismos aplicados a edificações}

Dissertação apresentada à Escola Politécnica da Universidade de São Paulo como parte dos requisitos para obtenção do título de Mestre em Ciências pelo Programa de Pós-graduação em Engenharia Civil.

Área de Concentração: Engenharia de Estruturas e Geotécnica

Orientador: Prof. Livre-Docente Reyolando Manoel Lopes Rebello da Fonseca Brasil

São Paulo 
Este exemplar foi revisado e corrigido em relação à versão original, sob responsabilidade única do autor e com a anuência de seu orientador.

São Paulo, de de

Assinatura do autor:

Assinatura do orientador:

FICHA CATALOGRÁFICA

\section{Brito, Ronnie Chtcot}

Acelerogramas artificiais de sismos aplicados a edificações / R. C. Brito versão corr. -- São Paulo, 2017.

$77 \mathrm{p}$.

Dissertação (Mestrado) - Escola Politécnica da Universidade de São Paulo. Departamento de Engenharia de Estruturas e Geotécnica.

1.Dinâmica das estruturas 2.Análise sísmica 3.Acelerograma artificial 4.Shear building 5.Elastoplasticidade I.Universidade de São Paulo. Escola Politécnica. Departamento de Engenharia de Estruturas e Geotécnica II.t. 


\section{Resumo}

BRITO, Ronnie Chtcot. Acelerogramas artificiais de sismos aplicados a edificações. 2017. 77f. Dissertação (Mestre em Engenharia) - Departamento de Engenharia - Estruturas, Escola Politécnica, Universidade de São Paulo, São Paulo, 2017.

Apesar de fortes eventos sísmicos serem raros no Brasil, engenheiros estruturais brasileiros são frequentemente envolvidos em tal análise para os países latino-americanos vizinhos. Informações sobre históricos de aceleração sísmica, de natureza aleatória, não estão em geral disponíveis, devido, em parte, à falta de registros. Para contornar tal situação, os códigos de construção indicam o uso de acelerogramas artificiais, mas não fornecem metodologia para sua obtenção. A informação normalizada é o chamado espectro de resposta elástico, que fornece a aceleração de resposta máxima para um sistema linear de um grau de liberdade. Muitas pesquisas estão sendo desenvolvidas a fim de gerar acelerogramas artificiais compatíveis com os espectros de norma. Assim, neste trabalho se apresenta uma proposta para a geração de acelerograma artificial compatível com espectro de resposta regulamentar. Para exemplo de aplicação, é gerado um acelerograma artificial compatível com a Norma Brasileira NBR 15421: 2006 e aplicado à base de um edifício shear building de dez pavimentos e através de integração numérica por diferenças finitas passo-a-passo no domínio do tempo é calculado o deslocamento do último pavimento deste edifício. De forma semelhante, é gerado um acelerograma artificial compatível com a Norma Venezuelana COVENIN 1756: 2001 e aplicado à base de um reservatório d'água sobre quatro pilares e estudado o seu comportamento elastoplástico perfeito.

Palavras-chave: dinâmica das estruturas, análise sísmica, acelerograma artificial, shear building, elastoplasticidade. 


\begin{abstract}
BRITO, Ronnie Chtcot. Acelerogramas artificiais de sismos aplicados a edificações. 2017. 77p. Dissertation (Master of Engineering) - Department of Structural Engineering, Polytechnic School, University of São Paulo, São Paulo, 2017.

Although strong seismic events are rare in Brazil, Brazilian structural engineers are often involved in such an analysis for neighboring Latin American countries. Information on seismic acceleration histories of a random nature is not generally available, due in part to the lack of records. To circumvent such a situation, building codes indicate the use of artificial accelerograms, but do not provide a methodology for obtaining them. The normalized information is the so-called elastic response spectrum, which provides the maximum response acceleration for a linear system of a degree of freedom. Many researches are being developed in order to generate artificial accelerograms compatible with the norm spectra. Thus, this paper presents a proposal for the generation of an artificial accelerogram compatible with a regulatory response spectrum. For an application example, an artificial accelerogram compatible with the Brazilian Standard NBR 15421: 2006 is generated and applied to the base of a ten-story shear building and through numerical integration by finite differences step-bystep in the time domain is calculated the displacement of the last floor of this building. Similarly, an artificial accelerogram is generated that is compatible with the Venezuelan Standard COVENIN 1756: 2001 and applied on the basis of a water reservoir on four pillars and studied its perfect elastoplastic behavior.
\end{abstract}

Keywords: Structural dynamics, seismic analysis, artificial accelerograms, shear buildings, elastoplasticity. 


\section{Lista de figuras}

Figura 1 - Conceito de espectro de resposta ................................................................... 18

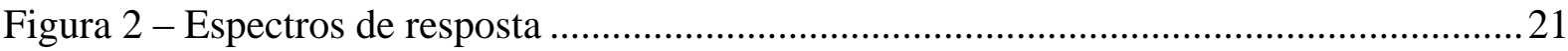

Figura 3 - Comportamento de uma estrutura muito rígida (a) e muito flexível (b) .................22

Figura 4 - Representação combinada de Espectro de resposta .............................................23

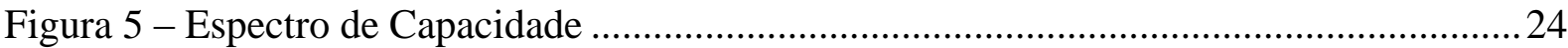

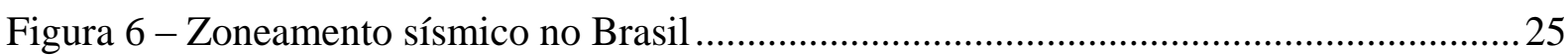

Figura 7 - Espectro de resposta de projeto - ABNT NBR 15421 (2006)................................26

Figura 8 - Espectro de resposta de projeto - COVENIN 1756 (2001) .....................................30

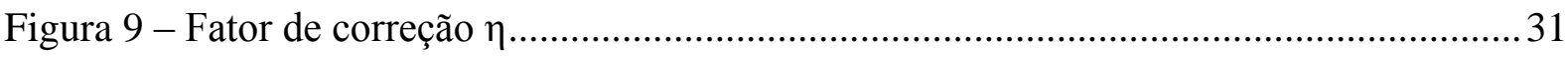

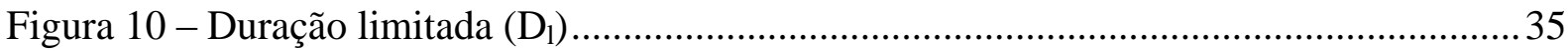

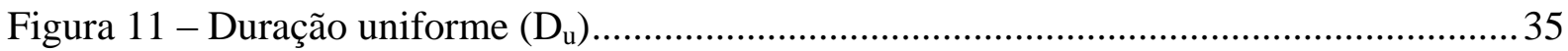

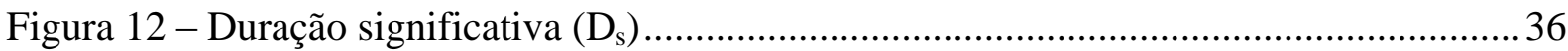

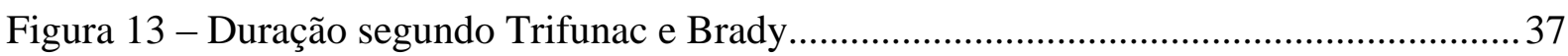

Figura 14 - Funções de intensidade para simular o caráter transitório dos sismos reais ..........37

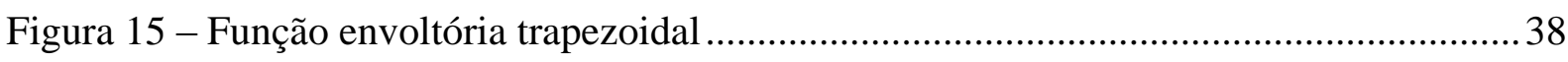

Figura 16 - PSD compatível com Espectro de resposta ...................................................... 41

Figura 17 - Modelo de edifício shear building. (a) Modelo sísmico; (b) equilíbrio de forças 48

Figura 18 - Modelo de edifício shear building .................................................................... 51

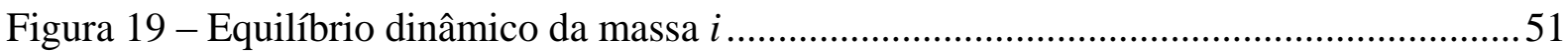

Figura 20 - Relação força-deformação do aço - comportamento elastoplástico ......................54

Figura 21 - Comportamento elastoplástico real e idealizado elastoplástico ............................54

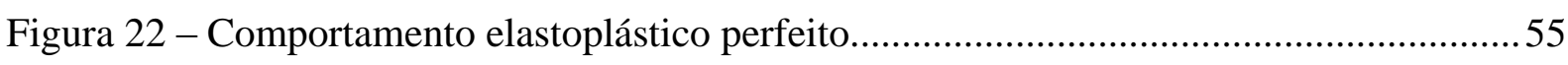

Figura 23 - Esquema elástico (a) e elastoplástico (b) .............................................................56

Figura 24 - Espectro de resposta NBR 15421(2006) - Caso A ..............................................58

Figura 25 - PSD compatível com espectro de resposta - Caso A...........................................59

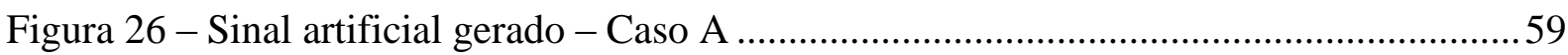

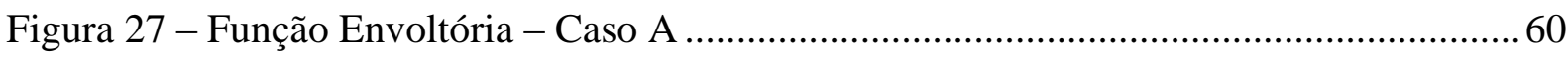

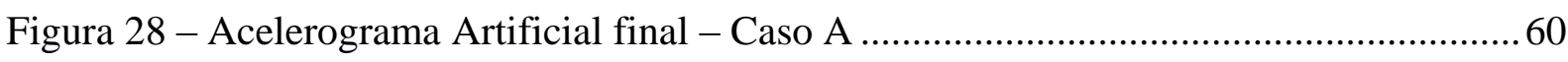

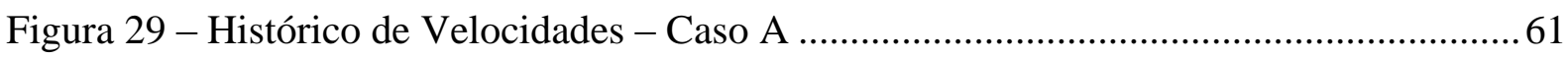

Figura 30 - Histórico de Deslocamentos - Caso A ................................................................ 61

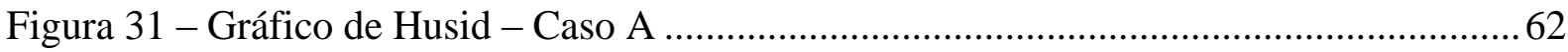

Figura 32 - Função Envoltória de Intensidade - Caso A ........................................................ 62 


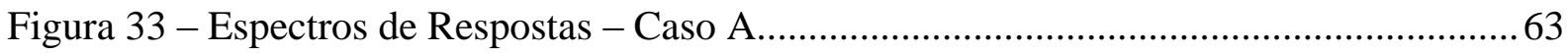

Figura 34 - Deslocamento no tempo do último pavimento - Caso A......................................64

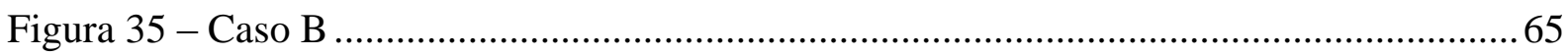

Figura 36 - Espectro de resposta COVENIN 1756(2001) - Caso B.....................................65

Figura 37 - PSD compatível com espectro de resposta - Caso B ..........................................66

Figura 38 - Acelerograma Artificial final - Caso B ........................................................66

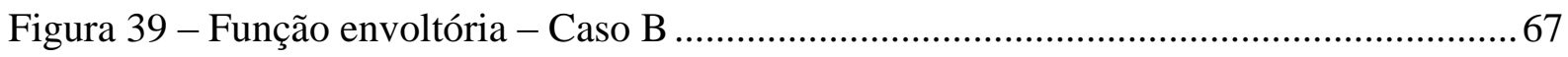

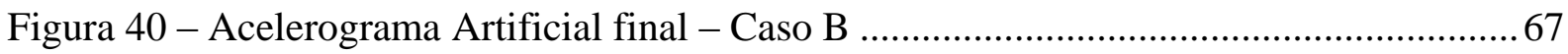

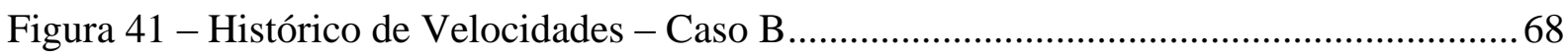

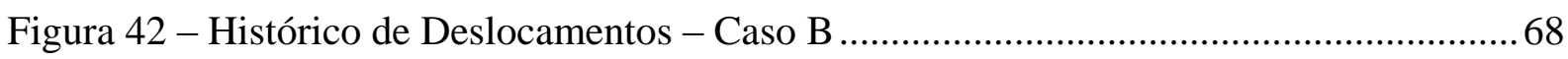

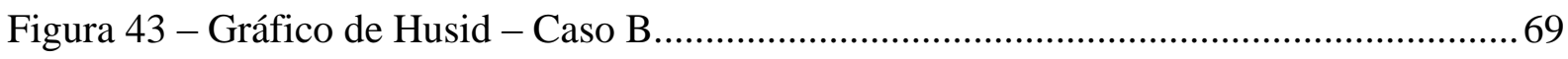

Figura 44 - Função Envoltória de Intensidade - Caso B ....................................................... 69

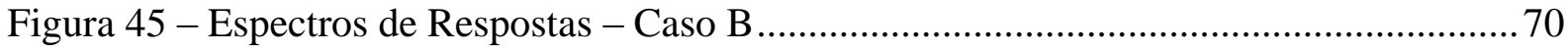

Figura 46 - Deslocamento no tempo com plastificação - Caso B ......................................... 71

Figura 47 - Força restauradora no tempo com plastificação - Caso B ................................... 71

Figura 48 - Deslocamento no tempo sem plastificação - Caso B........................................ 72

Figura 49 - Força restauradora no tempo sem plastificação - Caso B................................... 72 


\section{Lista de tabelas}

Tabela 1 - Fator de amplificação dinâmica - ABNT NBR 15421 (2006).................................27

Tabela 2 - Classificação do solo - ABNT NBR 15421 (2006) ..............................................27

Tabela 3 - Coeficiente de aceleração horizontal - COVENIN 1756 (2001) ...........................28

Tabela 4 - Forma espectral e Fator de correção $\varphi$ - COVENIN 1756 (2001) ........................28 


\section{Lista de símbolos}

\section{Capítulo 3}

\begin{tabular}{|c|c|}
\hline$x(t)$ & deslocamento do sistema em função do tempo \\
\hline$\dot{x}(t)$ & velocidade do sistema em função do tempo \\
\hline$\ddot{x}(t)$ & aceleração do sistema em função do tempo \\
\hline$\omega$ & frequência natural de vibração \\
\hline$v$ & taxa de amortecimento crítico \\
\hline$\ddot{y}(t)$ & aceleração do movimento sísmico do solo \\
\hline$S_{d}$ & pseudoespectros de resposta de deslocamentos \\
\hline$S_{v}$ & pseudoespectros de resposta de velocidades \\
\hline$S_{a}$ & pseudoespectros de resposta de acelerações \\
\hline $\mathrm{T}$ & período natural de vibração \\
\hline$C_{a}$ & fator de amplificação sísmica no solo, para o período $\mathrm{T}=0,0 \mathrm{~s}$ \\
\hline$C_{v}$ & fator de amplificação sísmica no solo, para o período $\mathrm{T}=1,0 \mathrm{~s}$ \\
\hline$a_{g}$ & aceleração característica de projeto \\
\hline$a_{g s 0}$ & aceleração espectral para o período $\mathrm{T}=0,0 \mathrm{~s}$ \\
\hline$a_{g s 1}$ & aceleração espectral para o período $\mathrm{T}=1,0 \mathrm{~s}$ \\
\hline$g$ & aceleração da gravidade \\
\hline $\bar{V}_{s}$ & velocidade de propagação das ondas de cisalhamento \\
\hline$H$ & profundidade cuja $\bar{V}_{s}$ é maior que $500 \mathrm{~m} / \mathrm{s}$ \\
\hline$A_{d}$ & aceleração espectral \\
\hline$a$ & fator de importância \\
\hline$A_{0}$ & coeficiente de aceleração horizontal \\
\hline$\varphi$ & fator de correção do coeficiente de aceleração horizontal \\
\hline$\beta$ & fator de amplificação médio \\
\hline$T_{0}$ & período a partir do qual o espectro possui valor constante \\
\hline$T^{*}$ & máximo período do espectro de resposta \\
\hline$R$ & fator de redução de resposta \\
\hline
\end{tabular}




\section{Capítulo 4}

\begin{tabular}{|c|c|}
\hline$a(t)$ & acelerograma artificial em função do tempo \\
\hline$a^{\prime}(t)$ & acelerograma artificial corrigido em função do tempo \\
\hline$n$ & número de iterações \\
\hline$I(t)$ & função envoltória \\
\hline$t_{f}$ & tempo de duração do sismo \\
\hline$\theta_{\mathrm{i}}$ & ângulos de fase gerado aleatoriamente entre 0 e $2 \pi$ \\
\hline$\omega i$ & frequências consideradas na série harmônica \\
\hline$A_{i}$ & amplitude do sinal artificial \\
\hline$D_{l}$ & duração limitada \\
\hline$D_{u}$ & duração uniforme \\
\hline$D_{s}$ & duração significativa \\
\hline$I_{A}$ & intensidade de Arias \\
\hline$g$ & aceleração da gravidade \\
\hline$G_{\ddot{U} g}$ & densidade espectral de potência (PSD) \\
\hline $\mathrm{G}_{0}$ & valor de pico do PSD \\
\hline$\sigma^{2}$ & variância de uma função \\
\hline$S_{a}$ & pseudoespectros de resposta de acelerações \\
\hline$\xi$ & taxa de amortecimento \\
\hline$\eta_{U}$ & fator de pico \\
\hline$\delta_{U}(\xi)$ & fator de propagação \\
\hline$\rho ; L ; \gamma$ & coeficientes para definição do PSD \\
\hline$e_{1} ; e_{2} ; e_{3}$ & coeficientes para definição do PSD \\
\hline$\beta_{2 ;} \beta_{3}$ & coeficientes para definição do PSD \\
\hline$c_{0}, c_{1}, c_{2} ; b_{k}$ & coeficientes de correção do acelerograma \\
\hline$v(t)$ & velocidade correspondente a $a(t)$ \\
\hline$S_{v}$ & pseudoespectros de resposta de velocidades \\
\hline
\end{tabular}

expoente que define o ramo descendente do espectro fator de correção da taxa de amortecimento taxa de amortecimento 


\section{Capítulo 5}

\begin{tabular}{|c|c|}
\hline$F_{i}$ & força de inercia \\
\hline$F_{e}$ & força elástica \\
\hline$F_{a}$ & força de amortecimento \\
\hline$[M]$ & matriz de massa \\
\hline$[K]$ & matriz de rigidez \\
\hline$[C]$ & matriz de amortecimento \\
\hline$\{u(t)\}$ & vetor de deslocamentos \\
\hline$\{\dot{u}(t)\}$ & vetor de velocidades \\
\hline$\{\ddot{u}(t)\}$ & vetor de acelerações \\
\hline$a(t)$ & aceleração em função do tempo \\
\hline$k_{i}$ & rigidez da estrutura \\
\hline$E$ & módulo de elasticidade do material \\
\hline$I$ & momento de inércia \\
\hline$l_{i}$ & comprimento do pilar \\
\hline$\omega$ & frequências natural de vibração \\
\hline$\alpha_{1} ; \alpha_{2}$ & coeficientes da matriz de amortecimento de Rayleigh \\
\hline$\xi$ & taxa de amortecimento \\
\hline$m_{i}$ & massa concentrada no nó i \\
\hline$w_{i}$ & força de inércia do nó i \\
\hline$u_{i}$ & deslocamento horizontal do nó i \\
\hline$h$ & passo de integração \\
\hline$f_{y}$ & tensão de escoamento \\
\hline$R$ & força cortante restauradora local equivalente \\
\hline$R_{e}$ & força cortante máxima restauradora \\
\hline$M_{a}$ e $M_{b}$ & momentos fletores de extremidade \\
\hline$Z$ & módulo de resistência plástico da coluna \\
\hline
\end{tabular}




\section{Sumário}

1 Introdução ........................................................................ 13

1.1 Revisão bibliográfica .....................................................13

1.2 Objetivos................................................................................................ 16

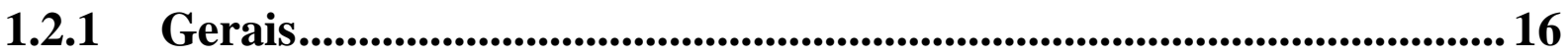

1.2.2 Específicos ........................................................................................................ 16

2 Ações Sísmicas.................................................................. 17

$3 \quad$ Espectro de $\operatorname{Resposta.............................................................~} 18$

3.1 Representações usuais do Espectro de Resposta.........................21

3.2 Espectros regulamentares de projeto.........................................24

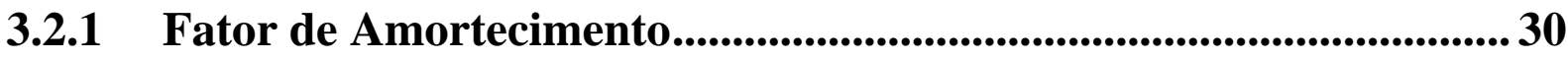

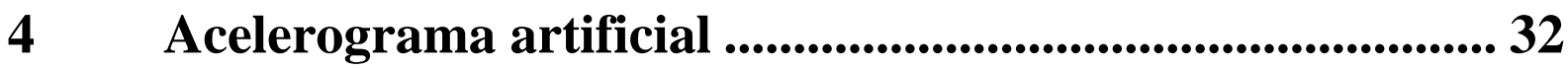

4.1 Métodos determinísticos..........................................................32

4.2 Métodos estocásticos .............................................................32

4.3 Acelerograma artificial compatível com espectro de resposta.33

4.3.1 Duração do sismo ................................................................................... 34

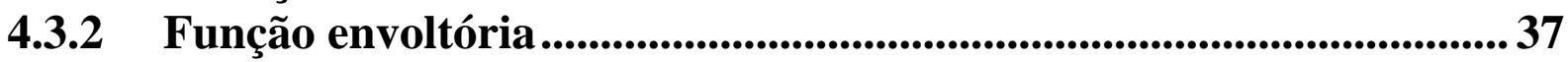

4.3.3 Cálculo das Amplitudes ..................................................................................... 38

4.3.4 Função Densidade Espectral de Potência (PSD) ................................... 39

4.3.5 Ajuste do acelerograma artificial gerado................................................... 43

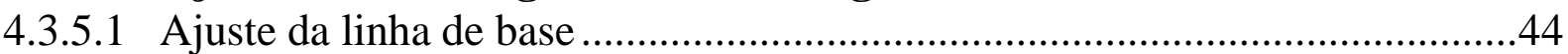

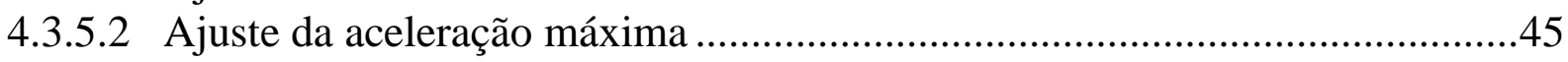

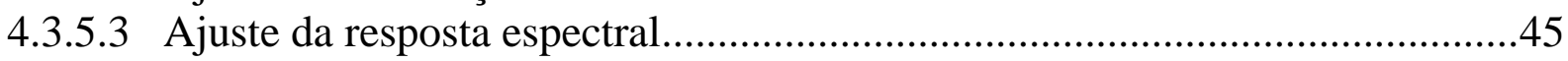

$5 \quad$ Shear Building.................................................................. 47

5.1 Modelo estrutural típico para estruturas tipo shear building .47

5.2 Equações de movimento para edifícios shear building.............47

5.3 Modelo shear building estudado......................................................51

5.4 Integração numérica passo-a-passo no tempo.........................52

5.5 Conceito de comportamento Elastoplástico...............................53

5.5.1 Idealização do Comportamento Elastoplástico ....................................55

5.5.2 Modelo Elastoplástico _................................................................................ 55

$6 \quad$ Resultados .................................................................................. 58

6.1 Caso A........................................................................................58

6.2 Caso B ........................................................................................65

$7 \quad$ Conclusões ............................................................................ 73 


\section{Introdução}

Apesar de fortes eventos sísmicos serem raros no Brasil, engenheiros estruturais brasileiros são frequentemente envolvidos em tal análise para os países latino-americanos vizinhos.

Informações sobre históricos de aceleração sísmica, de natureza aleatória, não estão em geral disponíveis, devido, em parte, à falta de registros. Para contornar tal situação, os códigos de construção indicam o uso de acelerogramas artificiais, mas não fornecem metodologia para sua obtenção. A informação normalizada é o chamado espectro de resposta elástico, que fornece a aceleração de resposta máxima para um sistema linear de um grau de liberdade. Muitas pesquisas estão sendo desenvolvidas a fim de gerar acelerogramas artificiais compatíveis com os espectros de norma. Neste trabalho se apresenta uma proposta para a geração de acelerograma artificial compatível com espectro de resposta regulamentar.

\subsection{Revisão bibliográfica}

O território brasileiro possui baixa atividade sísmica por localizar-se no centro de uma placa tectônica. No entanto, isto não significa que o território brasileiro possua inatividade sísmica. O estudo da sismicidade no Brasil, com base científica, começou nos anos 70. Desde esta década, dados sismológicos começaram a ser coletados, a partir de uma importante rede sismológica que foi implantada e que está no momento em operação contínua (SANTOS E SOUZA LIMA, 2006). Os estudos sísmicos no Brasil inicialmente adotavam metodologias empregadas em outros países. Falconi (2003) estudou as diferentes abordagens que as normas sul-americanas apresentam sobre estruturas sismos resistentes, a partir deste estudo, Santos e Souza Lima (2004) consolidaram um mapa de sismicidade do território brasileiro e no ano de 2005, Santos e Souza Lima (2005) expuseram conceitos e informações fundamentais para a elaboração da atual norma brasileira NBR15421 (2006), sendo uma das bases de referência para a aprovação da atual norma sísmica.

No ano de 2006, impulsionada pela verificação de eventos sísmicos registrados no Brasil nos últimos anos e pela necessidade de adequação das normas técnicas brasileiras às exigências internacionais, a ABNT - Associação Brasileira de Normas Técnicas- publicou a NBR 15421 (2006) - Projeto de estruturas resistentes a sismos. 
A norma brasileira NBR 15421(2006) indica que os efeitos sísmicos não podem ser desconsiderados no Brasil. Com o lançamento da norma brasileira, os estudos no Brasil ganharam mais força, com o intuito de melhor entender a ação sísmica frente às estruturas.

Santos e Souza Lima (2006) estudaram o impacto da consideração das ações sísmicas nos projetos estruturais de edifícios, fazendo análises comparativas dos efeitos dos sismos com os de vento em edifícios em várias cidades do Brasil, com diferentes relações entre as solicitações de vento e sismo e para varias condições de solo, assim como para diversas relações entre a área exposta ao vento. Esta análise foi feita através de um resumo da norma brasileira de sismos, concluindo que os efeitos das forças sísmicas poderão ser mais críticos do que os efeitos devido ao vento em algumas zonas sísmicas.

Parisenti (2011) realiza um estudo de análise dinâmica de edifícios submetidos a sismos, visando principalmente auxiliar projetistas estruturais na aplicação da norma NBR 15421(2006) por meio de exemplos ilustrativos, onde avalia a influência de parâmetros de projeto e compara os três métodos de análise sísmicas recomendados pela norma, análise estática equivalente, análise por espectro de resposta e análise dinâmica com histórico no tempo. O método das forças estáticas equivalentes mostrou-se de grande utilidade devido à facilidade de aplicação, mas apresenta limitações em relação à equação aproximada usada para avaliar o período fundamental da estrutura. $\mathrm{O}$ método com histórico no tempo é o mais refinado entre os métodos estudados, sendo o mais preciso para se analisar uma estrutura, principalmente se seu comportamento for não linear.

Peña (2012) estudou a importância que a geometria de uma estrutura possui diante a ação sísmica, para isso, aplicou um sinal à base de uma estrutura simétrica e uma irregular e estudou as respostas, detectando as concentrações de esforços e calculando a curva de capacidade resistente usando uma análise estática não linear para conhecer a perda de capacidade quando há irregularidades na geometria da estrutura. Dentre as irregularidades estudadas, as irregularidades em planta modificam mais a capacidade resistente da estrutura, o que ocasiona uma redistribuição de esforços e dissipação menor de energia.

Dantas (2013) discute os critérios da norma brasileira na consideração das ações sísmicas fazendo comparações com diversas normas internacionais. Para o melhor entendimento da norma brasileira, desenvolveu um estudo de caso prático através de um exemplo numérico, calculando-se os esforços sísmicos horizontais equivalentes e distribuindo ao longo da estrutura e um estudo do detalhamento estrutural das estruturas com o objetivo de aumentar a ductilidade da estrutura. Neste sentido a norma brasileira é praticamente omissa, tanto no aspecto de detalhamento, quanto na concepção estrutural. 
Orrala; Santos e Souza Lima (2016), realizaram uma comparação entre alguns dos métodos mais utilizados na análise sísmica, por histórico de tempo, análise por espectro de resposta e análise estática equivalente, de forma a entender possíveis causas das diferenças entre os seus resultados. Para isso, foi utilizado um modelo computacional de um prédio e analisado o momento segundo o eixo vertical, momento torçor. Como esperado, o método com histórico no tempo por sua consistência com a realidade física, assim como o trabalho de Parisenti (2001), apresentou os resultados mais confiáveis. No entanto a definição da ação sísmica com histórico no tempo, chamado de acelerograma, não estão em geral disponível, devido, em parte, à falta de registros. Como dito, para contornar tal situação, os códigos de construção indicam o uso de acelerogramas artificiais, mas não fornecem metodologia para sua obtenção. Dentre os poucos trabalhos desenvolvidos no Brasil para a geração de acelerogramas artificiais compatíveis com espectro de resposta regulamentar, destacam-se os trabalhos de Corbani (2006) e Rodrigues (2012):

Com base em uma simulação de Monte Carlo, Corbani (2006) propõe uma metodologia inspirada no processo "Vento Síntético" para geração de acelerogramas artificiais, determinando um acelerograma crítico para uma estrutura tipo shear building de comportamento elastoplástico perfeito.

Rodrigues (2012) apresenta uma metodologia para a geração de acelerogramas artificiais que seja compatível com um espectro de resposta que pode ser aplicado em análises sísmicas não lineares e analisa a influência de algumas premissas de cálculo nas características do sismo simulado. Adicionalmente, faz comparações entre as características do espectro de projeto, assim como de outros aspectos da norma brasileira com os de outras normas internacionais e avalia a influência dessas diferenças no processo de geração de um sinal sísmico. Foi concluído que a metodologia proposta é satisfatória e compatível com diversas normas internacionais.

Para a geração de acelerogramas artificias, é essencial determinar a Função de Densidade Espectral de Potência (PSD) de acelerações do solo coerente com os modelos propostos pelos códigos normativos. Diante disso, Baroni et al. (2015), propõe um método analítico aproximado para se obter o PSD a partir de espectros de resposta. Além disso, esse método é compatível com formas bastante genéricas de espectros de resposta, podendo ser utilizado para espectros de respostas de várias normas internacionais de sismos. Os parâmetros necessários são avaliados analiticamente por funções fechadas dos parâmetros dos espectros de resposta das normas. Assim, o modelo proposto pode ser usado no lugar do 
espectro de resposta e os engenheiros podem definir a ação sísmica em termos do PSD, utilizando ferramentas de análise estocástica.

Contudo, muitas pesquisas ainda continuam em desenvolvimento para melhor caracterizar as ações sísmicas e as respostas das estruturas. Com a evolução destas pesquisas, pode vir a ser possível um aprimoramento dos códigos normativos e assim melhor compreender este fenômeno.

\subsection{Objetivos}

\subsubsection{Gerais}

Este trabalho tem como objetivo desenvolver uma metodologia para a geração de acelerogramas artificiais compatíveis com espectros de respostas elásticos regulamentares e estudar estruturas resistentes a sismo analisando suas respostas mediante a ação sísmica.

\subsubsection{Específicos}

Os objetivos específicos são a seguir expostos.

Desenvolver metodologia para a geração de acelerograma artificial compatível com o espectro de resposta elástico proposto pelos códigos de construção de estruturas resistentes a sismo.

Citam-se, a seguir os exemplos desenvolvidos neste trabalho.

- Excitar a base de um edifício tipo shear building de dez pavimentos, com um acelerograma artificial compatível com a norma brasileira NBR 15421 (2006), gerado pela metodologia proposta e através de integração numérica por diferenças finitas, analisar o deslocamento no tempo do último pavimento.

- De forma semelhante aplicar acelerograma artificial compatível com a norma venezuelana COVENIN 1756 (2001) a base de um reservatório d'água sobre quatro pilares e estudar o seu comportamento elastoplástico perfeito. 


\section{Ações Sísmicas}

Para se quantificar o fenômeno sísmico é usual adotar parâmetros como a sua intensidade e/ou magnitude, mas para análise da resposta de uma estrutura quando sujeitas a este tipo de solicitação, estes parâmetros não são suficientes. Quando se pretende estudar a resposta sísmica das estruturas, esta ação deve ser caracterizada de forma que possa ser integrada nas metodologias de análise estrutural disponíveis. Deste modo, segundo Guerreiro (2011), são três as principais formas de caracterização da ação sísmica que cumprem tal requisito, a seguir listados.

- Representação por Espectro de Resposta.

- Representação através da Função de Densidade Espectral de Potência.

- Representação por série de acelerações.

A representação através de Espectro de Resposta constitui o procedimento mais divulgado de caracterização da ação sísmica, é a representação utilizada nas normas sísmicas internacionais de cálculo estrutural. Tem como principal vantagem, descrever as características mais importantes da resposta sem ter um histórico de excitação no tempo disponível. A aplicação deste procedimento de análise permite somente a obtenção de valores máximos da resposta estrutural em regime linear.

A representação em Função de Densidade Espectral de Potência é limitada a modelos com poucos graus de liberdade. No entanto, é uma ferramenta fundamental no processo de geração de acelerogramas artificiais como será exposto mais à frente.

A representação por série de acelerações é a forma mais direta de analisar o comportamento de uma estrutura quando sujeita à ação de um determinado sismo. No caso da estrutura a ser analisada ter comportamento não linear, a utilização de séries de acelerações torna-se praticamente inevitável (GUERREIRO, 2011). 


\section{Espectro de Resposta}

Segundo Jennings e Nigan (1969), os espectros de resposta foram obtidos pela primeira vez por Biot (1941), e depois desenvolvidos por Housner (1941) e Housner e McCann (1949).

Atualmente, o conceito de espectro de resposta é uma importante ferramenta na área sísmica sendo adotado nos códigos de construção de estrutura resistente a sismo em todo o mundo. Segundo Newmark e Hall (1982), de forma geral, se pode definir esse tipo de espectro como uma representação gráfica da resposta máxima aproximada, seja em deslocamentos, velocidades, aceleração ou qualquer outro parâmetro de interesse, obtida através de uma excitação sobre um conjunto de osciladores de um grau de liberdade, caracterizado por diferentes valores de frequência ou período próprio e todos com o mesmo valor de coeficiente de amortecimento. A Figura 1 ilustra o conceito.

Figura 1 - Conceito de espectro de resposta

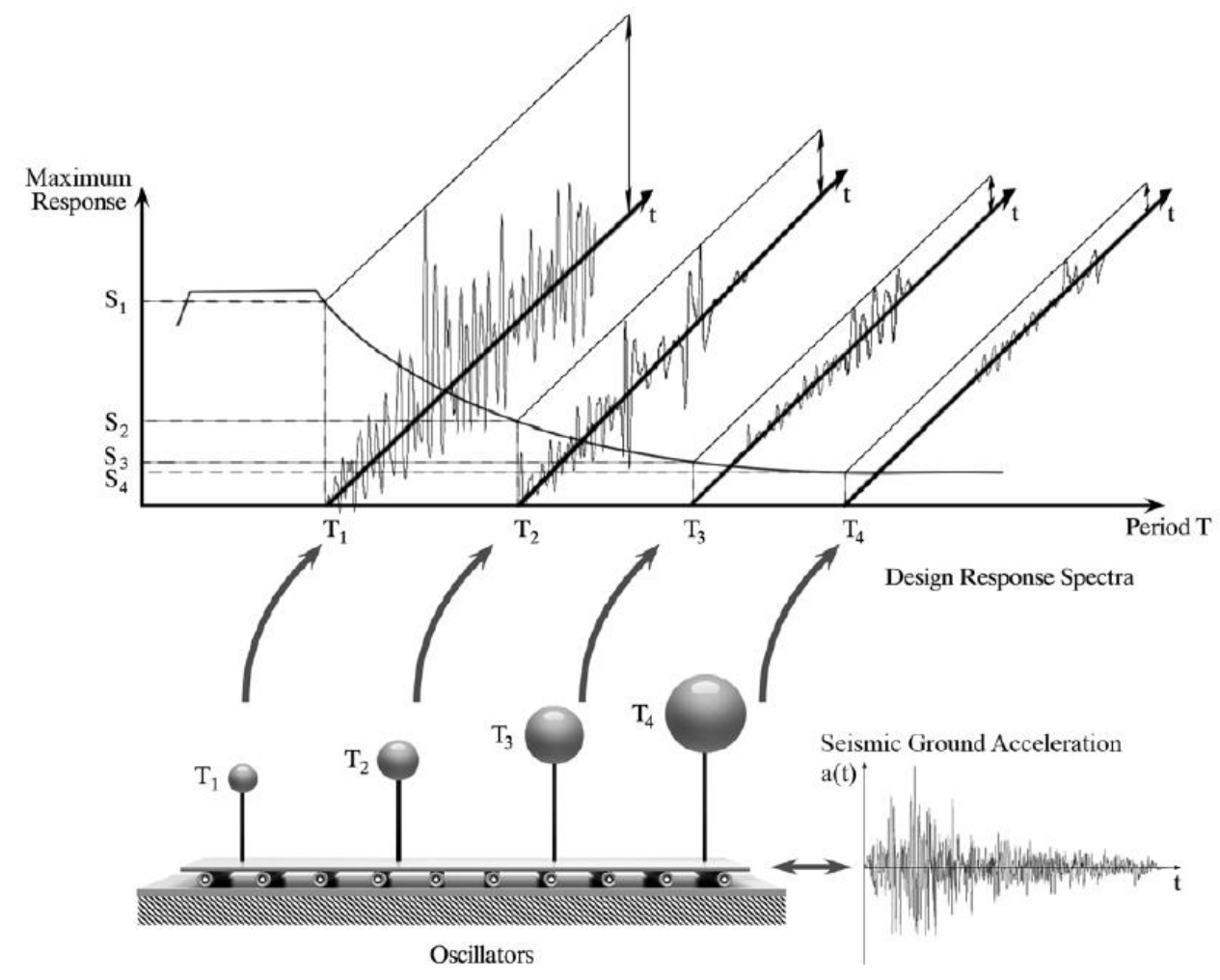

Fonte Vrochidou et al., (2014) 
A grande vantagem do uso dos espectros de resposta, é que permite uma descrição de importantes características da resposta da estrutura sem necessidade de dispor de um histórico de acelerações sísmico inicialmente conhecido.

O movimento deste sistema é descrito pela seguinte expressão:

$$
\ddot{x}(t)+2 v \omega \dot{x}(t)+\omega^{2} x(t)=-\ddot{y}(t)
$$

Nesta expressão, $x(t)$ representa o deslocamento da resposta do sistema, $\omega$ é a frequência própria de vibração $(\mathrm{rad} / \mathrm{s}), v$ é a taxa de amortecimento crítico e $\ddot{y}$ é a aceleração do movimento sísmico do solo. O cálculo da resposta do conjunto de osciladores pode ser feito através de qualquer técnica disponível para análise dinâmica de estruturas lineares, por exemplo, método de integração de Duhamel. A solução da eq.(3.1) é expressa como:

$$
x(t)=-\frac{1}{\omega_{v}} \int_{0}^{t} y(\tau) e^{-v \omega(t-\tau)} \operatorname{sen}\left[\omega_{v}(t-\tau)\right] d \tau
$$

Derivando a eq.(3.2) no tempo, se obtém a resposta em velocidades:

$$
\dot{x}(t)=-\int_{0}^{t} \ddot{y}(\tau) e^{-v \omega(t-\tau)} \cos \omega_{v}(t-\tau) d \tau+v \omega x(t)
$$

Derivando novamente se obtém a resposta em acelerações absolutas:

$$
\ddot{x}(t)+\ddot{y}(t)=\omega_{v} \int_{0}^{t} \ddot{y}(\tau) e^{-v \omega(t-\tau)} \operatorname{sen} \omega_{v}(t-\tau) d \tau-2 v \omega \dot{x}(t)-(v \omega)^{2} x(t)
$$

Os espectros de resposta de aceleração, velocidade e deslocamento é definido como os valores máximos das respostas do sistema expressados em função do período ou da frequência, para uma fração de amortecimento crítico dado $v$.

$$
\begin{aligned}
& S_{d}^{t}(\omega, v)=|x(t)|_{\text {max }} \\
& S_{v}^{t}(\omega, v)=|\dot{x}(t)|_{\text {max }}
\end{aligned}
$$




$$
S_{a}^{t}(\omega, v)=|\ddot{x}(t)+\ddot{y}(t)|_{\max }
$$

Igualando as eqs.(3.2), (3.3) e (3.4) às eqs.(3.5), (3.6) e (3.7) respectivamente, resulta nas seguintes expressões:

$$
\begin{gathered}
S_{d}^{t}(\omega, v)=\left|-\frac{1}{\omega_{v}} \int_{0}^{t} \ddot{y}(\tau) e^{-v \omega(t-\tau)} \operatorname{sen}\left[\omega_{v}(t-\tau)\right] d \tau\right|_{\max } \\
S_{v}^{t}(\omega, v)=\left|-\int_{0}^{t} \ddot{y}(\tau) e^{-v \omega(t-\tau)} \cos \omega_{v}(t-\tau) d \tau+v \omega x(t)\right| \\
S_{a}^{t}(\omega, v)=\left|\omega_{v} \int_{0}^{t} y(\tau) e^{-v \omega(t-\tau)} \operatorname{sen} \omega_{v}(t-\tau) d \tau-2 v \omega x(t)-(v \omega)^{2} x(t)\right|_{\max }
\end{gathered}
$$

Com o intuito de facilitar o uso das eqs.(3.8), (3.9) e (3.10), podem-se adotar algumas simplificações:

Igualando $\omega_{\mathrm{v}}$ a $\omega$, e os termos fora da integral no segundo membro das eqs.(3.9) e (3.10) que multiplicam a fração de amortecimento crítico, se despreza, já que o amortecimento nas aplicações mais frequentes da engenharia civil é pequeno $(2 \% \leq v \leq 20 \%)$.

A função cosseno que aparece na eq.(3.9) pode ser substituída para efeito de cálculo pela função seno, sem que isso implique importantes variações nos valores máximos de velocidade do sistema. Esta aproximação é válida no patamar usual das frequências que aparecem nos projetos sísmicos.

Estas simplificações permite definir três novas expressões denominadas pseudoespectros de resposta de deslocamentos, velocidades e acelerações, cujas expressões são:

$$
\begin{gathered}
S_{d}(\omega, v)=\left|-\frac{1}{\omega_{v}} \int_{0}^{t} \ddot{y}(\tau) e^{-v \omega(t-\tau)} \operatorname{sen} \omega(t-\tau) d \tau\right|_{\max } \\
S_{v}(\omega, v)=\left|-\int_{0}^{t} \ddot{y}(\tau) e^{-v \omega(t-\tau)} \operatorname{sen} \omega(t-\tau) d \tau\right| \\
S_{a}(\omega, v)=\left|\omega \int_{0}^{t} \ddot{y}(\tau) e^{-v \omega(t-\tau)} \operatorname{sen} \omega(t-\tau) d \tau\right|_{\max }
\end{gathered}
$$

onde se pode escrever a seguinte expressão 


$$
S_{d}(\omega)=\frac{1}{\omega} S_{v}(\omega)=\frac{1}{\omega^{2}} S_{a}(\omega)
$$

\subsection{Representações usuais do Espectro de Resposta}

Existem diversas formas de representar os espectros. A forma mais comumente encontrada é a de representar os deslocamentos, velocidades relativas e acelerações absolutas em função do período de vibração ou frequência, como ilustrado na Figura 2.

Figura 2 - Espectros de resposta
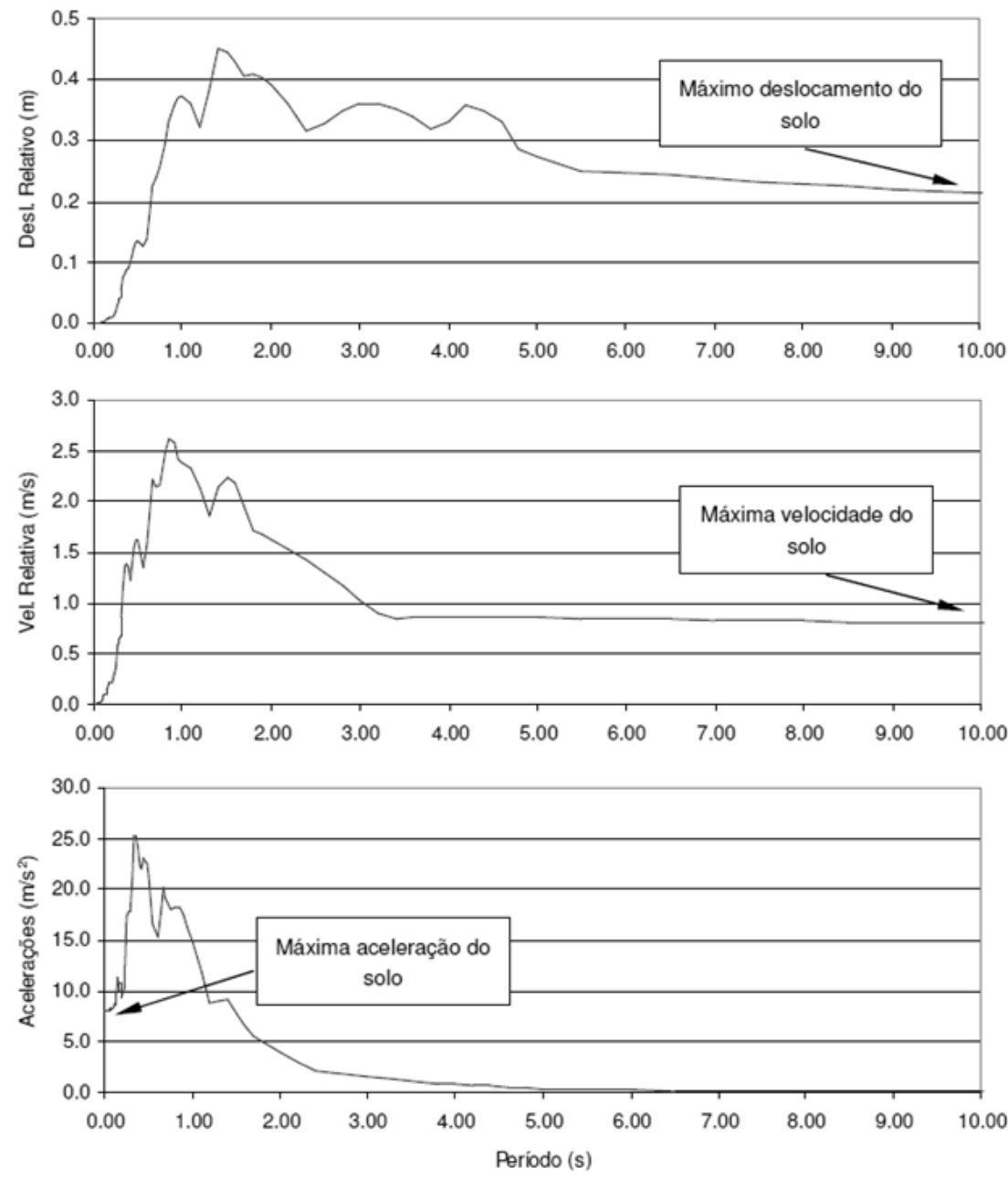

Fonte: Guerreiro (2011) 
Analisando a Figura 2, pode-se perceber que os espectros de resposta de acelerações absolutas tendem a zero quando o período natural dos osciladores tende para infinito (ou a frequência tende a ser nula), isto é, se considerarmos um oscilador muito flexível, com frequência própria muito baixa, pode ocorrer movimentação do solo sem que o oscilador se mova, ou seja, se não existe movimentação do oscilador as acelerações absolutas são nulas. De outra forma, se considerarmos um oscilador com uma rigidez muito alta, de período tendendo a zero, o movimento do oscilador será praticamente o mesmo do solo, com isso, a aceleração máxima registrada no oscilador corresponderá o valor da aceleração máxima do solo. Já o valor de pico do espectro de aceleração absoluta tenderá para valores elevados perto da frequência própria da estrutura (ressonância).

Analogamente, os espectros de resposta de velocidade e deslocamentos relativos, devem tender para zero para valores elevados de frequência, e que tendem respectivamente para velocidade e deslocamento máximo do solo quando a frequência própria dos osciladores tende a zero. Tais espectros representam o movimento relativo entre a estrutura e o solo, movimento que será nulo no caso de osciladores com elevada rigidez. A Figura 3 ilustra o mencionado.

Figura 3 - Comportamento de uma estrutura muito rígida (a) e muito flexível (b)

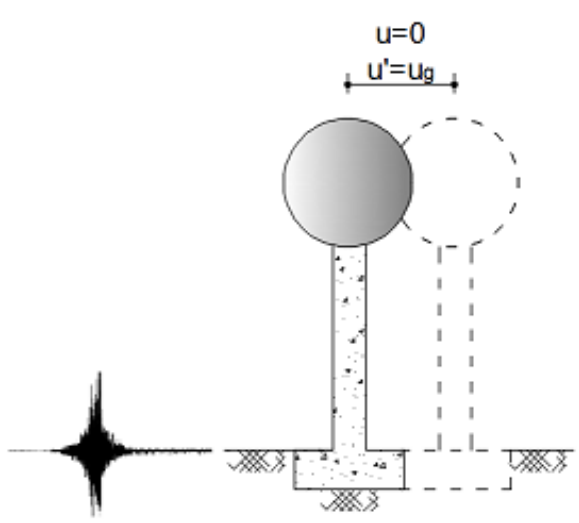

(a)

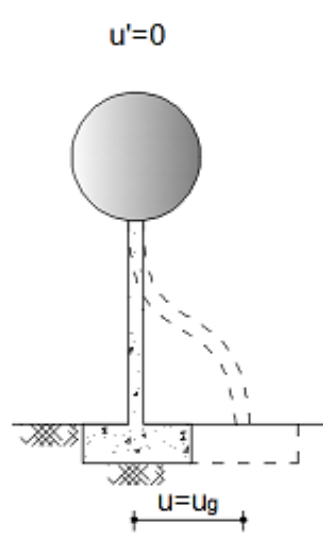

(b)

Fonte: Autor (2017)

Os três espectros representados na Figura 2 são simplesmente três formas diferentes de apresentação de um mesmo registro sísmico. O espectro de deslocamento proporciona 
diretamente o deslocamento máximo do sistema. $\mathrm{O}$ espectro de acelerações se relacionada diretamente com o valor máximo da força estática equivalente e cisalhante na base. Contudo, conhecendo um dos espectros, os outros podem ser obtidos através de operações algébricas para estruturas com baixo coeficiente de amortecimento como demonstrado anteriormente através da eq.(3.14).

Com a intenção de unir todas estas informações em apenas um diagrama, segundo Chopra (2011), Veletsos e Newmark (1960) apresentaram pela primeira vez essa combinação. A Figura 4 mostra um exemplo da representação de espectros em forma combinada.

Figura 4 - Representação combinada de Espectro de resposta

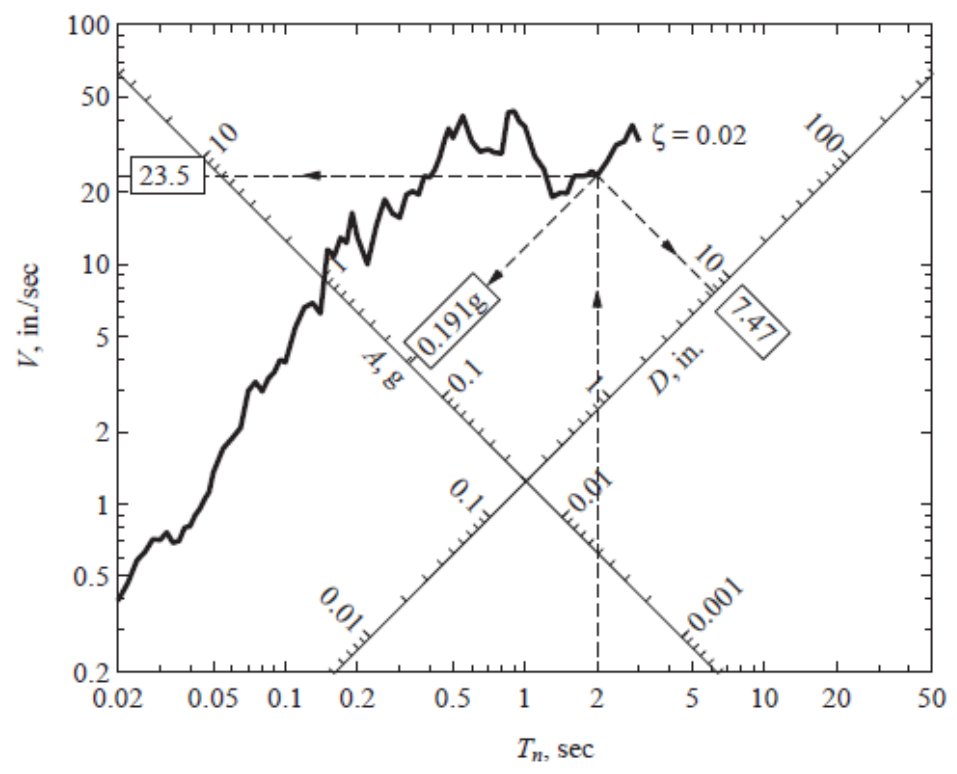

Fonte: Chopra (2011)

Os espectros também podem representar-se mediante um gráfico de aceleração em função dos deslocamentos, enquanto os períodos são indicados por linhas oblíquas como se mostra na Figura 5. Este tipo de representação é conhecido como espectro de capacidade. 
Figura 5 - Espectro de Capacidade

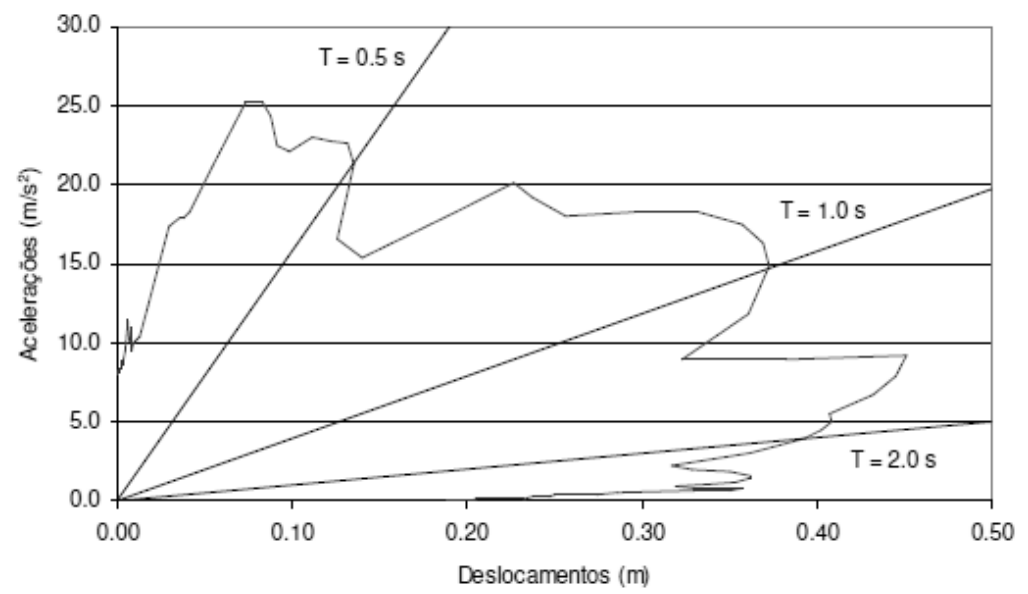

Fonte: Guerreiro (2011)

\subsection{Espectros regulamentares de projeto}

Os espectros de resposta regulamentares de projeto são curvas idealizadas que consideram o efeito de vários sismos, isto é, representa uma envoltória dos espectros de resposta dos sismos típicos de uma determinada região. O objetivo dos espectros de norma é estabelecer valores mínimos de resistência que devem apresentar as estruturas para uma dada região. Os espectros de projeto são obtidos mediante procedimentos estatísticos, cuja descrição detalhada foge do escopo deste trabalho. Para detalhes e desenvolvimento de espectros de projeto recomendam-se as referências Barbat et al. (1994), Bertero et al. (2009), Li et al. (2017).

No Brasil, desde 2006, está em vigor a primeira norma brasileira para projetos de estruturas resistentes a sismo, a NBR 15421 (2006) - Projeto de estruturas resistentes a sismos-Procedimento. Esta norma indica os requisitos para a verificação da segurança e da resistência das estruturas de edificações frente às ações sísmicas.

Os valores característicos para as ações sísmicas definidos nesta norma representam $10 \%$ de probabilidade de serem ultrapassados no sentido desfavorável, durante um período de 50 anos, o que representa um período de retorno de 475 anos.

Para efeito da definição das ações sísmicas, a NBR 15421 (2006) define o território brasileiro em cinco zonas sísmicas considerando a variação da aceleração sísmica horizontal $a_{g}$ normalizada para terrenos da classe B (rocha). A Figura 6 apresenta o zoneamento sísmico no Brasil. 
Figura 6 - Zoneamento sísmico no Brasil

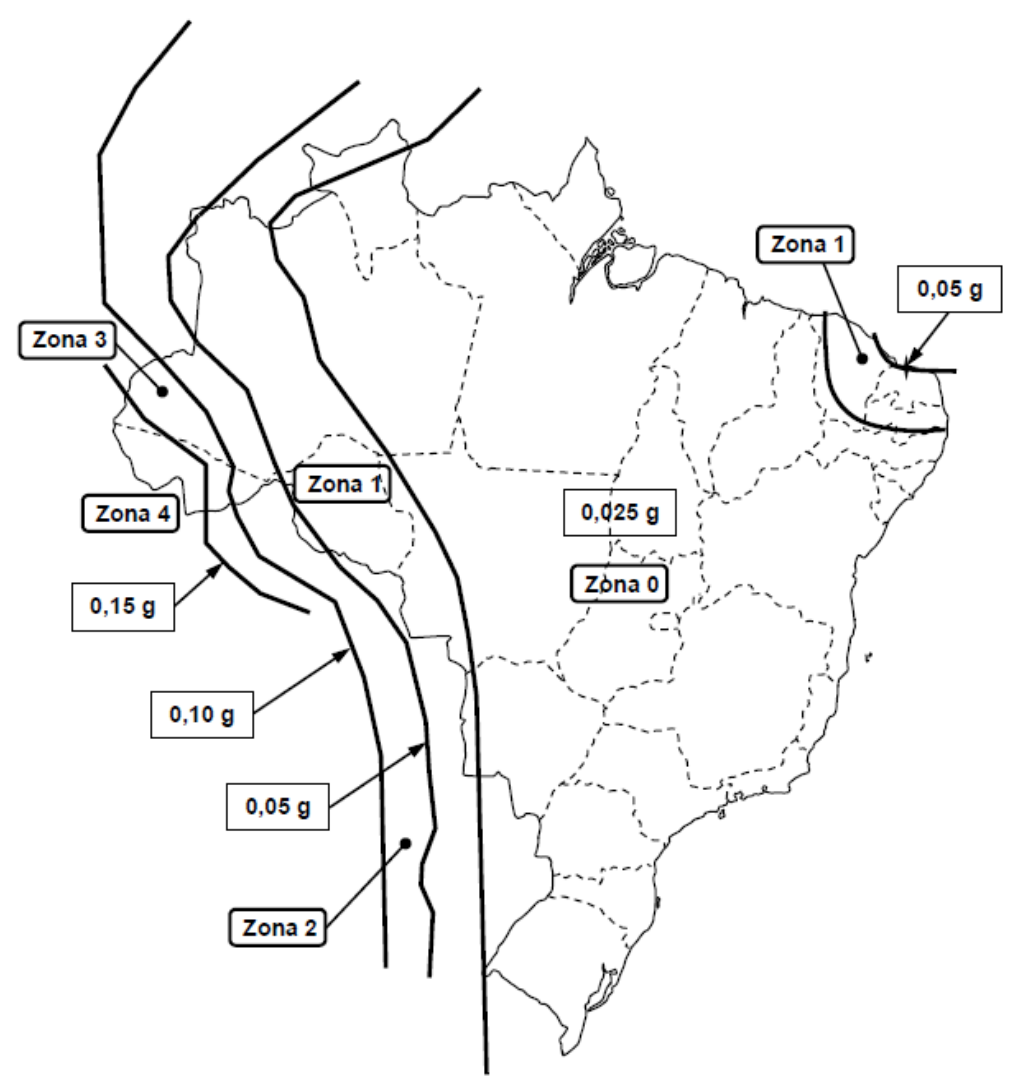

Fonte: ABNT NBR 15421 (2006)

A NBR 15421 (2006) define os critérios para a obtenção do espectro de resposta de projeto para acelerações horizontais, para uma fração do amortecimento crítico de $5 \%$ a partir da aceleração sísmica característica horizontal e a classe do terreno.

O espectro de resposta é definido matematicamente em três faixas de períodos, pelas seguintes expressões:

$$
S_{a}(T)=\left\{\begin{array}{lc}
a_{g s 0}\left(18,75 \frac{C_{a}}{C_{v}}+1\right), & 0 \leq T<0,08 \frac{C_{a}}{C_{v}} \\
2,5 a_{g s 0}, & 0,08 \frac{C_{a}}{C_{v}} \leq T<0,4 \frac{C_{a}}{C_{v}} \\
\frac{a_{g s 1}}{T}, & T \geq 0,4 \frac{C_{a}}{C_{v}}
\end{array}\right.
$$

onde:

$T=$ Período natural de vibração, associado com cada modo de vibração da estrutura; 
$S_{a}(T)=$ é o espectro de resposta de pseudo-acelerações;

$C_{a}=$ é o fator de amplificação sísmica no solo, para o período $\mathrm{T}=0,0 \mathrm{~s}$;

$C_{v}=$ é o fator de amplificação sísmica no solo, para o período $\mathrm{T}=1,0 \mathrm{~s}$;

$a_{g s 0}=$ é a aceleração espectral para o período $\mathrm{T}=0,0 \mathrm{~s}$;

$a_{g s l}=$ é a aceleração espectral para o período $\mathrm{T}=1,0 \mathrm{~s}$.

Sendo:

$$
\begin{aligned}
& a_{g s 0}=C_{a} a_{g} \\
& a_{g s 1}=C_{v} a_{g}
\end{aligned}
$$

onde:

$a_{g}=$ é a aceleração característica de projeto, corresponde à aceleração sísmica horizontal característica normalizada em relação aos terrenos da Classe B (rocha). A

Figura 7 mostra o espectro de projeto segundo a NBR 15421 (2006).

Figura 7 - Espectro de resposta de projeto - ABNT NBR 15421 (2006)

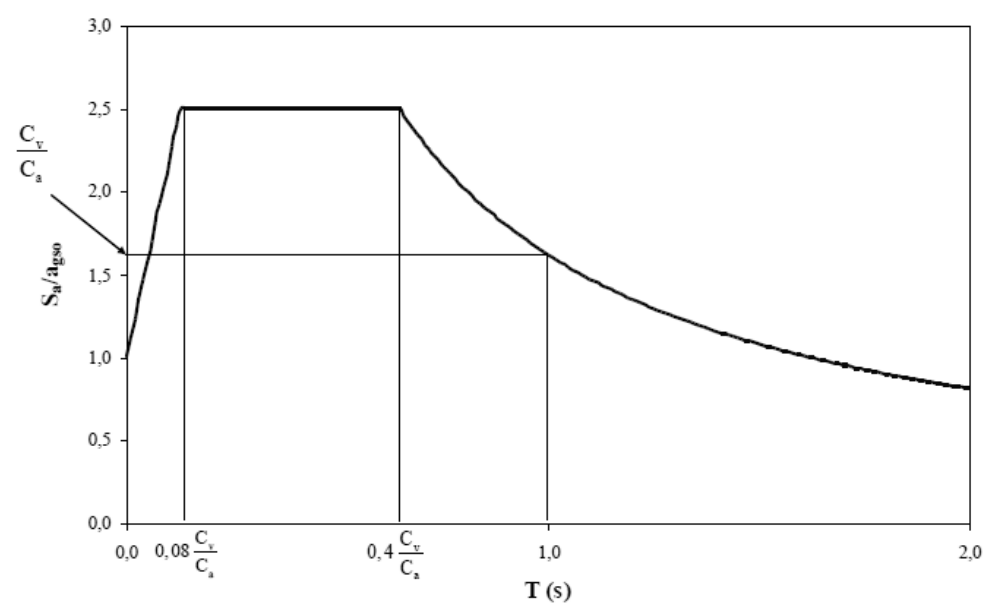

Fonte: ABNT NBR 15421 (2006)

Os fatores de amplificação do solo sísmicos podem ser obtidos, em função da classe do terreno pela Tabela 1, sendo permitido fazer uma interpolação linear para obter valores intermediários entre $0,10 \mathrm{~g}$ e $0,15 \mathrm{~g}$. A categorização da classe do terreno está associada à velocidade de propagação das ondas de cisalhamento $\left(\bar{V}_{s}\right)$ média nos 30 metros mais elevado 
do terreno, através da Tabela 2. É permitida ainda a classificação, em alguns casos, a partir dos resultados médios do SPT $(\bar{N})$.

Tabela 1 - Fator de amplificação dinâmica - ABNT NBR 15421 (2006)

\begin{tabular}{|c|c|c|c|c|}
\hline \multirow{2}{*}{ Classe do terreno } & \multicolumn{2}{|c|}{$C \mathrm{c}$} & \multicolumn{2}{c|}{$C v$} \\
\cline { 2 - 5 } & $\mathrm{ag} \leq 0.10 \mathrm{~g}$ & $\mathrm{ag} \leq 0.15 \mathrm{~g}$ & $\mathrm{ag} \leq 0.10 \mathrm{~g}$ & $\mathrm{ag} \leq 0.15 \mathrm{~g}$ \\
\hline$A$ & 0.8 & 0.8 & 0.8 & 0.8 \\
\hline$B$ & 1.0 & 1.0 & 1.0 & 1.0 \\
\hline$C$ & 1.2 & 1.2 & 1.7 & 1.7 \\
\hline$D$ & 1.6 & 1.5 & 2.4 & 2.2 \\
\hline$E$ & 2.5 & 2.1 & 3.5 & 3.4 \\
\hline
\end{tabular}

Fonte: ABNT NBR 15421 (2006)

Tabela 2 - Classificação do solo - ABNT NBR 15421 (2006)

\begin{tabular}{|c|c|c|c|}
\hline \multirow{2}{*}{$\begin{array}{l}\text { Classe } \\
\text { do } \\
\text { terreno }\end{array}$} & \multirow{2}{*}{$\begin{array}{l}\text { Designação da } \\
\text { classe do terreno }\end{array}$} & \multicolumn{2}{|c|}{ Propriedades médias para os $30 \mathrm{~m}$ superiores do terreno } \\
\hline & & $\bar{V}_{s}$ & $\bar{N}$ \\
\hline$A$ & Rocha sã & $\bar{V}_{s} \geq 1.500 \mathrm{~m} / \mathrm{s}$ & (não aplicável) \\
\hline$B$ & Rocha & $1.500 \mathrm{~m} / \mathrm{s} \geq \bar{V}_{s} \geq 760 \mathrm{~m} / \mathrm{s}$ & (não aplicável) \\
\hline$C$ & $\begin{array}{l}\text { Rocha alterada ou } \\
\text { solo muito rígido }\end{array}$ & $760 \mathrm{~m} / \mathrm{s} \geq \bar{V}_{\mathrm{s}} \geq 370 \mathrm{~m} / \mathrm{s}$ & $\bar{N} \geq 50$ \\
\hline$D$ & Solo rígido & $370 \mathrm{~m} / \mathrm{s} \geq \bar{V}_{\mathrm{s}} \geq 180 \mathrm{~m} / \mathrm{s}$ & $\bar{N} \geq 15$ \\
\hline & Solo mole & $\bar{V}_{s} \leq 180 \mathrm{~m} / \mathrm{s}$ & $\bar{N} \leq 15$ \\
\hline & - & \multicolumn{2}{|c|}{ Qualquer perfil, incluindo camada com mais de $3 \mathrm{~m}$ de argila mole } \\
\hline F & - & \multicolumn{2}{|c|}{$\begin{array}{l}\text { Solo exigindo avaliação específica, como: } \\
\text { 1. Solos vulneráveis à ação sísmica, como solos liquefazíveis, } \\
\text { argilas muito sensíveis e solos colapsíveis fracamente } \\
\text { cimentados } \\
\text { 2. Turfa ou argilas muito orgânicas } \\
\text { 3. Argilas muito plásticas; } \\
\text { 4. Extratos muito espessos }(\geq 35 \mathrm{~m} \text { ) de argila mole ou média }\end{array}$} \\
\hline
\end{tabular}

Fonte: ABNT NBR 15421 (2006)

Como segunda exemplificação e para efeito de comparação, a seguir é apresentando o espectro de projeto segundo prescrições da Norma Venezuelana COVENIN 1756 (2001). A norma venezuelana divide o pais em 8 zonas sísmicas caracterizada conforme o perigo sísmico e coeficiente de aceleração horizontal variando até 0,40 da gravidade conforme Tabela 3. 
Tabela 3 - Coeficiente de aceleração horizontal - COVENIN 1756 (2001)

\begin{tabular}{|c|c|c|}
\hline ZONAS SÍSMICAS & PELIGRO SÍSMICO & A0 \\
\hline 7 & \multirow{3}{*}{ Elevado } & 0.40 \\
\hline 6 & & 0.35 \\
\hline 5 & & 0.30 \\
\hline 4 & \multirow{2}{*}{ Intermedio } & 0.25 \\
\hline 3 & & 0.20 \\
\hline 2 & \multirow{3}{*}{ Bajo } & 0.15 \\
\hline 1 & & 0.10 \\
\hline 0 & & - \\
\hline
\end{tabular}

Fonte: COVENIN 1756 (2001)

Esta norma recomenda um fator de correção para o coeficiente de aceleração horizontal dependendo das características do perfil geotécnico do terreno de fundação e está dividida em quatro formas espectrais ( $\mathrm{S} 1 \mathrm{a}$ S4) conforme Tabela 4.

Tabela 4 - Forma espectral e Fator de correção $\varphi$ - COVENIN 1756 (2001)

\begin{tabular}{|c|c|c|c|c|c|c|}
\hline \multirow[t]{2}{*}{ Material } & \multirow{2}{*}{$\begin{array}{l}\text { Vsp } \\
(\mathrm{m} / \mathrm{s})\end{array}$} & \multirow{2}{*}{$\begin{array}{c}\mathbf{H} \\
(\mathrm{m})\end{array}$} & \multicolumn{2}{|c|}{ Zonas Sísmicas 1 a 4} & \multicolumn{2}{|c|}{ Zonas Sísmicas 5 a 7} \\
\hline & & & $\begin{array}{c}\text { Forma } \\
\text { Espectral }\end{array}$ & $\varphi$ & \begin{tabular}{c|} 
Forma \\
Espectral
\end{tabular} & $\varphi$ \\
\hline Roca sana/fracturada & $>500$ & - & S1 & 0.85 & S1 & 1.00 \\
\hline \multirow{3}{*}{$\begin{array}{l}\text { Roca blanda o meteori- } \\
\text { zada y suelos muy } \\
\text { duros o muy densos }\end{array}$} & \multirow{3}{*}{$>400$} & $<30$ & S1 & 0.85 & S1 & 1.00 \\
\hline & & $30-50$ & S2 & 0.80 & $\mathbf{S 2}$ & 0.90 \\
\hline & & $>50$ & S3 & 0.70 & S2 & 0.90 \\
\hline \multirow{3}{*}{ Suelos duros o densos } & \multirow{3}{*}{$250-400$} & $<15$ & S1 & 0.80 & S1 & 1.00 \\
\hline & & $15-50$ & S2 & 0.80 & S2 & 0.90 \\
\hline & & $>50$ & S3 & 0.75 & S2 & 0.90 \\
\hline \multirow{2}{*}{$\begin{array}{ll}\text { Suelos } & \text { firmes/medio } \\
\text { densos } & \end{array}$} & \multirow{2}{*}{$170-250$} & $\leq 50$ & S3 & 0.70 & S2 & 0.95 \\
\hline & & $>50$ & $\mathbf{S 3}^{(\text {(a) }}$ & 0.70 & S3 & 0.75 \\
\hline \multirow[t]{2}{*}{ Suelos blandos/sueltos } & \multirow[t]{2}{*}{$<170$} & $\leq 15$ & S3 & 0.70 & S2 & 0.90 \\
\hline & & $>15$ & $\mathbf{S 3}^{(\mathbf{a})}$ & 0.70 & S3 & 0.80 \\
\hline 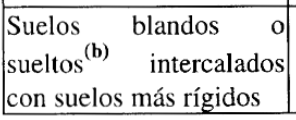 & - & $\mathrm{H}_{1}$ & $\mathbf{S} 2^{(\mathbf{c})}$ & 0.65 & $\mathbf{S 2}$ & 0.70 \\
\hline \multicolumn{7}{|c|}{$\begin{array}{l}\text { a) Si Ao } \leq 0.15 \text { úsese S4 } \\
\text { b) El espesor de los estratos blandos o sueltos }(\mathrm{Vsp}<170 \mathrm{~m} / \mathrm{s} \text { ) debe ser mayor que } 0.1\end{array}$} \\
\hline
\end{tabular}

Fonte: COVENIN 1756 (2001)

Sendo:

Vsp = Velocidade média das ondas de cisalhamento;

$\mathrm{H}=$ Profundidade a qual se consegue material cuja velocidade das ondas de cisalhemento, Vs é maior que $500 \mathrm{~m} / \mathrm{s}$. 
O espectro também é definido numericamente em três faixas de períodos, pelas expressões:

$$
A d= \begin{cases}\frac{\alpha \varphi A_{0}\left[1+\frac{T}{T^{+}}(\beta-1)\right]}{1+\left(\frac{T}{T^{+}}\right)^{C}(R-1)}, & T<T^{+} \\ \frac{\alpha \varphi \beta A_{0}}{R}, & T^{+} \leq T \leq T^{*} \\ \frac{\alpha \varphi \beta A_{0}}{R}\left(\frac{T^{*}}{T}\right)^{p}, & T>T^{*}\end{cases}
$$

onde:

$A_{d}=$ Aceleração espectral;

$a=$ Fator de importância;

$\mathrm{A}_{0}=$ Coeficiente de aceleração horizontal;

$\varphi=$ Fator de correção do coeficiente de aceleração horizontal;

$\beta$ = Fator de amplificação médio;

$\mathrm{T}_{0}=0,25 \mathrm{~T}^{*}$ Período a partir do qual o espectro possui valor constante (seg.);

$\mathrm{T}^{*}=$ Máximo período no intervalo onde o espectro possui valor constante (seg.);

$T^{+} \geq T^{*}=$ Período característico de variação da resposta dúctil (seg.);

$\mathrm{c}=\sqrt[4]{R / \beta}$

$\mathrm{R}=$ Fator de redução de resposta;

$\mathrm{p}=$ Expoente que define o ramo descendente do espectro.

O espectro de resposta típico segundo as prescrições na norma venezuelana é mostrado na Figura 8: 
Figura 8 - Espectro de resposta de projeto - COVENIN 1756 (2001)

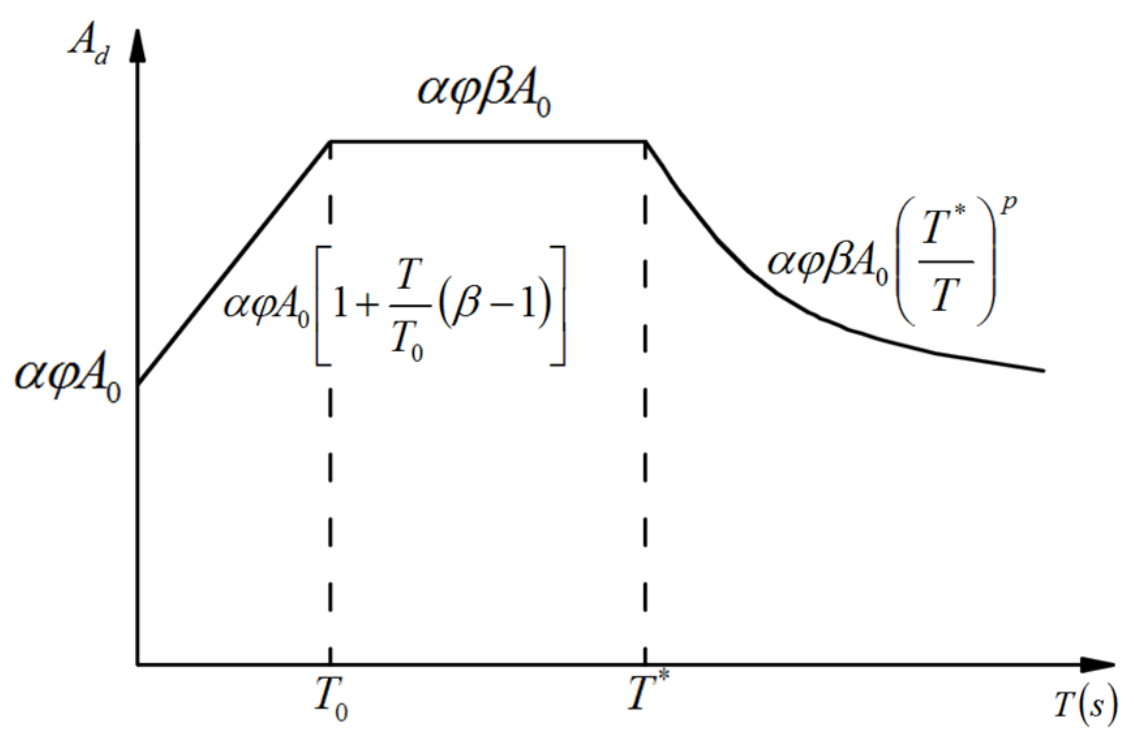

Fonte: COVENIN 1756 (2001)

\subsubsection{Fator de Amortecimento}

Dissipação de energia ocorre em todo sistema mecânico oscilatório. Essa dissipação é útil quando a vibração é indesejável, e é mais relevante quando a estrutura oscila próxima a ressonância. O conjunto dos mecanismos dessa dissipação é genericamente chamado de amortecimento, suas causas são complexas e associadas às características da estrutura, ao meio circundante e aos elementos não estruturais agregados a mesma (SORIANO, 2014).

Como já dito, o projeto sísmico e a avaliação das estruturas geralmente são baseados no espectro de resposta, análises em que os espectros de resposta correspondem à resposta elástica de um sistema de um grau de liberdade com uma fração de amortecimento crítico igual a 5\%. É uma prática comum nos códigos normativos adotar este valor. No entanto, para estruturas de base isoladas, estruturas com dispositivos de amortecimento e estruturas que não se comportam linearmente, os valores espectrais frequentemente requerem níveis distintos de amortecimento. Assim, a taxa de amortecimento deve ser ajustada por fatores de correção de amortecimento. A NBR 15421 (2006) indica a necessidade de aplicar fator de correção para fração de amortecimento crítico diferente de 5\%, mas não apresenta nenhuma metodologia para tal correção.

A adoção do fator de correção de amortecimento em códigos normativos foi inspirada principalmente no trabalho pioneiro de Newmark (1973) e Hall (1982). 
Newmark e Hall (1973) propuseram fatores de correção $\eta$ para região de velocidade, aceleração e deslocamento constante, conforme eq.(3.19). O fator de correção foi derivado da estimativa mediana da resposta de deslocamento máximo de um sistema de oscilador de um grau de liberdade com taxa de amortecimento $\xi$ menor que $20 \%$. A relação proposta por Newmark e Hall (1973) foi adotada no ATC-40(1996) e FEMA 273(1997), UBC(1997) e ASCE7-05(2006) (SHEIKH et al., 2013).

$$
\eta= \begin{cases}1,514-0,321 \ln (\xi) & \text { (Região de velocidade constante) } \\ 1,400-0,248 \ln (\xi) & \text { (Região de aceleração constante) } \\ , 1,309-0,194 \ln (\xi) & \text { (Região de deslocamento constante) }\end{cases}
$$

No espectro de projeto do EC8, também indica a necessidade do uso de fatores de correção para valores de amortecimento diferente de 5\%. Esta correção é baseada no modelo proposto por Bommer et al. (2000) através da eq.(3.20). O fator é aplicado diretamente as equações que compõem o espectro de resposta, de maneira a deslocar o patamar do trecho de acelerações constantes.

$$
\eta=\sqrt{\frac{10}{(5+\xi)} \geq 0,55}
$$
Figura 9.

O fator de correção $\eta$ em função da taxa de amortecimento $\xi(\%)$ é representado na

Figura 9 - Fator de correção $\eta$

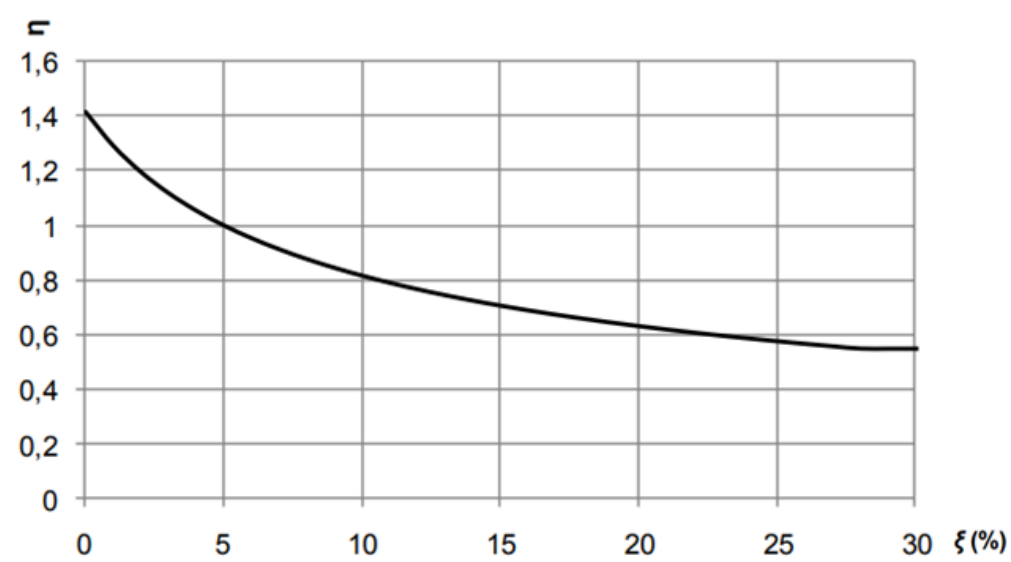

Fonte: Bisch et al. (2001) 


\section{Acelerograma artificial}

Dentre os diversos métodos existentes na literatura para a geração de acelerogramas artificiais, os mais utilizados são os métodos deterministas e os estocásticos (LAM et al., 2000).

\subsection{Métodos determinísticos}

Um dos primeiros métodos utilizados para gerar acelerogramas artificiais, é baseado na teoria dos deslocamentos (AKI, 1968). Este método utiliza o momento sísmico, onde se impõe uma função de deslizamento de falha para caracterizar a fonte sísmica e através da teoria de ondas se simula a transmissão das ondas sísmicas de cisalhamento geradas. Outros métodos de simulação deterministas mais sofisticados têm sido desenvolvidos para gerar acelerogramas mais realistas compatíveis com o aumento dos registros sísmicos. Segundo González (2006), são dois os métodos de simulação contemporâneo mais populares, o método da função empírica de Green (EGC: Empirical Green Function) e o método da teoria dos raios. O método da função empírica de Green define uma onda gerada através de um pequeno impulso movendo-se sobre um meio elástico (IRIKURA, 1986). No método EGC as mesmas funções empíricas derivadas da função de Green a partir de um evento sísmico, são superpostas em intervalos curtos de tempo, para gerar acelerogramas de eventos sísmicos maiores, baseado na lei de escala estabelecida. O método tem como vantagem a sua simplicidade, mas é limitado pelo fato de eventos sísmicos reais representativos e as funções empíricas adequadas de Green não estarem sempre disponíveis.

No método da teoria dos raios, os acelerogramas são gerados mediante a convolução de uma função teórica de Green, que se sintetiza pela teoria dos raios, com uma função de tempo, empírica ou teórica, por qual se baseia na geometria de falha suposta e na profundidade local (LAM et al., 2000).

\subsection{Métodos estocásticos}

Os métodos estocásticos consistem basicamente em definir o espectro de Fourier, ou seja, o conteúdo de frequências e um grupo de ângulos aleatórios que definem as fases de chegada (VANNMARCKE, 1977). A amplitude máxima e a duração do sinal sísmico se 
modelam através de uma função específica de amplitude. O conhecido filtro de Kanai (1957) e Tajimi (1960) foi desenvolvido dentro de um marco estocástico para gerar acelerogramas artificiais. Os processos estocásticos permitem produzir acelerogramas concretos, que se caracterizam através de uma variável aleatória, que pode ser vetorial ou escalar em função do tempo (GONZALEZ, 2006).

Dentre os métodos estocásticos, destacam-se os métodos estacionários e não estacionários.

Um processo estacionário é caracterizado por não variar as suas propriedades probabilísticas em função do tempo. Um processo estacionário pode ser decomposto em uma soma infinita de harmônicos de amplitudes aleatórias, que podem ser relacionadas estatisticamente com a sua respectiva frequência mediante uma função aleatória que tenha uma natureza espectral (HURTADO, 1998).

Por outro lado os processos não estacionários não podem ser representados como uma soma de funções harmônicas.

Em qualquer caso, os registros sísmicos são altamente não estacionários devido às diferenças de tempos de chegada das diferentes fases, em suas componentes de frequências, assim como a sua amplitude e duração. Assim, a ação sísmica deve ser considerada como um processo aleatório não estacionário (GONZALEZ, 2006).

A seguir se descreve o procedimento utilizado para a geração de acelerogramas compatíveis com espectro de resposta.

\subsection{Acelerograma artificial compatível com espectro de resposta}

Como já mencionado, os espectros de resposta propostos pelas normas de construção são determinados pela resposta esperada de um sistema de um grau de liberdade em um determinado local. Assim, eles dependem da sismicidade do local, das propriedades do solo, da importância da estrutura e também, em normas mais avançadas, da ductilidade do sistema resistente a carregamentos laterais e do estado limite em consideração.

Para o caso de sistemas não lineares, é necessário realizar a integração no tempo da resposta estrutural. Para estruturas resistentes a sismo, é necessário dispor de registros de acelerogramas do solo do local requerido. Devido à baixa quantidade de registros disponíveis, para alguns locais inexistentes, a solução é a geração de acelerogramas artificiais compatíveis com um espectro de resposta de norma, que procura caracterizar a sismicidade do local. 
Segundo Barbat et al, (2000), a maioria dos procedimentos existentes para gerar registros sísmicos artificiais compatíveis com um espectro de resposta dado, se baseia no fato de que qualquer função periódica pode ser expandida em uma série de ondas sinusoidais.

$$
a(t)=I(t) \sum_{i=1}^{n} A_{i} \sin \left(\omega_{i} t+\theta_{i}\right)
$$

onde:

$a(t)=$ é o acelerograma buscado;

$n$ = é o número dado que, ao aumentar, melhora a compatibilidade do espectro;

$I(t)$ = é uma envoltória que confere ao acelerograma o caráter não estacionário;

$\theta_{i}=$ são os ângulos de fase gerado aleatoriamente entre 0 e $2 \pi$;

$\omega_{i}=$ é cada uma das frequências consideradas na série harmônica;

$A_{i}=\mathrm{o}$ sinal artificial é compatível com o espectro de resposta, onde as amplitudes $A_{i}$ se calculam a partir da função estacionária de densidade espectral de potência $G \ddot{U} g(\omega)$ que se obtém a partir do espectro de resposta $S_{a}(T)$.

\subsubsection{Duração do sismo}

A duração do movimento sísmico é muito importante, onde a quantidade de dano nas estruturas aumenta com o número de ciclos de carga. A duração do movimento está relacionada com a magnitude e a distância da fonte, e ao aumentar a magnitude, aumenta também à duração.

A NBR 15421 (2006) não indica nenhum requisito quanto à duração dos acelerogramas artificiais de projeto, tampouco a norma europeia EC8 (2004).

A definição da duração é um parâmetro de ampla variabilidade, uma previsão confiável é difícil de ser feita. Contudo, até o momento não há uma definição universal aceita para a duração aparente de um movimento do solo devido a um sismo (GONZALEZ, 2006). Nas últimas décadas um grande número de pesquisadores indicaram definições da duração do movimento sísmico, estas definições foram revisadas por Bommer e Martínez-Perereira(1999) e classificadas em quatro grupos genéricos: duração limitada $\left(D_{1}\right)$, duração uniforme $\left(D_{u}\right)$, duração significativa $\left(D_{\mathrm{s}}\right)$ e duração baseada na resposta da estrutura mediante a ação sísmica.

A duração limitada $\left(D_{1}\right)$ é definida pelo tempo que decorre entre a primeira e última vez que um valor de aceleração específico é atingido. A Figura 10 ilustra o conceito. 
Figura 10 - Duração limitada $\left(\mathrm{D}_{1}\right)$

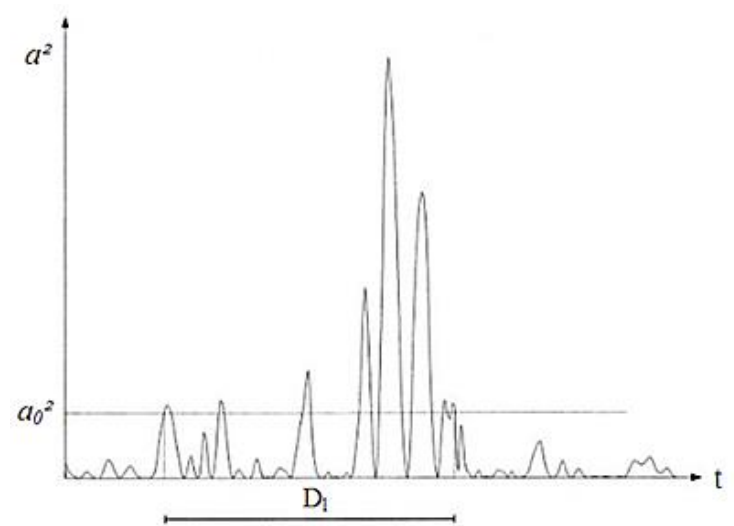

Fonte: Bommer e Martínez-Perereira (1999) - adaptado

O fato de não levar em conta o que se passa neste intervalo de tempo pode levar a um aumento significativo da duração, sendo uma desvantagem, pois um aumento mínimo do nível de aceleração de referência pode-se aumentar expressivamente a duração.

Com a intenção de não ignorar o que se passa no intervalo definido pela duração limitada $\left(D_{1}\right)$, a duração uniforme $\left(D_{u}\right)$ é definida como o somatório de todos os instantes que o acelerograma registra valores superiores ao valor da aceleração de referência. A Figura 11 ilustra o conceito.

$$
D_{u}=\sum_{i=1}^{n} t_{i}
$$

Figura 11 - Duração uniforme $\left(\mathrm{D}_{\mathrm{u}}\right)$

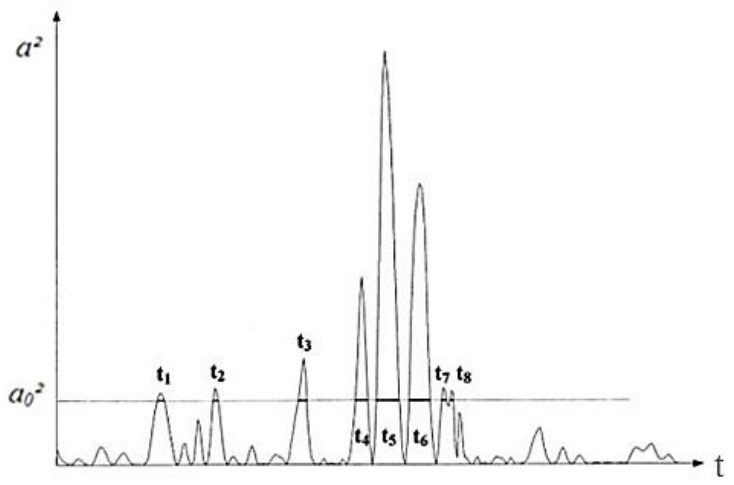

Fonte: Bommer e Martínez-Perereira (1999) - adaptado 
Ao contrário da duração limite, a duração uniforme apresenta menor instabilidade, ou seja, uma alteração do nível de aceleração de referência faz com que a duração não aumente expressivamente. A desvantagem desta definição é não atribuir uma janela contínua de tempo, na qual as contribuições das acelerações são graves à estrutura (MOUTINHO, 2014).

A duração significativa $\left(\mathrm{D}_{\mathrm{s}}\right)$ está associada com a energia acumulada do acelerograma e tem como vantagem a característica de considerar o acelerograma inteiro e definir uma janela de tempo contínua. Esta definição está relacionada com a intensidade de Arias (ARIAS, 1970) e é definida pela seguinte expressão:

$$
I_{A}=\frac{\pi}{2 g} \int_{0}^{t f} a^{2}(t) d t
$$

onde $I_{A}$ é definido com a Intensidade de Arias, $a(t)$ corresponde ao registro de acelerações ao longo do tempo, $t f$ é a duração total do acelerograma e $g$ é a aceleração devido à gravidade.

A duração significativa $\left(D_{s}\right)$ é definida como o intervalo sobre o qual uma proporção da área é acumulada. O conceito descrito é apresentado na Figura 12 através de um gráfico Husid, gráfico que representa a intensidade de Arias em função do tempo.

Figura 12 - Duração significativa $\left(\mathrm{D}_{\mathrm{s}}\right)$

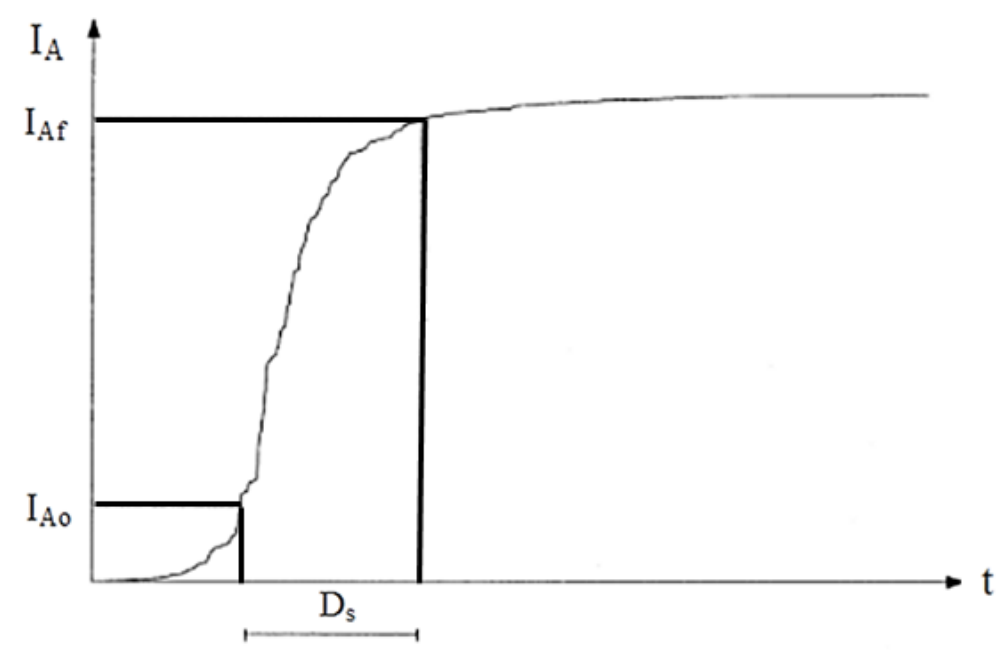

Fonte: Bommer e Martínez-Perereira (1999) - adaptado

A recomendação mais usual é a de Trifunac e Brady (1975), onde indica uma duração significativa $\left(D_{s}\right)$ com intervalo correspondente a $5 \%$ e a $95 \%$ de toda a energia desenvolvida. A Figura 13 ilustra esta indicação. 
Figura 13 - Duração segundo Trifunac e Brady

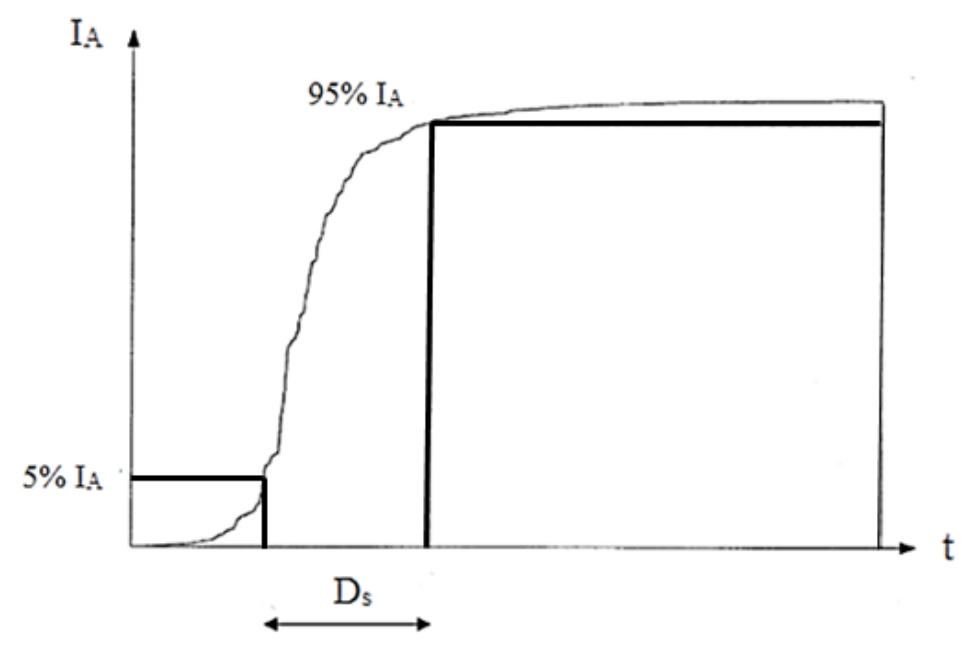

Fonte: Trifunac e Brady (1975) - adaptado

\subsubsection{Função envoltória}

Para simular o caráter transitório dos sismos reais, se utiliza uma função de intensidade envoltória determinista $I(t)$ predefinida (BARBAT et al., 1994). Existe uma vasta gama de funções envoltórias para cada tipo de sismo. Na Figura 14 são ilustrados alguns exemplos de funções obtidas a partir das observações dos registros reais.

Figura 14 - Funções de intensidade para simular o caráter transitório dos sismos reais
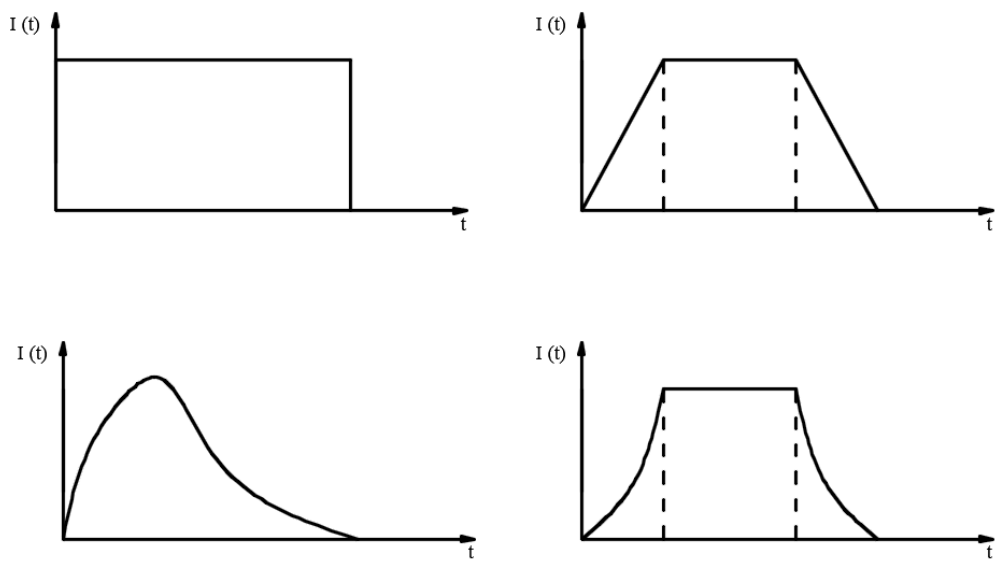

Fonte: Carr (1997) - adaptado

Neste trabalho, optou-se pela função de forma trapezoidal proposta por Hou (1968). A Figura 15 ilustra esta função: 
Figura 15 - Função envoltória trapezoidal

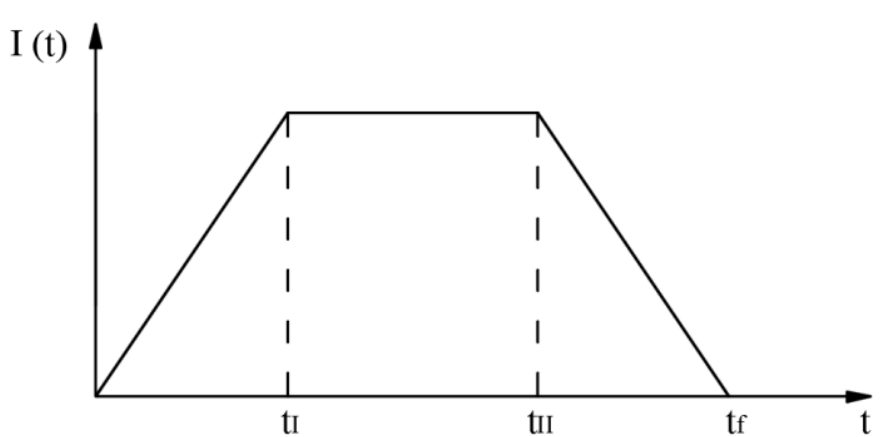

Fonte: Hou (1968) - adaptado

$$
I(t)= \begin{cases}\frac{t}{t_{1}}, & 0 \leq t<t_{I} \\ 1, & t_{I} \leq t<t_{I I} \\ \frac{\left(t-t_{f}\right)}{\left(t_{I I}-t_{f}\right)}, & t_{I I} \leq t \leq t_{f}\end{cases}
$$

\subsubsection{Cálculo das Amplitudes}

Sabe-se que em um processo dado por uma função aleatória estacionária com média nula, a variância da função é igual à potência total de sua função de densidade espectral (BARBAT et al., 1994).

$$
\sigma_{\ddot{U} g}^{2}=\int_{0}^{\infty} G_{\ddot{U} g}(\omega) d \omega
$$

Além disso, a variância de uma função sinusoidal, dada pela equação

$$
\ddot{y}(t)=A \sin (t)
$$

é igual a 


$$
\sigma_{\ddot{y}}^{2}=\frac{1}{2 \pi} \int_{0}^{2 \pi} A^{2} \sin ^{2}(t) d t=\frac{A^{2}}{2}
$$

Consequentemente, a potência total do processo definido pela eq.(4.1) de acordo com as Eqs. (4.5) e (4.7) é:

$$
\int_{0}^{\infty} G_{\ddot{U} g}(\omega) d \omega=\sigma_{\ddot{U} g}^{2}=\sum_{i=n}^{n} \frac{A_{i}^{2}}{2}
$$

Aproximando a potência total como o integral da área sob a curva $G_{\ddot{U} g}(\omega)$,

$$
\sum_{i=1}^{n} G_{\ddot{U} g}\left(\omega_{i}\right) \Delta \omega_{i}=\sum_{i=n}^{n} \frac{A_{i}^{2}}{2}
$$

Esta expressão será válida apenas quando o número de funções senoidais $n$ na função que define o processo $a(t)$ seja grande.

Uma vez que a densidade espectral de potência $G_{\ddot{U} g}(\omega)$ representa a contribuição relativa de cada $\omega_{i}$ frequência, pode-se aceitar a hipótese de igualdade da somatória na eq. (4.9):

$$
G_{\ddot{U} g}\left(\omega_{i}\right) \Delta \omega_{i} \approx \frac{A_{i}^{2}}{2}
$$

Portanto, a amplitude expressa na eq.(4.1) é definida como:

$$
A_{i} \approx \sqrt{2 G_{\ddot{U} g}\left(\omega_{i}\right) \Delta \omega_{i}}
$$

\subsubsection{Função Densidade Espectral de Potência (PSD)}

Para o cálculo da Função de Densidade de Espectral de Potência (PSD), a literatura apresenta diversos métodos. Neste trabalho optou-se pelo método proposto por Barone et al. (2015), devido a sua simplicidade de aplicação. Contudo, fizeram-se necessárias algumas adaptações do método para compatibilizar com espectros de resposta composto por três patamares de acelerações, como o da norma brasileira, por exemplo.

Em particular, uma função PSD $G_{U ̈ g}(\omega)$ da aceleração do solo é considerada compatível com o espectro de aceleração especificado $S_{a}(T)$, se um sistema de um grau de liberdade com uma taxa de amortecimento especificada sujeito às amostras de acelerogramas 
gerados a partir de $G_{\ddot{U}_{g}}(\omega)$, gerar acelerações máximas absolutas $S_{a}(T)$ para cada $T$, dentro de uma janela de tempo da duração nominal da parte pseudo-estacionária do sismo $T_{s}$ (BARONI et al., 2015).

Segundo Soriano (2000), a aceleração espectral também pode ser expressa como:

$$
S_{a}(\omega, \xi)=\omega^{2} \eta_{U}(\omega, \xi) \sigma_{U}(\omega, \xi)
$$

onde o fator de pico $\eta_{U}$ (VANNMARCKE, 1972) é definido pela equação:

$$
\eta_{U}(\omega, \xi)=\sqrt{2 \ln \left\{2 N_{U}(\omega)\left[1-\exp \left(-\delta_{U}^{1,2}(\xi) \sqrt{\left.\pi \ln \left(2 N_{U}(\omega)\right)\right)}\right]\right\}\right.}
$$

Apesar da resposta do sistema não ser previamente conhecida, o parâmetro $N_{U}(\omega)$ e o fator de propagação $\delta_{U}(\xi)$ podem ser expressos pelas seguintes expressões aproximadas (KIUREGHIAN, 1980):

$$
\begin{gathered}
N_{U}(\omega)=-\frac{T_{s}}{2 \pi} \frac{\omega}{\ln (0,5)} \\
\delta_{U}(\xi)=\sqrt{1-\frac{1}{1-\xi^{2}}\left[1-\frac{2}{\pi} \arctan \left(\frac{\xi}{\sqrt{1-\xi^{2}}}\right)\right]^{2}}
\end{gathered}
$$

Sendo $\xi=0,05, \delta_{U}(\xi)=0,24561$. Uma vez conhecido o PSD, o espectro de resposta pode ser facilmente encontrado. No entanto, o problema inverso não é fácil devido a não linearidade da equação de $S_{a}(\omega, \xi)$. Para superar esse problema, uma expressão aproximada para a variância da resposta pode ser usada (VANMARCKE, 1977) para se determinar o PSD:

$$
\begin{gathered}
G_{\ddot{U} g}(\omega)=\frac{\gamma}{\omega_{C}}\left[\left(\frac{S_{a}(\omega, \xi)}{\eta_{U}(\omega, \xi)}\right)^{2}-\int_{0}^{\omega} G_{\ddot{U} g}(\omega) d \omega\right] \\
\gamma=\frac{4 \xi}{(\pi-4 \xi)}
\end{gathered}
$$


Não é simples determinar de forma fechada o PSD com a expressão anterior, uma vez que a determinação da função $G_{\ddot{U} g}(\omega)$, em uma determinada frequência requer o conhecimento do mesmo PSD para todas as frequências anteriores. Uma solução numérica foi proposta por Cacciola; Colajanni e Muscolino (2004), em que o PSD é discretizado através de funções por partes constantes:

$$
G_{\ddot{U} g}\left(\omega_{i}\right)=\frac{4 \xi}{\left(\pi \omega_{i}-4 \xi_{i-1}\right) \omega_{C}}\left[\left(\frac{S_{a}\left(\omega_{i}, \xi\right)}{\eta_{U}\left(\omega_{i}, \xi\right)}\right)^{2}-\Delta \omega \sum_{j=1}^{i-1} G_{\ddot{U} g}\left(\omega_{j}\right)\right]
$$

Vale ressaltar que a efetividade do procedimento não depende da forma do espectro de resposta e ele pode ser utilizado para espectros de resposta não suavizados como no caso de históricos no tempo de sismos naturais. No entanto, é necessário realizar o procedimento diversas vezes para vários parâmetros do espectro de resposta. Diante disso, Baroni et al. (2015) realizaram uma extensa campanha numérica variando a intensidade e o formato do espectro de resposta e avaliando o PSD correspondente. Os autores observaram que o método numérico sempre retornava PSDs com o formato indicado na Figura 16.

Figura 16 - PSD compatível com Espectro de resposta

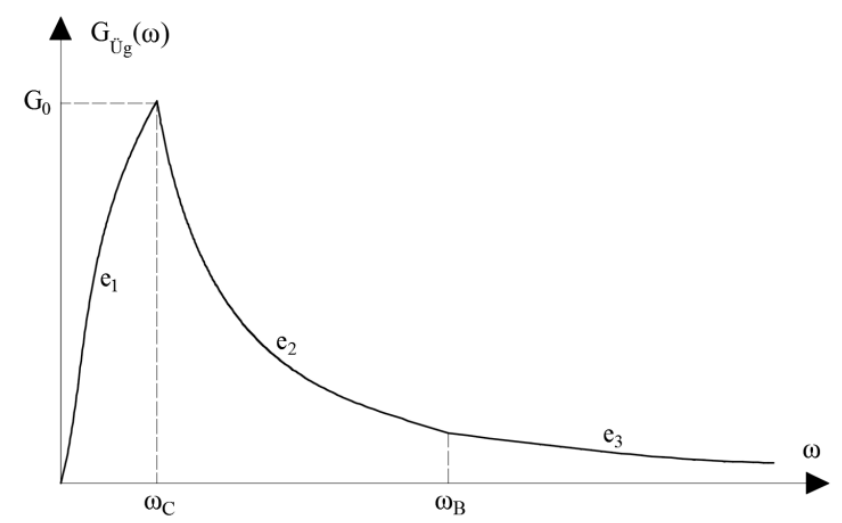

Fonte: Baroni et al., (2015) - adaptado

Portanto, pode-se descrever o PSD como uma função com três intervalos e com uma estrutura matemática simples e totalmente definida por apenas alguns parâmetros determinados a partir da equação exata de $G_{\ddot{U} g}(\omega)$, sendo $\mathrm{G}_{0}$ o valor de pico do PSD para $\omega=\omega_{C}:$ 


$$
G_{\ddot{U} g}(\omega)= \begin{cases}G_{0}\left(\frac{\omega}{\omega_{C}}\right)^{e 1} & 0 \leq \omega \leq \omega_{C} \\ G_{0}\left(\frac{\omega}{\omega_{C}}\right)^{e 2} & \omega_{C}<\omega \leq \omega_{B} \\ G_{0}\left(\frac{\omega_{B}}{\omega_{C}}\right)^{e 2}\left(\frac{\omega}{\omega_{B}}\right)^{e 3} & \omega>\omega_{B}\end{cases}
$$

Para determinar o expoente $e_{1}$, a eq.(4.16) é reescrita para $\omega=\omega_{\mathrm{C}}$

$$
G_{0} \frac{\omega_{C}^{e l+1}}{\omega_{B}^{e 1}}=\frac{\gamma}{\omega_{C}}\left[\left(\frac{2,5 a_{g s 0}\left(\frac{\omega_{C}}{\omega_{B}}\right)}{\eta_{U}\left(\omega_{C}\right)}\right)^{2}-\int_{0}^{\omega_{C}} G_{\ddot{U} g}(\omega) d \omega\right]
$$

E substituindo a eq.(4.19) no segundo termo:

$$
G_{0} \omega_{C}\left(\frac{\omega_{C}}{\omega_{B}}\right)^{e_{1}+1} \frac{\gamma+1}{\gamma}=\left(\frac{2,5 a_{g s 0}\left(\frac{\omega_{C}}{\omega_{B}}\right)}{\eta_{U}\left(\omega_{C}\right)}\right)^{2}
$$

Então seguindo o mesmo raciocínio, mas considerando uma nova frequência $\omega=\omega_{\mathrm{C}} \rho(\rho>1)$, é obtida a seguinte expressão:

$$
G_{0} \omega_{C}\left(\frac{\omega_{C}}{\omega_{B}}\right)^{e_{1}+1} \frac{\gamma+1}{\gamma}=\left(\frac{2,5 a_{g s 0}\left(\frac{\omega_{C}}{\omega_{B}}\right)}{\eta_{U}\left(\frac{\omega_{C}}{\rho}\right)}\right)^{2} \rho^{-1}
$$

Comparando as Eqs. (4.21) e (4.22) e considerando o limite $\rho=1$, pode ser demonstrado que o expoente $\mathrm{e}_{1}$ pode ser expresso como:

$$
e_{1}=2-L\left(\omega_{D}\right)
$$

onde a função $L(\omega)$ é definida como:

$$
L(\omega)=2 \omega \frac{d\left(\log \left(\eta_{U}(\omega)\right)\right)}{d \omega}
$$


A avaliação das expressões de forma fechada para os outros parâmetros é baseada nos mesmos conceitos, mas, considerando os pontos sobre os outros três ramos do PSD. Depois de alguma álgebra, o seguinte conjunto de parâmetros é obtido:

$$
\begin{gathered}
e_{1}=1-L\left(\omega_{C}\right) \\
e_{2}=-1-\gamma-\beta_{2} L\left(\omega_{C}\right) \\
e_{3}=-1-\gamma-\beta_{3}\left(L\left(\omega_{B}\right)+1,2\right) \\
G_{0}=\frac{\gamma}{\beta_{2} \omega_{C}}\left(\frac{2,5 a_{g s 0}}{\eta_{U}^{2}\left(\omega_{C}\right)}\right)^{2}
\end{gathered}
$$

com as seguintes posições:

$$
\begin{gathered}
\beta_{2}=\frac{\gamma+e_{1}+1}{e_{1}+1} \\
\beta_{3}=\left(\frac{\omega_{C}}{\omega_{B}}\right)^{e_{2}+1} \beta_{2}+\left(1-\left(\frac{\omega_{C}}{\omega_{B}}\right)^{e_{2}+1}\right) \frac{\gamma+e_{2}+1}{e_{2}+1}
\end{gathered}
$$

\subsubsection{Ajuste do acelerograma artificial gerado}

Uma vez calculada a função de densidade espectral de potência segundo o item 4.3.4, pode-se gerar um sinal de excitação, compatível com o espectro de resposta, usando as eqs.(4.11) e (4.1). Logo se multiplica pela função de intensidade $I(t)$, com o que se obtém a função não estacionária $a(t)$. Além das acelerações, outras características do solo geralmente são de interesse, como a velocidade e deslocamento. No entanto, o sinal gerado apresenta algumas deficiências que facilmente podem ser eliminadas ou melhoradas para que os resultados obtidos tenham uma maior semelhança com os fenômenos observados. Assim por 
exemplo, normalmente se deseja especificar a aceleração máxima que terá o sinal, sendo importante que a velocidade final e o deslocamento do solo sejam praticamente nulos. Segundo Husid (1973), as correções que geralmente são feiras são por ajuste da linha de base ou de zeros, ajuste da aceleração máxima e ajuste da resposta espectral. Nos itens a seguir são apresentados estes ajustes com maiores detalhes.

\subsubsection{Ajuste da linha de base}

Às vezes, ocorre que os valores dos acelerogramas gerados se encontram deslocados do eixo zero de aceleração. Embora este erro possa ser desprezível tratando-se de acelerações, pode ser muito importante quando obtido velocidades e deslocamentos por integração. $\mathrm{O}$ acelerograma $a(t)$ gerado pode ser processado da mesma forma que se faz com um acelerograma registrado de um terremoto real. Assim, a correção da linha de base pode ser feita da mesma forma que foi descrita por Berg e Housner (1961) para tentar que tanto a velocidade quanto o deslocamento tendem a ser zero no final do terremoto. Isto pode ser conseguido com uma correção da linha de base do acelerograma, onde os coeficientes de correção são escolhidos de maneira tal que minimizem o valor quadrático médio da velocidade.

Sendo $a(t)$ um acelerograma gerado mediante o procedimento descrito, o acelerograma corrigido $a^{\prime}(t)$ tem a seguinte forma:

$$
a^{\prime}(t)=a(t)+c_{0}+c_{1} \frac{t}{t_{f}}+c_{2}\left(\frac{t}{t_{f}}\right)^{2}
$$

Sendo $t_{f}$ a duração total do sinal. A velocidade é obtida integrando a eq.(4.31) com condições nulas e os coeficientes $c_{0}, c_{1}$, e $c_{2}$ são escolhidos de maneira que o valor quadrático médio seja mínimo no intervalo 0 a $\mathrm{t}_{\mathrm{f}}$ Com isso chega-se a seguinte relação:

$$
\left\{\begin{array}{l}
c_{0} \\
c_{1} \\
c_{2}
\end{array}\right\}=\left[\begin{array}{ccc}
-300 & 900 & -630 \\
1800 & -5760 & 4200 \\
-1890 & 6300 & -4725
\end{array}\right]\left\{\begin{array}{l}
b_{0} \\
b_{1} \\
b_{2}
\end{array}\right\}
$$


onde

$$
b_{k}=t f^{-k-3} \int_{0}^{t f} v(t) t^{k+1} d t \quad \mathrm{k}=0,1,2
$$

Sendo $v(t)$ a velocidade correspondente a $a(t)$.

As integrais da eq.(4.33) são valoradas numericamente, sob a hipótese de que a aceleração $a(t)$ varia linearmente entre os instantes de tempos consecutivos. Depois desta correção, a integração dupla de $a^{\prime}(t)$ proporciona as velocidades e deslocamentos, respectivamente. Embora normalmente as funções $a(t)$ e $a^{\prime}(t)$ são similares, é importante a modificação da velocidade $v(t)$ (BARBAT et al., 1994).

\subsubsection{Ajuste da aceleração máxima}

Deve-se notar que a aceleração máxima resultante do algoritmo descrito, é uma variável aleatória e embora o espectro de resposta fosse adequadamente escalado segundo uma aceleração máxima, o procedimento descrito não garante que o resultado final proporcione esta aceleração. No entanto, é de se esperar que a diferença entre a obtida e a esperada seja relativamente pequena. Por isso, se pode impor diretamente o valor desejado da aceleração máxima tendo em conta duas alternativas possíveis:

Se o valor absoluto da aceleração máxima encontrada é menor que a especificada, simplesmente se modifica seu valor absoluto ao valor desejado;

Se este valor absoluto é maior, se escalam todas aquelas acelerações cujo valor absoluto ultrapasse o especificado.

O procedimento descrito garantirá que somente exista uma aceleração máxima de valor absoluto igual ao especificado. Finalmente, se deve notar que esta modificação artificial somente afeta a resposta no patamar de frequências bem altas (BARBAT et al., 1994).

\subsubsection{Ajuste da resposta espectral}

O caráter aproximado das expressões anteriores e os ajustes de linha de base e aceleração máxima fazem que o espectro de resposta do acelerograma artificial, embora compatível, não seja exatamente igual ao especificado. Consequentemente, pode-se melhorar 
o ajuste entre ambos os espectros. Para isto, se utiliza um procedimento cíclico em que se compara o espectro de resposta com o especificado em um conjunto de frequências de controle $\mathrm{j}=1, \ldots, \mathrm{m}$. Em cada frequência de controle $\mathrm{j}$ se obtém a relação entre a resposta desejada e calculada. Para melhorar o ajuste, se modifica o valor correspondente da função de densidade espectral de potência em proporção ao quadrado desta relação com a que gera um novo sinal sísmico.

$$
G_{\ddot{U} g}\left(w_{j}\right)_{i+1}=G_{\ddot{U} g}\left(w_{j}\right)_{i}\left[\frac{S_{v}\left(w_{j}\right)}{S_{v}^{i}\left(w_{j}\right)}\right]^{2} \quad j=1, \ldots, \mathrm{m}
$$

Este procedimento não é convergente em todas as frequências de controle. O processo iterativo descrito é baseado na hipótese de que o valor da densidade espectral de potência em uma frequência dada depende exclusivamente de tal frequência. No entanto, esta depende também dos valores desta função em frequência próximas. Por esta razão, o algoritmo iterativo descrito melhora o ajuste somente nas primeiras iterações, nas que o efeito das frequências distantes é desprezível. 


\section{Shear Building}

\subsection{Modelo estrutural típico para estruturas tipo shear building}

A determinação da resposta sísmica de uma estrutura depende tanto das características estruturais como de uma definição dos movimentos do solo adequada.

Um modelo de edifício tipo shear building é definido como uma estrutura na qual não se produzem rotações nos membros horizontais à altura das lajes devido à elevada rigidez dessas e que as colunas são inextensíveis. Para que a estrutura apresente tal comportamento, as seguintes hipóteses devem ser obedecidas. (BRASIL e SILVA, 2013):

- os pavimentos têm rigidez muito grande em relação às colunas, e essas são consideradas inextensíveis;

- toda a massa da estrutura está concentrada no nível das lajes.

Em outras palavras, o edifico é simétrico, as lajes são infinitamente rígidas e as colunas não sofrem deformação axial. Em consequência, o único movimento dos nós é horizontal.

\subsection{Equações de movimento para edifícios shear building}

As expressões matemáticas que expressam a resposta dinâmica das estruturas são conhecidas como equações do movimento. Estas equações podem ser expressas utilizando qualquer um dos princípios da mecânica clássica. Na Figura 17 é representado um esquema para a determinação das equações de movimento segundo o Princípio de d'Alembert. 
Figura 17 - Modelo de edifício shear building. (a) Modelo sísmico; (b) equilíbrio de forças

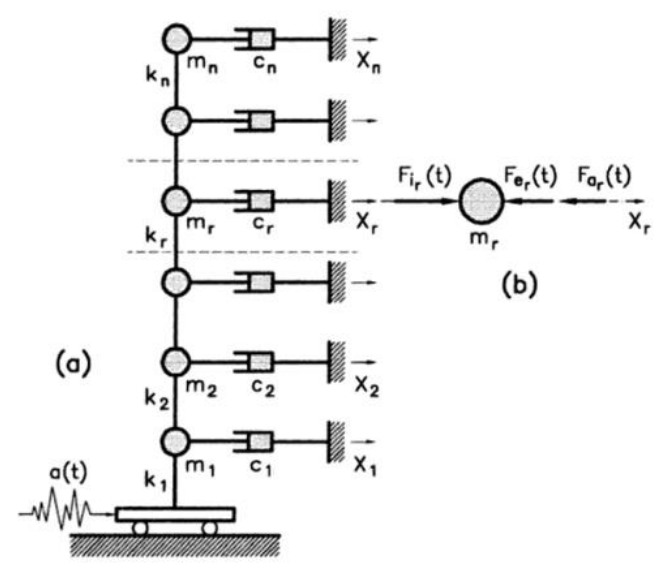

Fonte: Rotondo e Barbat (2009)

O modelo está submetido a uma aceleração horizontal na base $a(t)$ de origem sísmica. Isolando as massas $m$ e introduzindo todas as forças correspondentes, resultará no esquema da Figura 17(b), que pode ser expresso matematicamente:

$$
F_{i}(t)-F_{e}(t)-F_{a}(t)=0
$$

onde $F_{i}(t), F_{e}(t), F_{a}(t)$ são as forças de inércia, elásticas e de amortecimento respectivamente para cada grau de liberdade.

Os vetores das forças elásticas, de inercia e de amortecimento se definem mediante as expressões matriciais:

$$
\begin{aligned}
& F_{e}(t)=[K]\{u(t)\} \\
& \left.F_{i}(t)=-[M][\ddot{u}(t)\}+\{1\} a(t)\right] \\
& F_{a}(t)=[C]\{\dot{u}(t)\}
\end{aligned}
$$

onde $\{\mathrm{u}(\mathrm{t})\}=\left[\mathrm{u}_{1}(\mathrm{t}) \ldots \mathrm{u}_{\mathrm{i}}(\mathrm{t})\right]$ é o vetor de deslocamento da base do edifício.

[K] é a matriz de rigidez, cujas componentes são as forças elásticas que se desenvolvem em um grau de liberdade quando se impõe um deslocamento unitário a um outro 
grau de liberdade. Para um comportamento elástico a rigidez $k_{i}$ que representa a rigidez do pilares entre lajes é

$$
k_{i}=\frac{12 E I}{l_{i}^{3}}
$$

sendo $E$ o módulo de elasticidade do material, $I_{i}$ a somatória dos momentos de inércia dos pilares para cada pavimento e $\mathrm{l}_{\mathrm{i}}$ indica o comprimento do pilar.

Genericamente, a matriz de rigidez que representará todo o edifício terá o seguinte aspecto:

$$
[K]=\left[\begin{array}{ccccccc}
k_{1}+k_{2} & -k_{2} & 0 & 0 & & & \\
-k_{2} & k_{2}+k_{3} & -k_{3} & 0 & & 0 & \\
0 & -k_{3} & k_{3}+k_{4} & -k_{4} & & & \\
\ldots & \ldots & \ldots & \ldots & & & \\
& & & & k_{i}+k_{i+1} & -k_{i+1} & 0 \\
& 0 & & & \ldots & \ldots & \ldots \\
& & & & \ldots & \ldots & k_{n}
\end{array}\right]
$$

[M] é a matriz de massa cuja componente é à força de inércia na direção $\ddot{u}_{i}$ em virtude da imposição de aceleração unitária, esta matriz é diagonal, pois, não existe interação entre as massas associadas a dois graus de liberdade do sistema. [C] é a matriz de amortecimento cujas componentes são as forças de amortecimento na direção $\dot{u}_{i}$ em virtude de da imposição de velocidade unitária a outra coordenada.

Para detalhamento da construção das matrizes das equações de movimento, a literatura possui inúmeros bons trabalhos tratando sobre o assunto. Dentre esses trabalhos, recomendase as referências Brasil e Silva (2013), Clough e Penziem (1975), Soriano (2014).

Referente à matriz de amortecimento $[\mathrm{C}]$, a força de amortecimento é produzida principalmente por efeito da própria viscosidade do material. Habitualmente se utiliza um amortecimento viscoso proporcional a velocidade, que é baseado no modelo de Kelvin-Voigt. Segundo Barbat (2004), sua utilização se deve a capacidade de descrever de uma maneira simples o amortecimento global de toda a estrutura e obter a solução fechada na equação diferencial do movimento. Nestas condições se obtém a matriz de amortecimento 
proporcional a matriz de massa e rigidez, proposto por Rayleigh, apresentado em Clough e Penziem (1975).

$$
C=\alpha_{1}[M]+\alpha_{2}[K]
$$

onde $\alpha_{1}$ e $\alpha_{2}$ são obtidos resolvendo o sistema:

$$
\frac{1}{2}\left[\begin{array}{cc}
\frac{1}{\omega_{r}} & \omega_{r} \\
\frac{1}{\omega_{s}} & \omega_{s}
\end{array}\right]\left[\begin{array}{l}
\alpha_{1} \\
\alpha_{2}
\end{array}\right]=\left[\begin{array}{l}
\xi_{r} \\
\xi_{s}
\end{array}\right]
$$

Os valores $\omega_{r}$ e $\omega_{s}$ são as frequências naturais de vibração da estrutura para os dois modos para os quais foram definidas as taxas de amortecimento $\xi_{r}$ e $\xi_{s}$.

Substituindo essas matrizes, se obtém as seguintes equações de movimento para o edifício tipo shear building submetido a uma aceleração na base,

$$
[M]\{\ddot{u}(t)\}+[C]\{\dot{u}(t)\}+[K]\{u(t)\}=-[M]\{1\} a(t)
$$

As vibrações livres amortecidas em um modelo dinâmico são expressas como

$$
[M]\{\ddot{u}(t)\}+[C]\{\dot{u}(t)\}+[K]\{u(t)\}=0
$$

Desprezando-se o amortecimento e adotando carregamento nulo, os únicos movimentos possíveis se devem às condições iniciais de deslocamento,

$$
[M]\{\ddot{u}(t)\}+[K]\{u(t)\}=0
$$

que é o sistema de equações que descreve as vibrações livres não amortecidas. 


\subsection{Modelo shear building estudado}

A estrutura em estudo é um edifício do tipo shear building de 10 pavimentos, sendo cada pavimento idealizado como uma massa concentrada de 25 toneladas a cada 3,5 metros. A estrutura é esquematizada na Figura 18.

Figura 18 - Modelo de edifício shear building

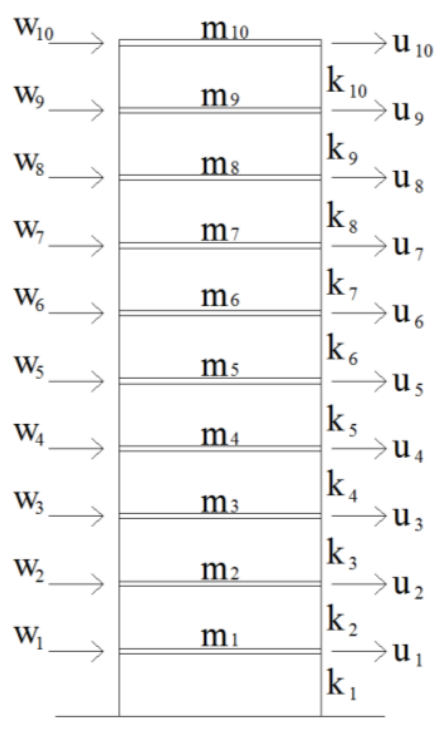

Fonte: Brasil e Brito (2016)

Isolando-se a massa $m$ o equilíbrio dinâmico do pavimento $i$ é dado pela Figura 19.

Figura 19 - Equilíbrio dinâmico da massa $i$

$$
\begin{aligned}
& \mathrm{k}_{\mathrm{i}+1}\left(\mathrm{u}_{\mathrm{i}}-\mathrm{u}_{\mathrm{i}+1}\right) \\
& \mathrm{k}_{\mathrm{i}}\left(\mathrm{u}_{\mathrm{i}}-\mathrm{u}_{\mathrm{i}-1}\right) \\
& \mathrm{m}_{\mathrm{i}} \longrightarrow \mathrm{W}_{\mathrm{i}}
\end{aligned}
$$

Fonte: Brasil e Brito (2016)

Que resulta na seguinte equação de movimento:

$$
m_{i} \ddot{u}_{i}-k_{i} u_{i+1}+\left(k_{i}+k_{i+1}\right) u_{i}-k_{i+1} u_{i+1}=w_{i}
$$


Como todos os pavimentos possuem a mesma massa, a matriz de massa diagonal é a seguinte:

$$
[M]=\left[\begin{array}{cccccccccc}
m & 0 & 0 & 0 & 0 & 0 & 0 & 0 & 0 & 0 \\
0 & m & 0 & 0 & 0 & 0 & 0 & 0 & 0 & 0 \\
0 & 0 & m & 0 & 0 & 0 & 0 & 0 & 0 & 0 \\
0 & 0 & 0 & m & 0 & 0 & 0 & 0 & 0 & 0 \\
0 & 0 & 0 & 0 & m & 0 & 0 & 0 & 0 & 0 \\
0 & 0 & 0 & 0 & 0 & m & 0 & 0 & 0 & 0 \\
0 & 0 & 0 & 0 & 0 & 0 & m & 0 & 0 & 0 \\
0 & 0 & 0 & 0 & 0 & 0 & 0 & m & 0 & 0 \\
0 & 0 & 0 & 0 & 0 & 0 & 0 & 0 & m & 0 \\
0 & 0 & 0 & 0 & 0 & 0 & 0 & 0 & 0 & m
\end{array}\right]
$$

E a matriz de rigidez

$$
[K]=\left[\begin{array}{cccccccccc}
2 k & -k & 0 & 0 & 0 & 0 & 0 & 0 & 0 & 0 \\
-k & 2 k & -k & 0 & 0 & 0 & 0 & 0 & 0 & 0 \\
0 & -k & 2 k & -k & 0 & 0 & 0 & 0 & 0 & 0 \\
0 & 0 & -k & 2 k & -k & 0 & 0 & 0 & 0 & 0 \\
0 & 0 & 0 & -k & 2 k & -k & 0 & 0 & 0 & 0 \\
0 & 0 & 0 & 0 & -k & 2 k & -k & 0 & 0 & 0 \\
0 & 0 & 0 & 0 & 0 & -k & 2 k & -k & 0 & 0 \\
0 & 0 & 0 & 0 & 0 & 0 & -k & 2 k & -k & 0 \\
0 & 0 & 0 & 0 & 0 & 0 & 0 & -k & 2 k & -k \\
0 & 0 & 0 & 0 & 0 & 0 & 0 & 0 & -k & 2 k
\end{array}\right]
$$

\subsection{Integração numérica passo-a-passo no tempo}

A eq.(5.7) é integrada numericamente no tempo, usando as seguintes aproximações de diferenças finitas centrais para os vetores de velocidade e aceleração, no tempo $t_{\mathrm{i}}$ com o passo $h:$ 


$$
\begin{gathered}
\left\{\dot{u}_{i}\right\}=\frac{\left\{u_{i+1}\right\}-\left\{u_{i-1}\right\}}{2 h} \\
\left\{\ddot{u}_{i}\right\}=\frac{\left\{u_{i+1}\right\}-2\left\{u_{i}\right\}+\left\{u_{i-1}\right\}}{h^{2}}
\end{gathered}
$$

A forma resultante para cada passo de tempo é:

$$
\lfloor\hat{k}\rfloor\left\{u_{i+1}\right\}=\left\{\hat{p}_{i}\right\}
$$

onde

$$
\begin{gathered}
{[\hat{k}]=\frac{1}{h^{2}}[m]+\frac{1}{2 h}[c]} \\
\left\{\hat{p}_{i}\right\}=\left\{w_{i}\right\}-\left([k]-\frac{2}{h^{2}}[m]\right)\left\{u_{i}\right\}-\left(\frac{1}{h^{2}}[m]-\frac{1}{2 h}[c]\right)\left\{u_{i-1}\right\}
\end{gathered}
$$

\subsection{Conceito de comportamento Elastoplástico}

O interesse em estudar a resposta dinâmica de sistemas inelásticos provém do fato de que muitas estruturas são projetadas com a expectativa de que elas vão sofrer danos residuais durante a movimentação intensa causada por sismos. O desafio para o engenheiro é projetar a estrutura para que o dano seja controlado para um nível aceitável.

Desde 1960 centenas de testes de laboratório foram realizados para determinar o comportamento de componentes estruturais para condições sísmicas. Os resultados experimentais indicam que o comportamento da relação força-deformação cíclica depende do material estrutural e da tipologia da estrutura. A relação força-deformação para um componente estrutural de aço submetido a deformações cíclicas esperadas durante um sismo é mostrado na Figura 20 (CHOPRA, 2011). 
Figura 20 - Relação força-deformação do aço - comportamento elastoplástico

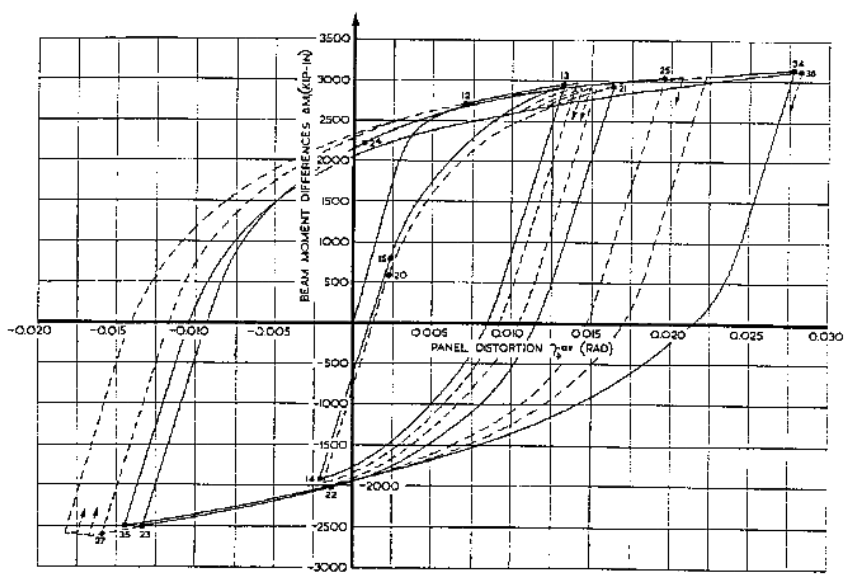

Fonte: Chopra (2011)

Durante um sismo, estruturas se submetem a um movimento oscilatório com inversão da deformação. Na Figura 20 a curva de solicitação inicial não é linear na maioria das amplitudes de deformação. Quando cessada a solicitação a curva difere do seu estado inicial, ou seja, retorna com uma deformação residual. Um sistema deste tipo se denomina elastoplástico.

\subsubsection{Idealização do Comportamento Elastoplástico}

Considere-se a relação tensão-deformação de uma estrutura durante o seu carregamento inicial mostrada na Figura 21.

Figura 21 - Comportamento elastoplástico real e idealizado elastoplástico

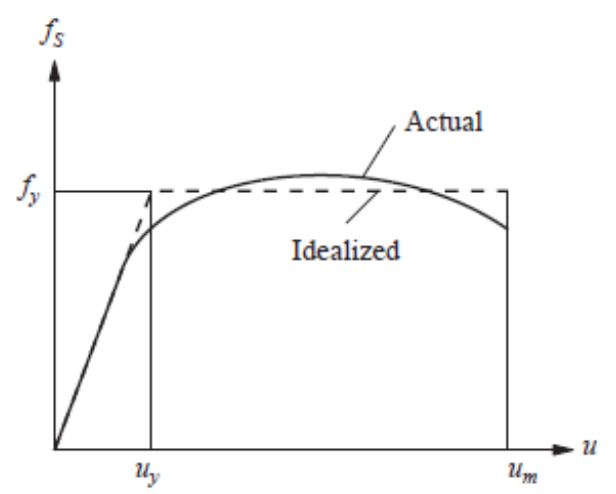

Fonte: Chopra (2011) 
A aproximação elastoplástica da relação força-deslocamento real é feita de modo que as áreas abaixo das curvas sejam as mesmas para o deslocamento máximo unitário. Neste sistema a solicitação inicial pode ser considerada elástica com rigidez $k$ sempre e quando a força é menor que $f_{y}$, resistência ao escoamento. A deformação na qual começa o escoamento é $u_{y}$, sendo que a partir deste ponto a resistência ao escoamento é constante, ou seja, rigidez é zero.

Dada as considerações acima, o comportamento conhecido como elastoplástico perfeito é obtido e pode ser observado na Figura 22.

Figura 22 - Comportamento elastoplástico perfeito

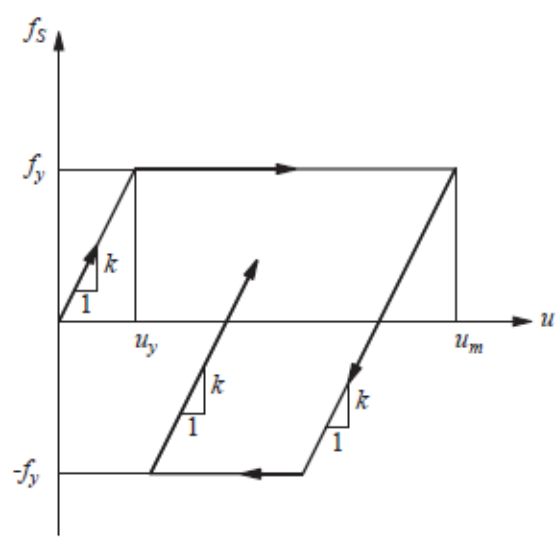

Fonte: Autor (2017)

A resistência à deformação é a mesma nos dois sentidos da deformação. O descarregamento a partir de um ponto de deformação máxima ocorre paralelamente ao patamar elástico inicial. De forma semelhante, a recarga de um ponto de deformação mínima ocorre também paralelamente ao patamar elástico inicial.

\subsubsection{Modelo Elastoplástico}

Assumindo-se que o material se comporta de maneira elastoplástica perfeita, é exibido na Figura 23 um esquema de grau de liberdade para o comportamento elástico e elastoplástico. 
Figura 23 - Esquema elástico (a) e elastoplástico (b)

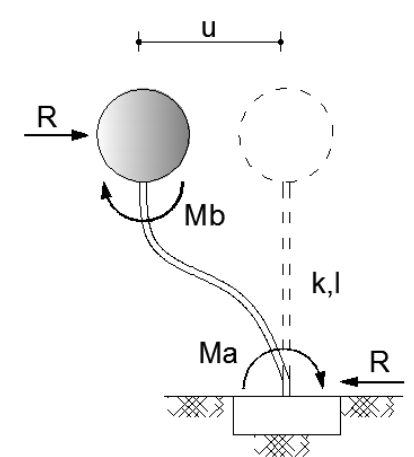

(a)

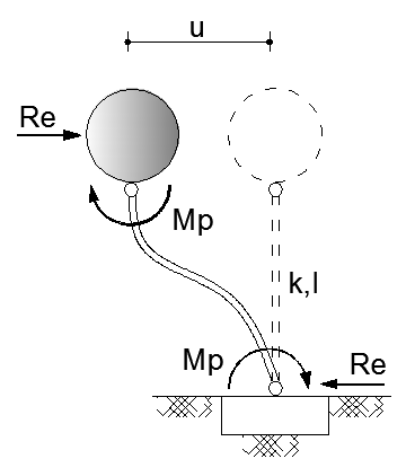

(b)

Fonte: Autor (2017)

O parâmetro utilizado para determinar o comportamento atuante é a força cortante restauradora local equivalente. Essa força cortante restauradora local equivalente $R$ é determinada para a coluna e é computada a partir dos momentos fletores em suas extremidades.

$$
R=\frac{M a+M b}{l}
$$

onde, $M a$ e $M b$ são os momentos fletores de extremidade. Para o caso elástico, com $n$ colunas, tem-se:

$$
M a=M b=n \frac{12 E I}{l_{i}^{3}} u
$$

onde $I$ é o momento de inércia da coluna e $u$ indica o deslocamento horizontal.

O valor máximo para o momento fletor, de acordo com o modelo elastoplástico ideal, é um valor absoluto igual ao momento de plastificação $M p$, dada pela expressão:

$$
M p=f_{y} Z
$$

sendo $Z$, o módulo de resistência plástico da coluna.

Consequentemente, a força cortante máxima restauradora Re para a coluna será: 


$$
\operatorname{Re}=2 \frac{M p}{l}
$$

Quando a força cortante restauradora local atuante for superior à força cortante máxima implicará em uma rigidez correspondente aquela coluna de valor nulo, ou seja, k=0. 


\section{Resultados}

Para a aplicação da teoria descrita, são estudados dois exemplos de aplicação do desenvolvimento teórico contido neste texto. O primeiro denominado caso A, inicia-se com a geração de um acelerograma artificial compatível com o espectro de resposta segundo as prescrições da norma brasileira NBR 15421(2006). Com a ação sísmica definida, é aplicada a base de um edifício tipo shear building, modelo apresentado no item 5.3, e através de integração numérica por diferenças finitas, é calculada sua resposta em deslocamento no tempo do último pavimento.

O segundo exemplo, denominado caso $\mathrm{B}$, também se inicia com a geração de um acelerograma artificial, neste compatível com a norma venezuelana COVENIN 1756 (2001). Com a ação definida, é aplicada a base de uma caixa d'água sob quatro pilares de perfis metálicos e é estudado o seu comportamento elastoplástico perfeito.

\subsection{Caso A}

Como já mencionado, a estrutura em estudo é a descrita no item 5.3. Para a definição da ação sísmica, os espectros de respostas são calculados segundo as prescrições na norma brasileira NBR 15421:2006. Foi considerada a aceleração sísmica horizontal do solo $a_{g}=0,15 g$ para terreno classificado como "C", tendo como fatores de amplificação dinâmica do solo, $C_{a}=1,2$ e $C_{v}=1,7$ e fator de amortecimento $\xi=5 \%$. O espectro de resposta resultante é mostrado na Figura 24.

Figura 24 - Espectro de resposta NBR 15421(2006) - Caso A

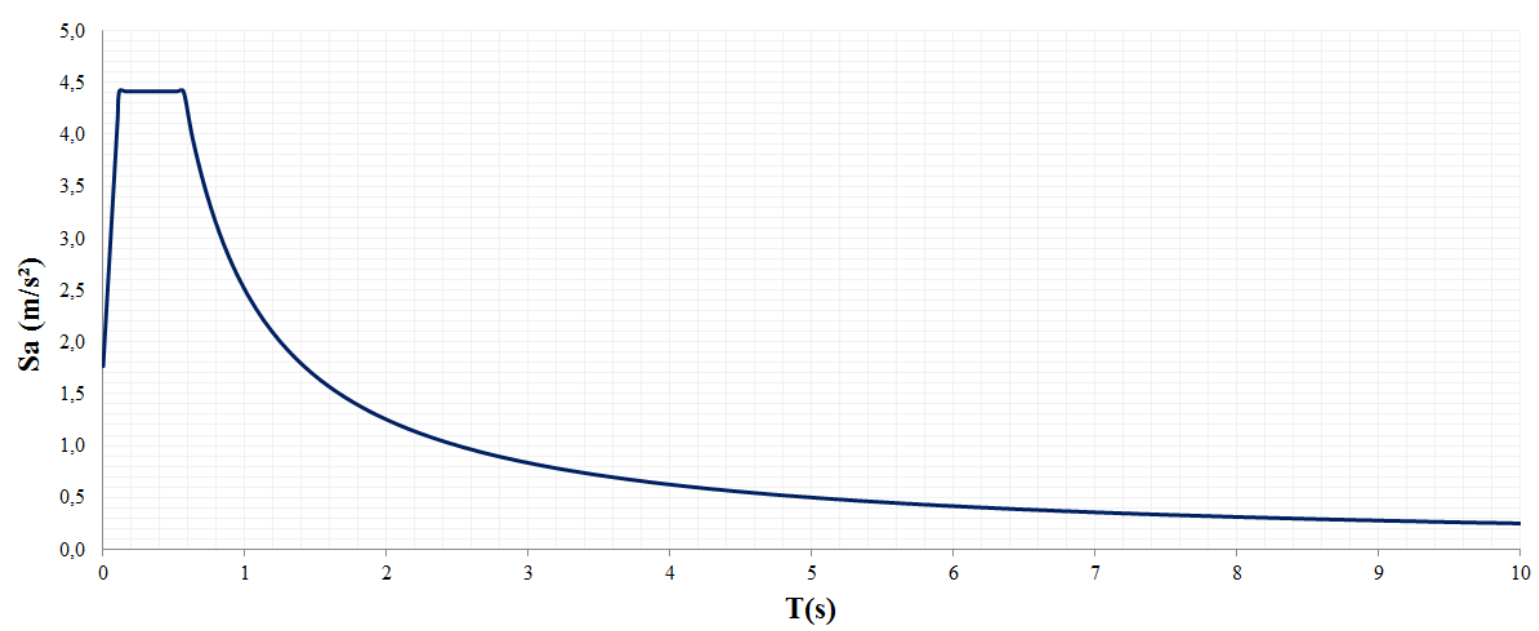

Fonte: Autor (2017) 
Aplicando-se a metodologia descrita no item 4.3.4, a Função de Densidade Espectral de Potência compatível como o espectro de resposta apresentado é mostrado na Figura 25.

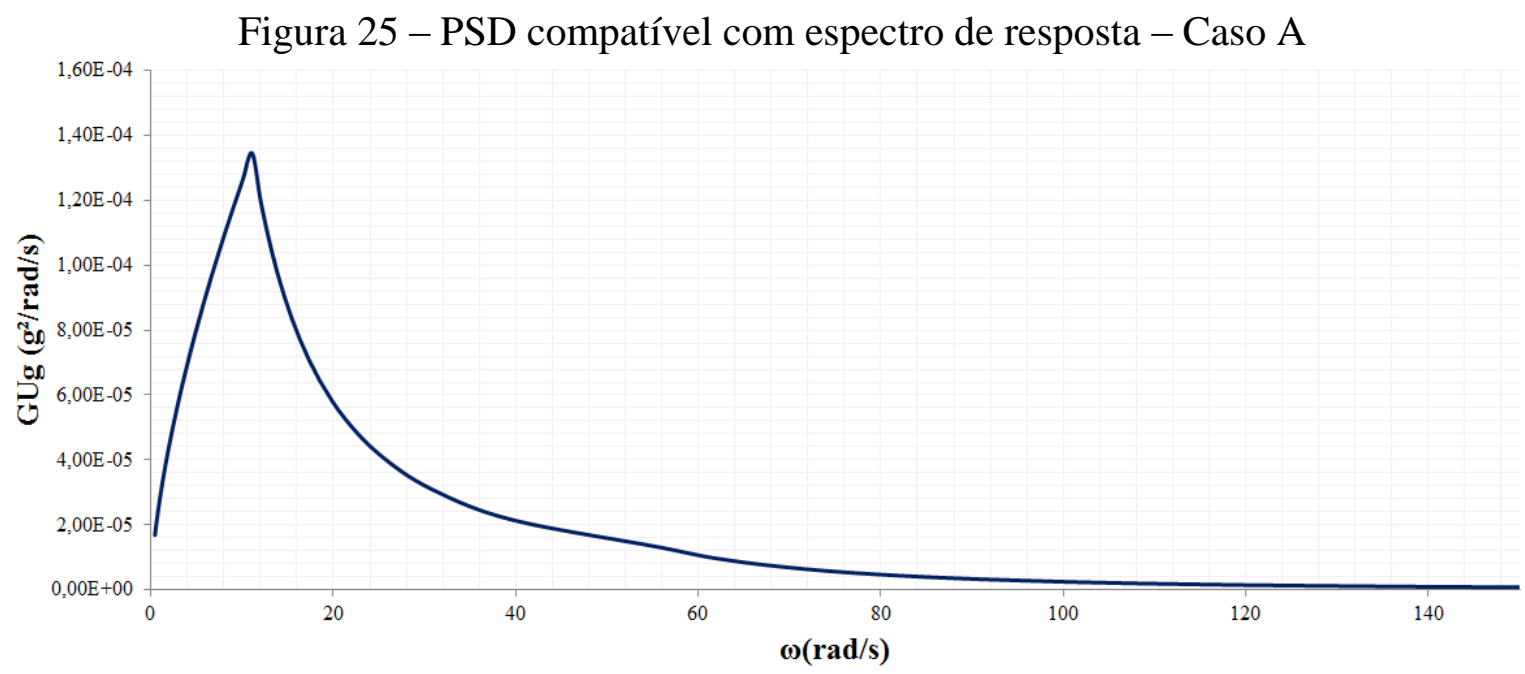

Fonte: Autor (2017)

Para a geração do sinal, foi considerado um tempo total de 9 segundos do evento. O sinal resultante é mostrado na Figura 26.

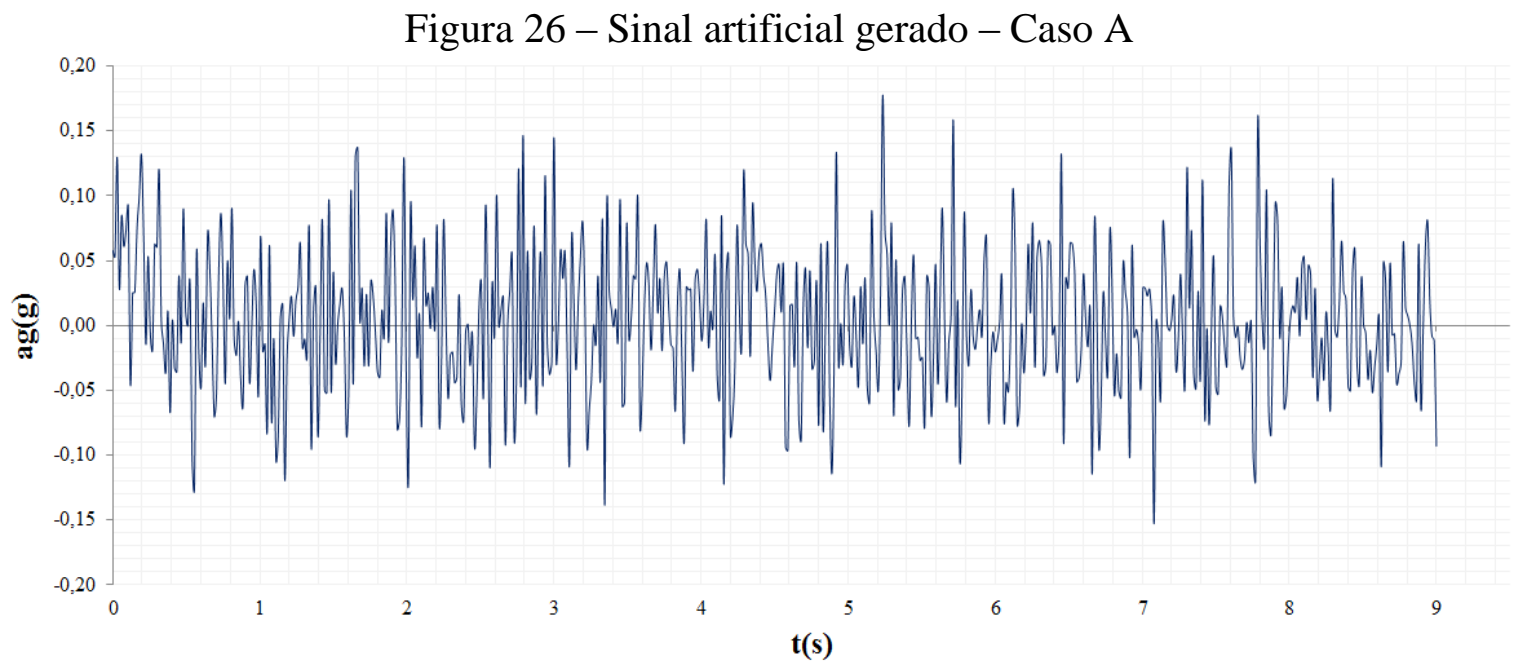

Fonte: Autor (2017)

Para simular o caráter transitório de um sismo real, foi utilizada a função envoltória trapezoidal. Seguindo a recomendação de Trifunac e Brady (1975), a duração significativa (Ds) compreende o intervalo de 5\% a 95\% de toda a energia 
desenvolvida. Neste caso função estabelece que o período de acelerações máximas esta contido entre 1,5 e 7 segundos. A função é mostrada na Figura 27.

Figura 27 - Função Envoltória - Caso A

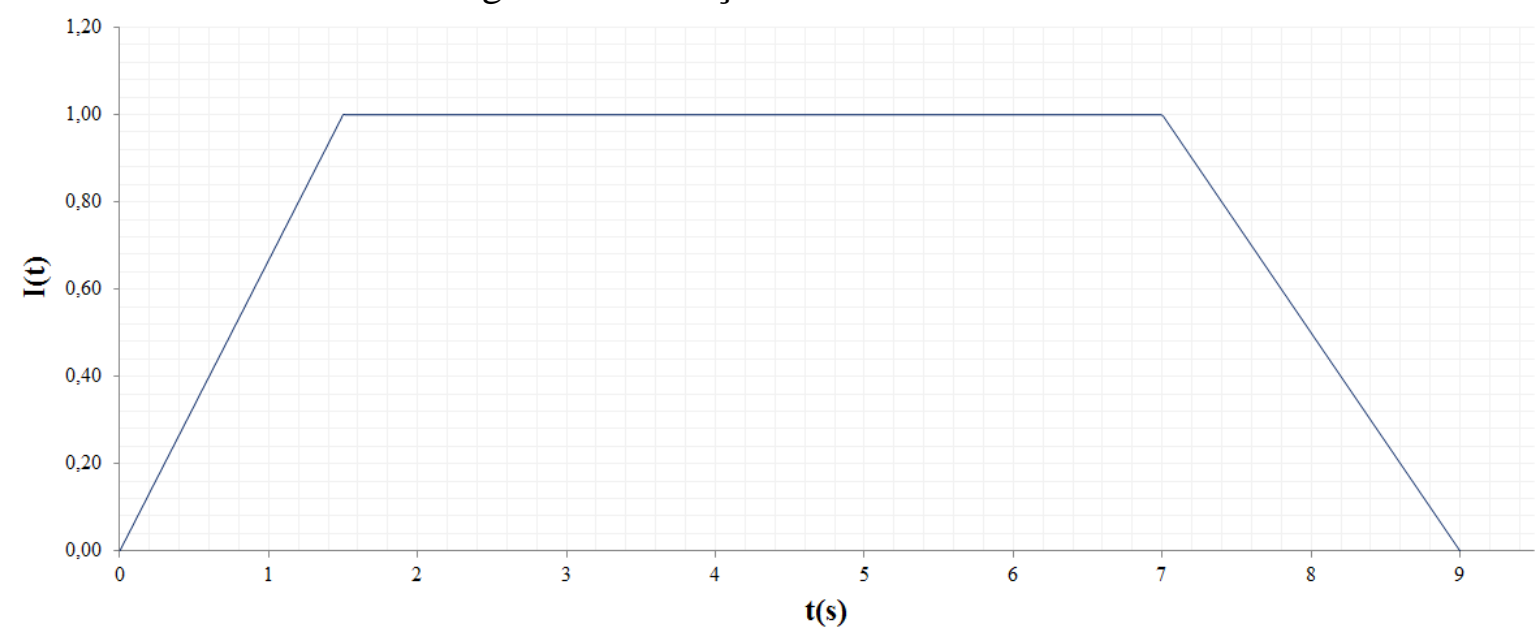

Fonte: Autor (2017)

Após definido todos os parâmetros necessário para resolver a eq.(4.1), o acelerograma artificial compatível com o espectro de resposta é obtido. O acelerograma é ilustrado na Figura 28.

Figura 28 - Acelerograma Artificial final - Caso A

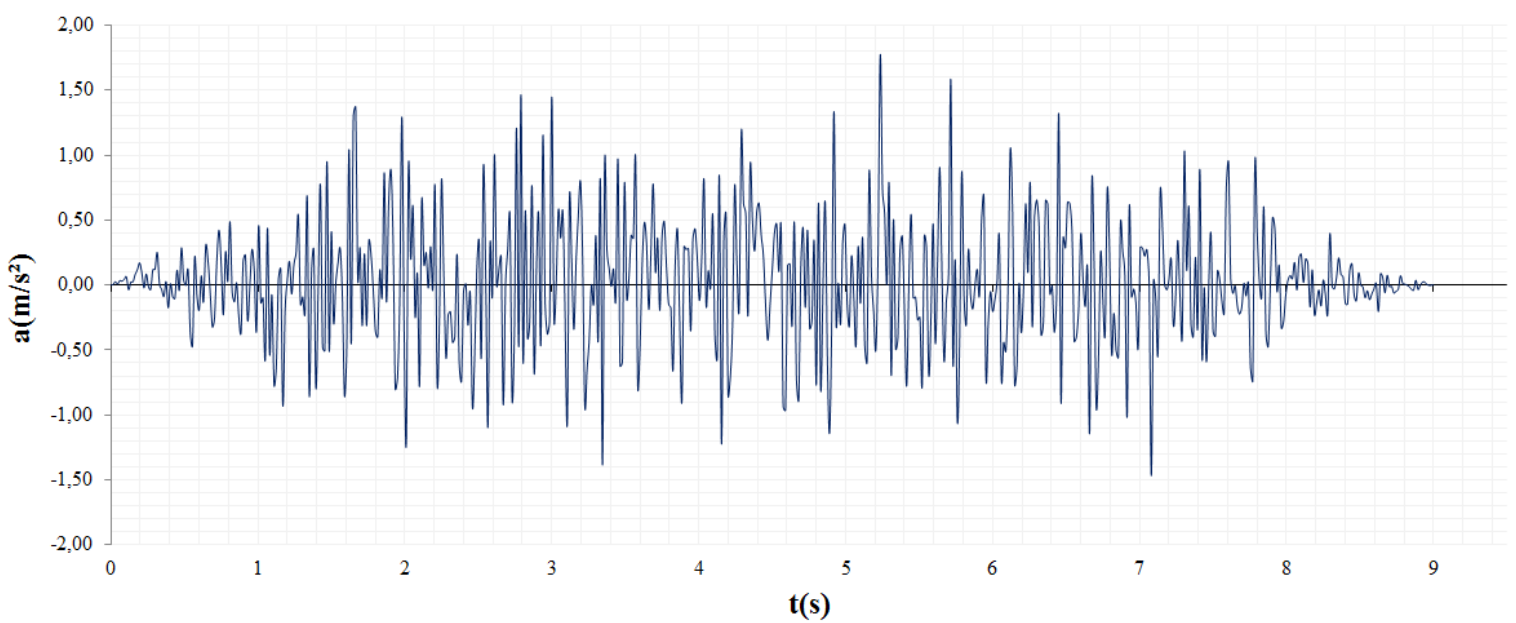

Fonte: Autor (2017)

No acelerograma gerado, é possível perceber que os critérios de ajustes produziram os resultados esperados. O acelerograma está ajustado no eixo zero, e a aceleração máxima obtida foi à esperada $a_{g}=1,8 \mathrm{~m} / \mathrm{s}^{2}$. 
Na Figura 29 é apresentado o histórico de velocidades e na Figura 30 é apresentado o histórico de deslocamentos do acelerograma gerado.

Figura 29 - Histórico de Velocidades - Caso A

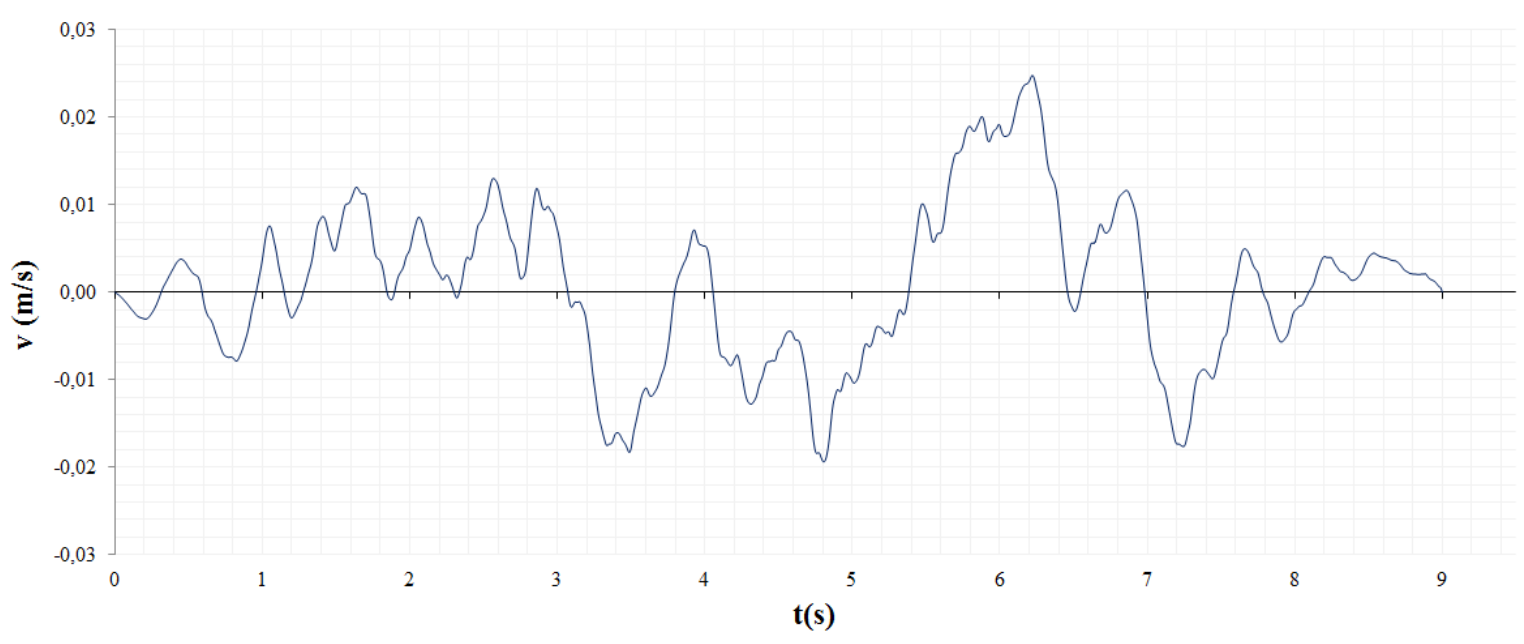

Fonte: Autor (2017)

Figura 30 - Histórico de Deslocamentos - Caso A

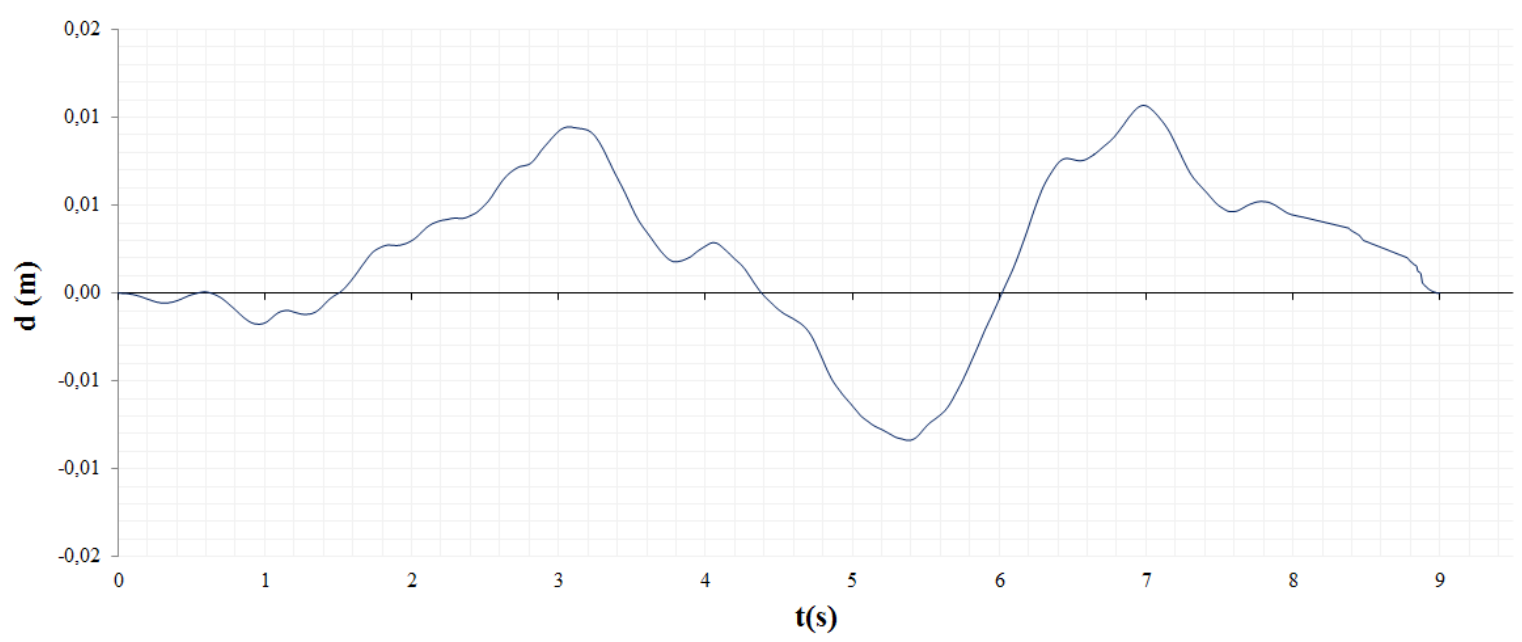

Fonte: Autor (2017)

Com o intuito de verificar a duração significativa $\left(D_{s}\right)$ entre $5 \%$ a $95 \%$ de toda a energia desenvolvida, foi calculada a intensidade de Arias em função do tempo e representada graficamente na Figura 31, representação conhecida como gráfico de Husid. Nele, pode-se perceber que a duração significativa está entre 1,5 e 7 segundos. Na Figura 32 é apresentada graficamente a função envoltória de intensidade resultante. 
Figura 31 - Gráfico de Husid - Caso A

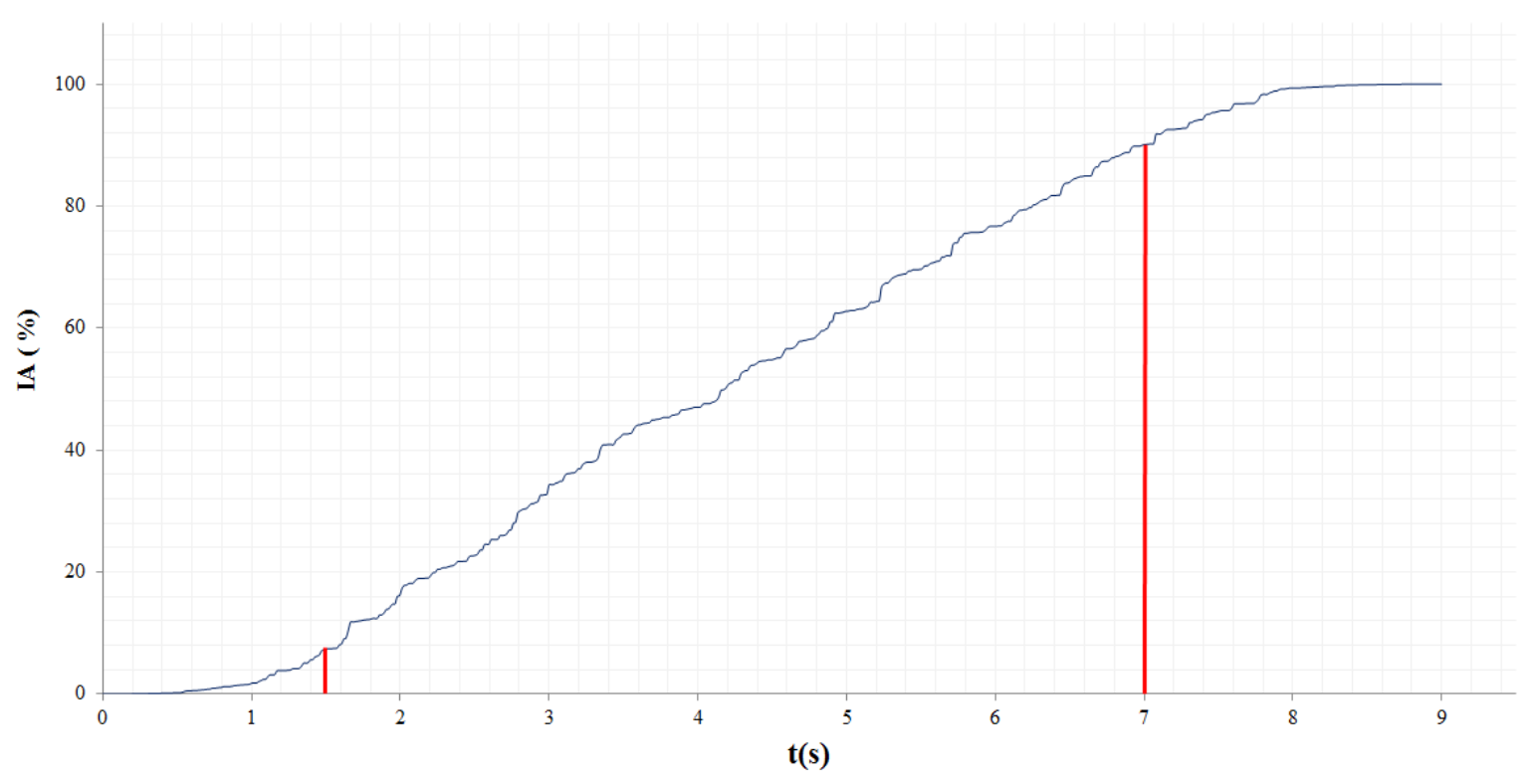

Fonte: Autor (2017)

Figura 32 - Função Envoltória de Intensidade - Caso A

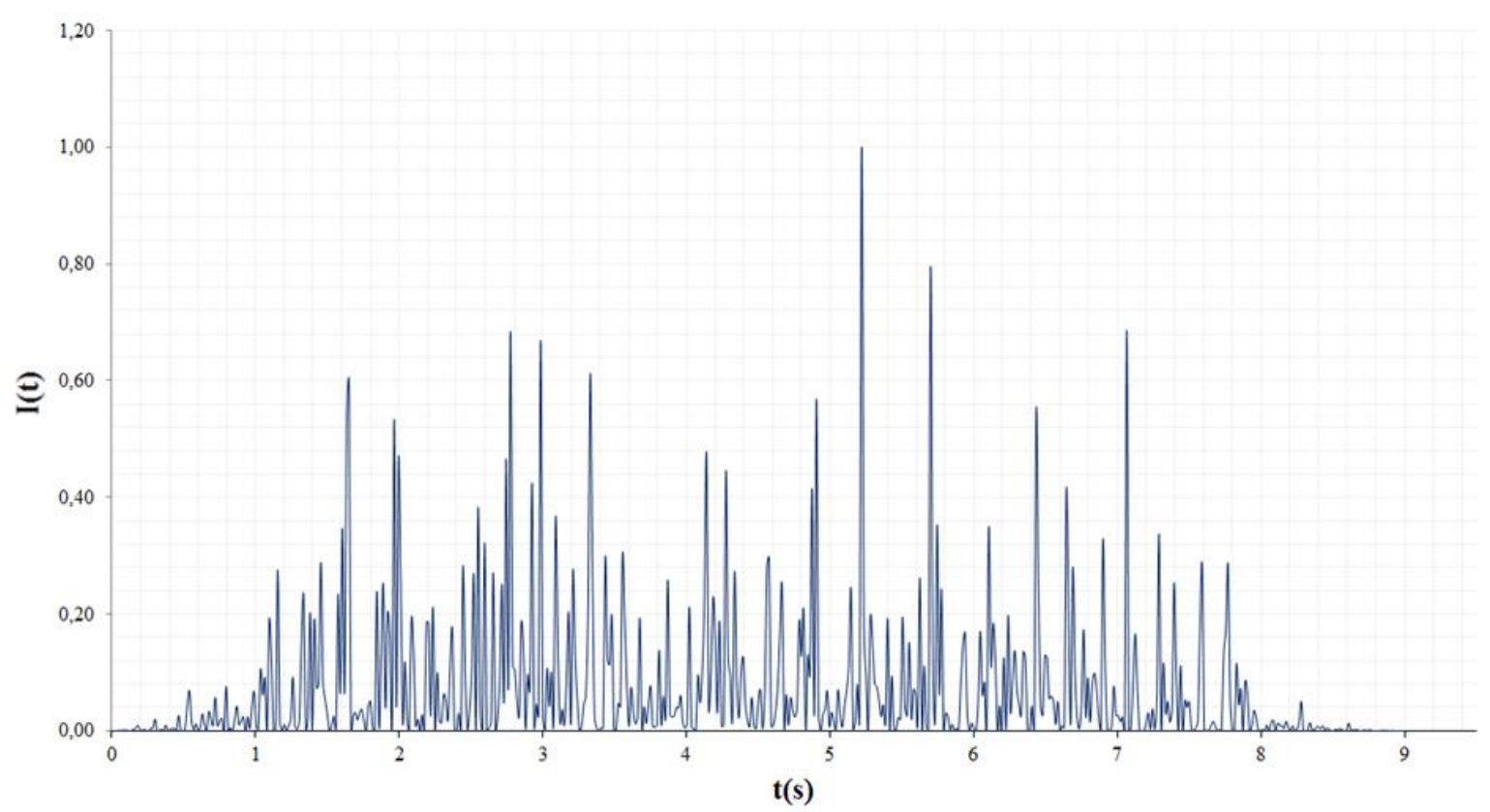

Fonte: Autor (2017)

Após definição de todos os parâmetros apresentados, resta verificar a compatibilidade do acelerograma artificial com o espectro de resposta normativo. Para tal, foi calculado espectros de respostas a partir do acelerograma artificial gerado e comparado com os espectros de respostas de norma. Para o cálculo do espectro de acelerações foi buscado um erro médio de $5 \%$ ao espectro de norma, para isso, foi necessários 15 iterações. Os resultados são apresentados na Figura 33. 
Figura 33 - Espectros de Respostas - Caso A

(a) Espectro de Acelerações

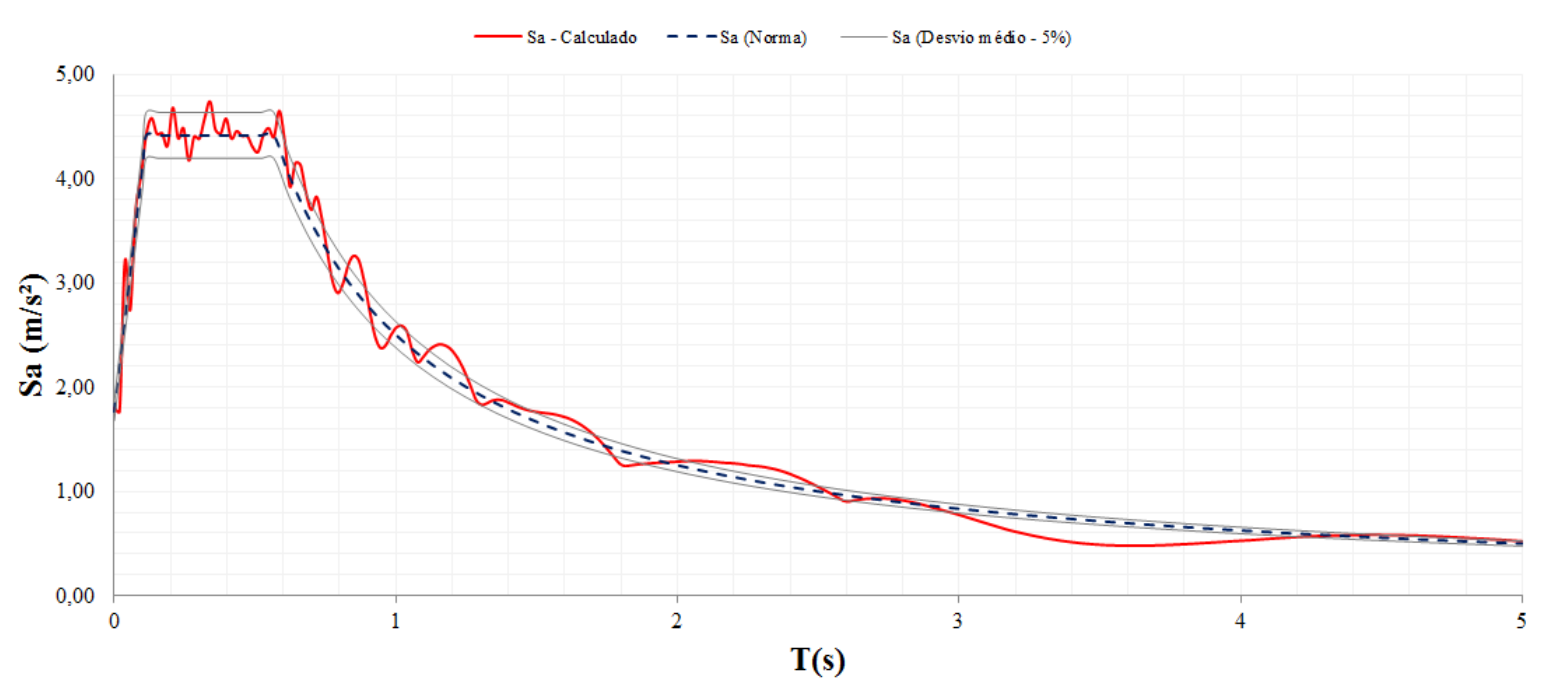

(b) Espectro de Velocidades

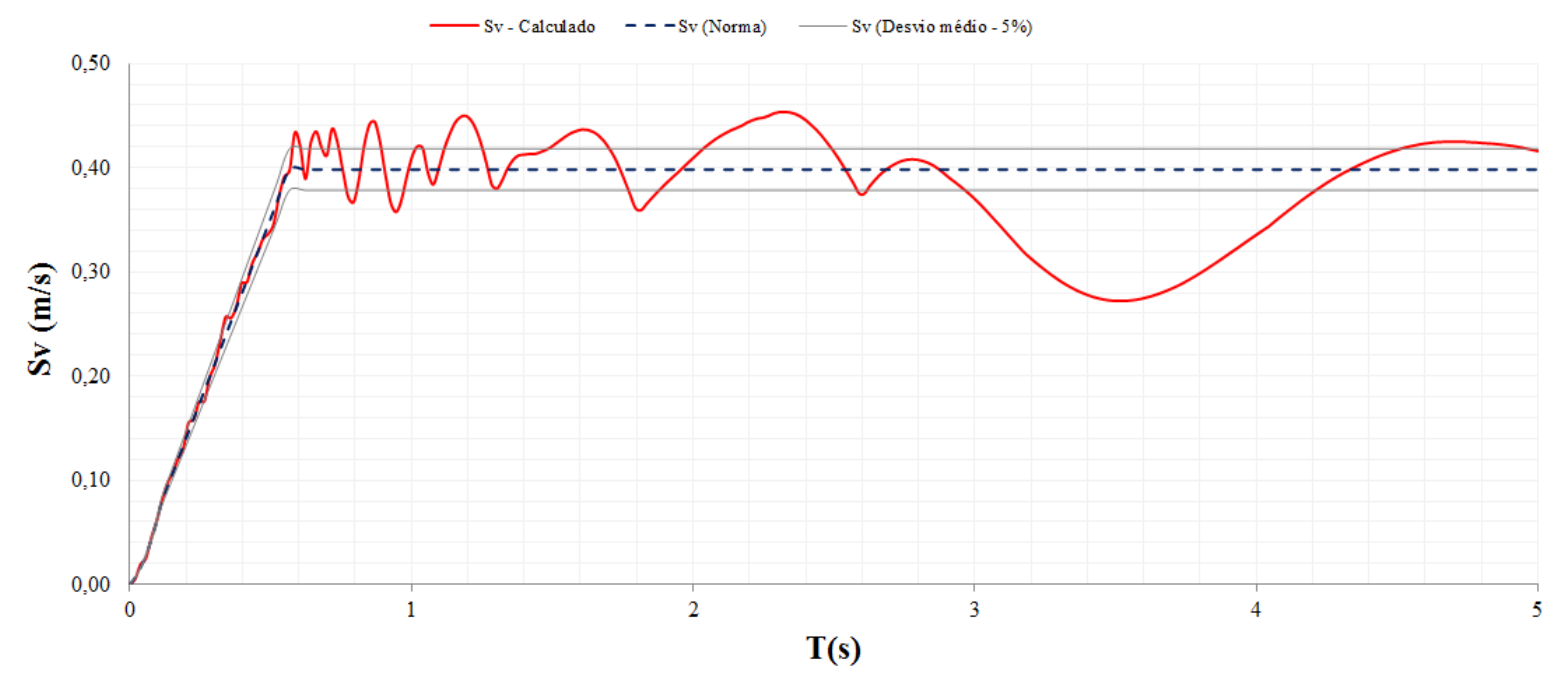

(c) Espectro de Deslocamentos

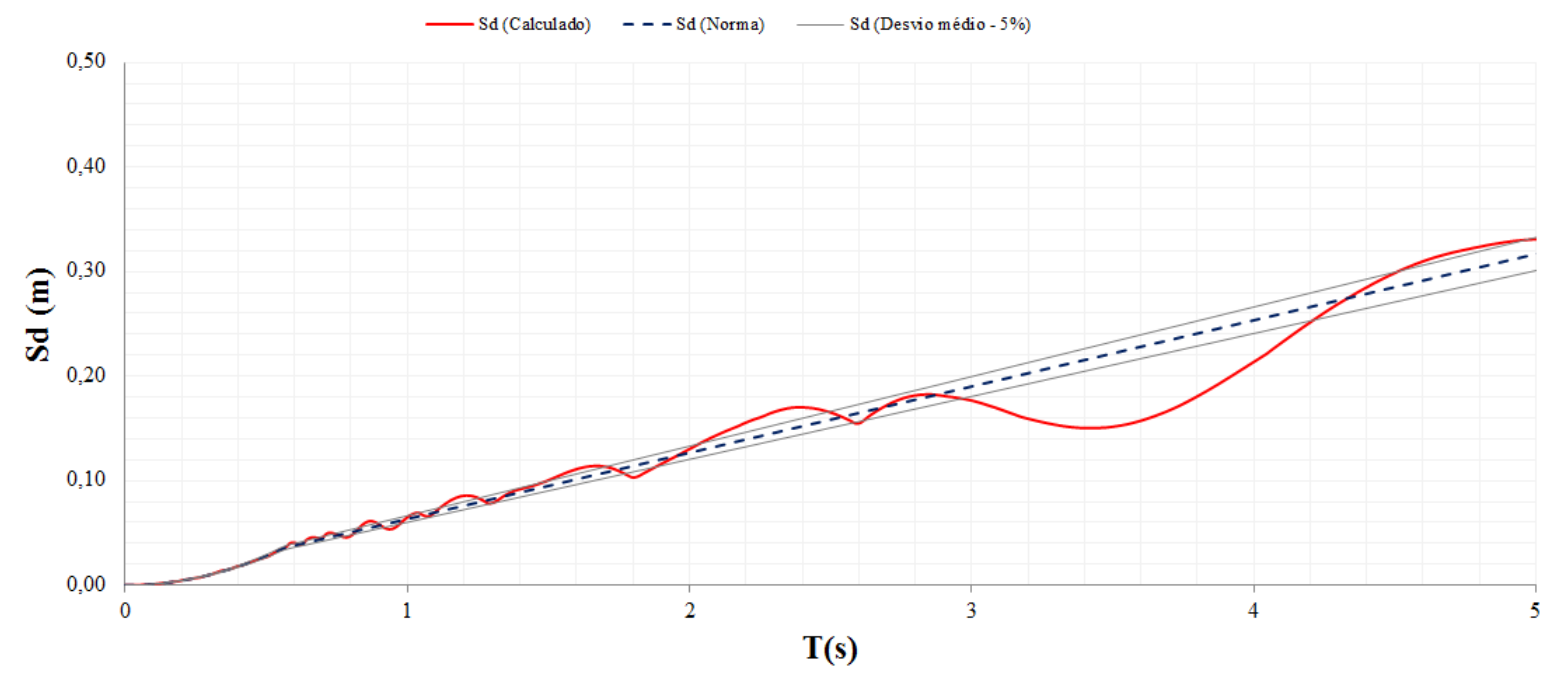

Fonte: Autor (2017) 
Pelo método da integração numérica das equações de movimento passo - a - passo no tempo por diferenças finitas, é obtido o histórico de deslocamentos em metros do último piso. Como se pode ver na Figura 34 o deslocamento máximo do último piso é de 6 centímetros.

Figura 34 - Deslocamento no tempo do último pavimento - Caso A

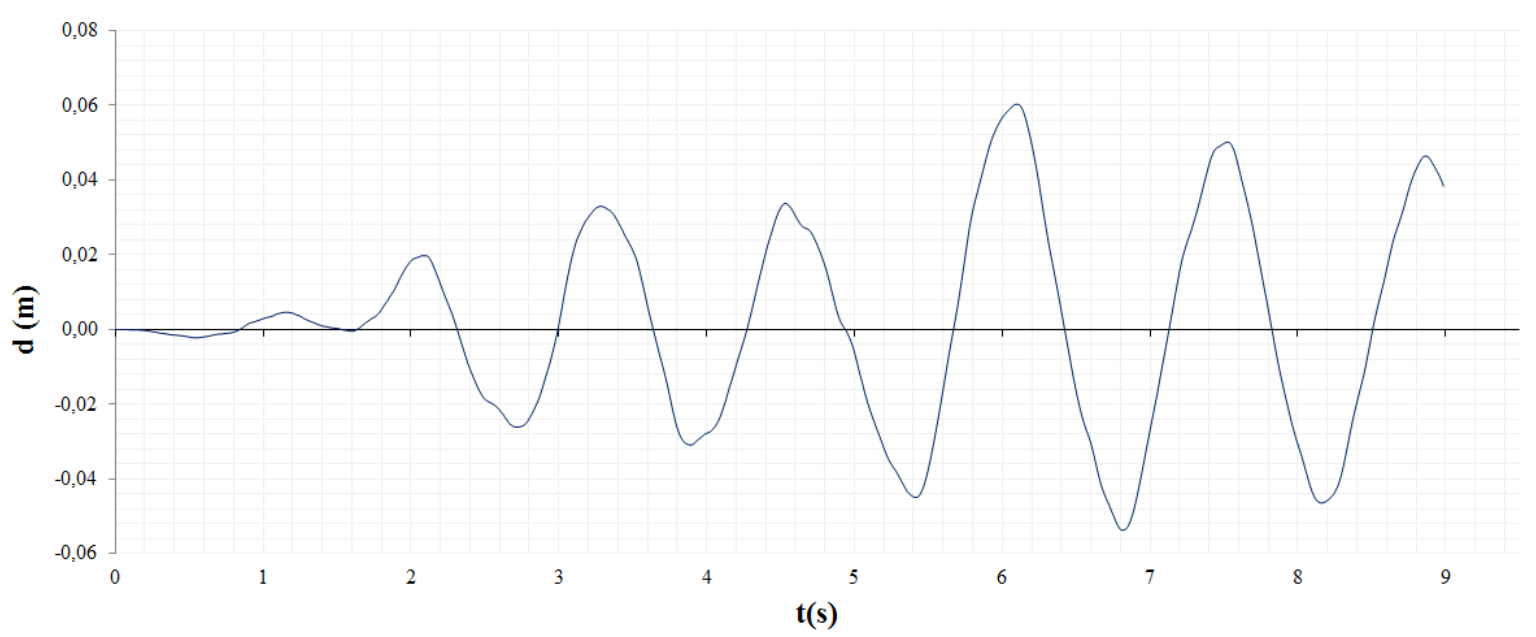

Fonte: Autor (2017) 


\subsection{Caso B}

A estrutura em estudo do caso B é um reservatório d'água de 23,5 toneladas, sobre 4 colunas de perfil metálico VS 150x15 de 4,68 metros de comprimento. O aço utilizado é o ASTM A36 com tensão de escoamento $f y=250 \mathrm{MPa}$ e módulo de elasticidade $E=2,05 \cdot 10^{11} \mathrm{~N} / \mathrm{m}^{2}$. A Figura 35(a) apresenta esquematicamente a estrutura. Adota-se um modelo de um grau de liberdade para o cálculo da resposta estrutural, como mostrado na Figura 35(b).

Figura 35 - Caso B

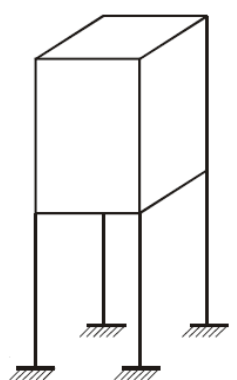

(a)

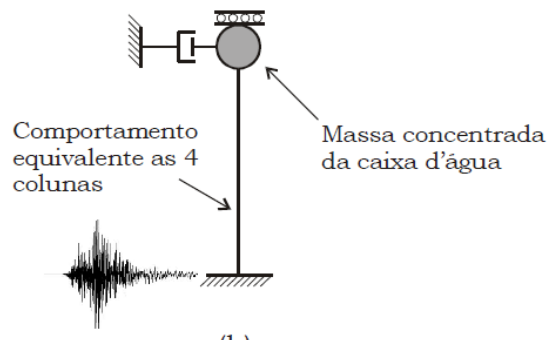

(b)

Fonte: Autor (2017)

Para a definiçãa da ação sísmica, os espectros de respostas são calculados segundo as prescrições na norma venezuelana COVENIN 1756 (2001). Foi considerada a aceleração sísmica horizontal do solo $a g=0,4 g$. As constantes $T^{*}=1, \beta=2,80$ e o perfil adotado do solo foi $S 3$ com fator de importância $\alpha=1$ e fator de amortecimento $\xi=5 \%$. O espectro de resposta resultante é mostrado na Figura 36.

Figura 36 - Espectro de resposta COVENIN 1756(2001) - Caso B

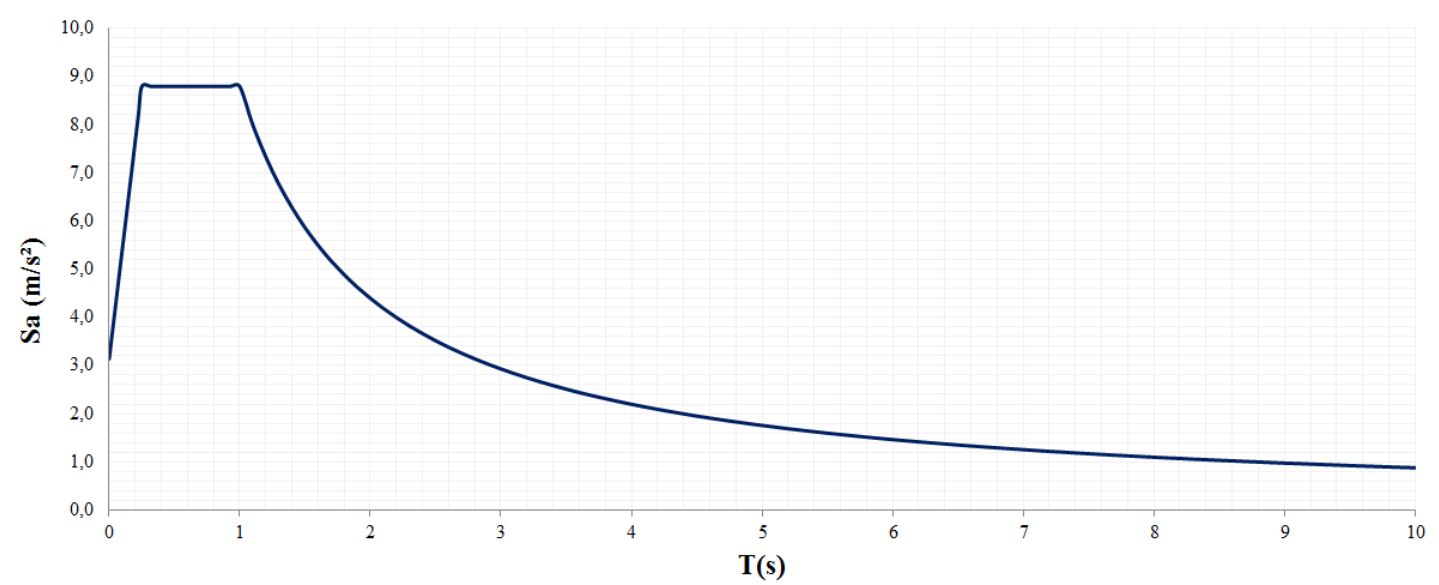

Fonte: Autor (2017) 
Aplicando-se a metodologia descrita no item 4.3.4, a Função de Densidade Espectral de Potência compatível como o espectro de resposta apresentado é mostrado na Figura 37.

Figura 37 - PSD compatível com espectro de resposta - Caso B

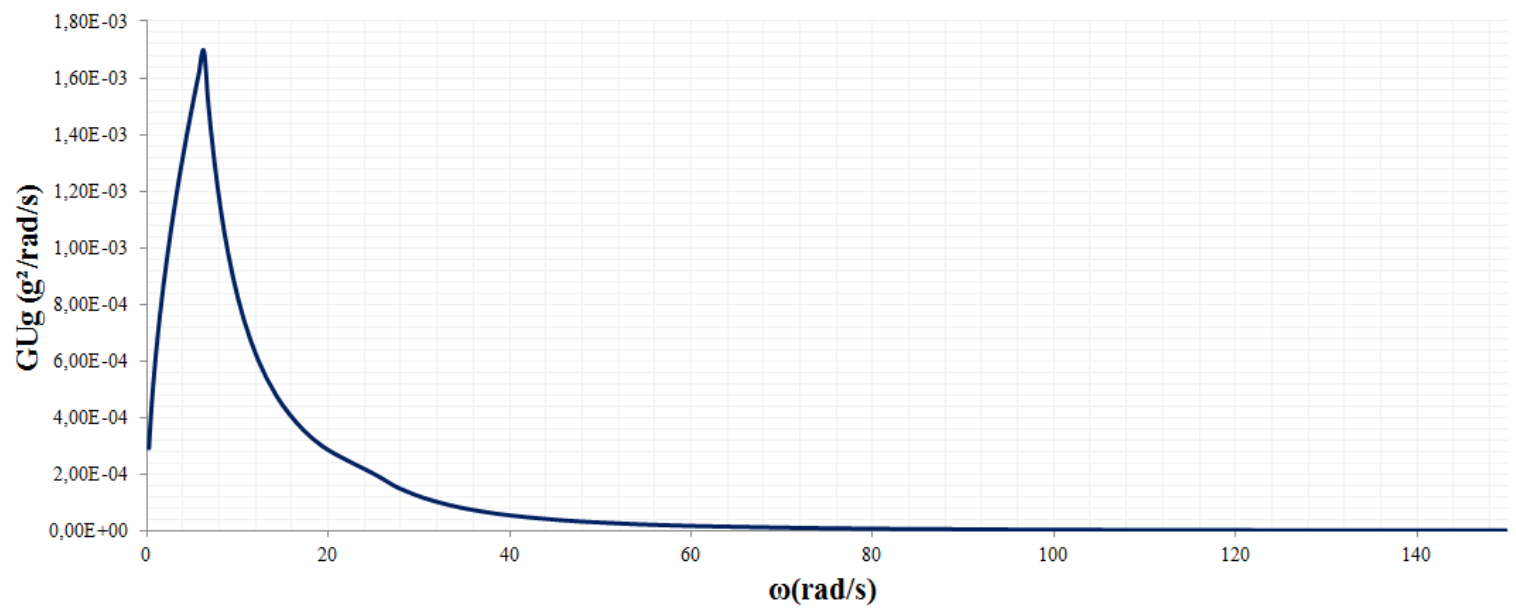

Fonte: Autor (2017)

Para a geração do sinal, foi considerado um tempo total de 9 segundos do evento. O sinal resultante é mostrado na Figura 38.

Figura 38 - Acelerograma Artificial final - Caso B

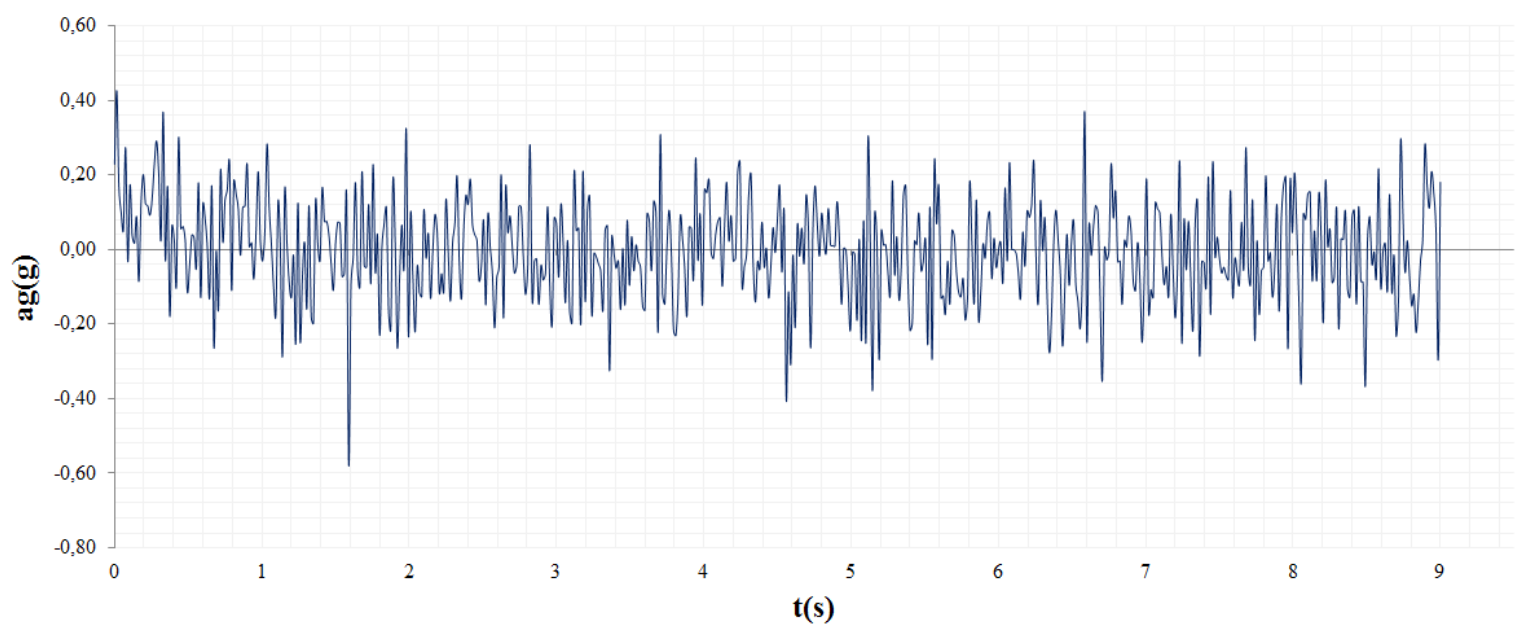

Fonte: Autor (2017)

Para simular o caráter transitório de um sismo real, foi utilizada a função envoltória trapezoidal. Seguindo a recomendação de Trifunac e Brady (1975), a duração significativa (Ds) compreende o intervalo de $5 \%$ a $95 \%$ de toda a energia desenvolvida. Neste 
caso função estabelece que o período de acelerações máximas esta contido entre 1,5 e 7,5 segundos. A função é mostrada na Figura 39.

Figura 39 - Função envoltória - Caso B

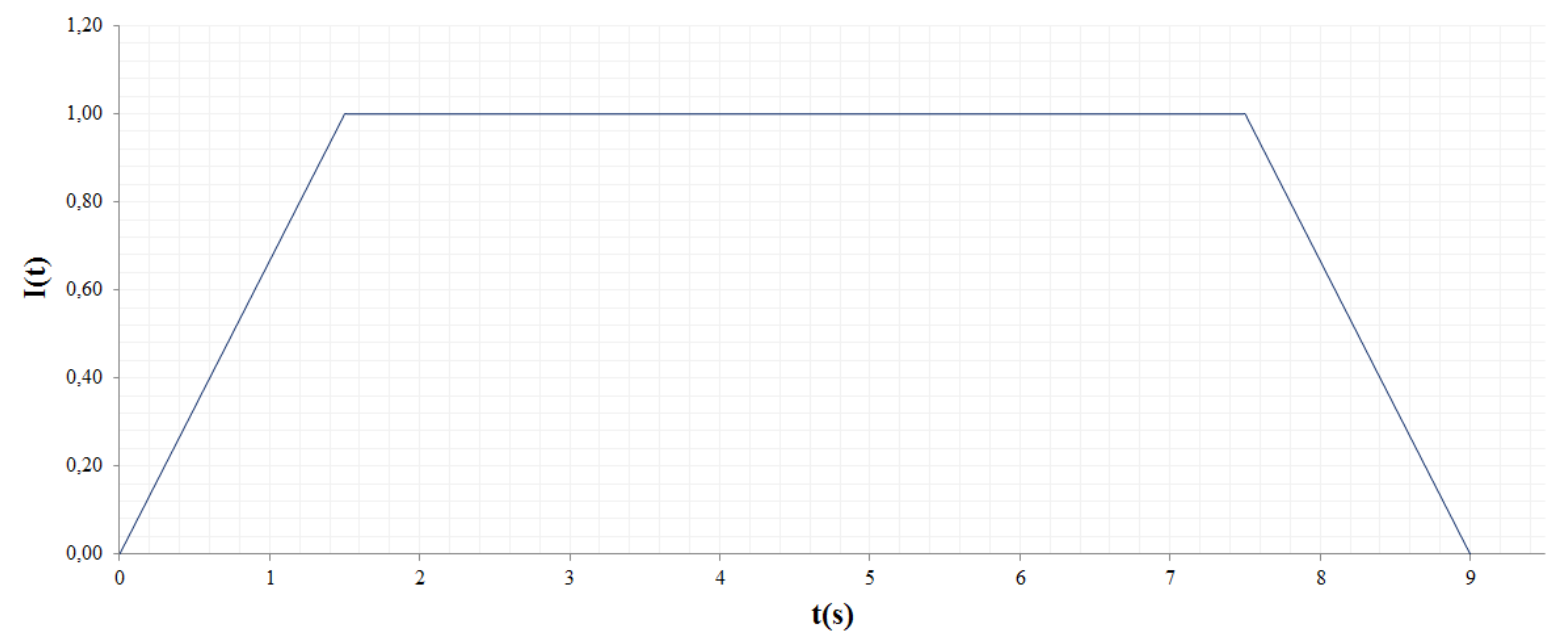

Fonte: Autor (2017)

Após definido todos os parâmetros necessário para resolver a eq.(4.1), o acelerograma artificial compatível com o espectro de resposta é obtido. O acelerograma é ilustrado na Figura 40.

Figura 40 - Acelerograma Artificial final - Caso B

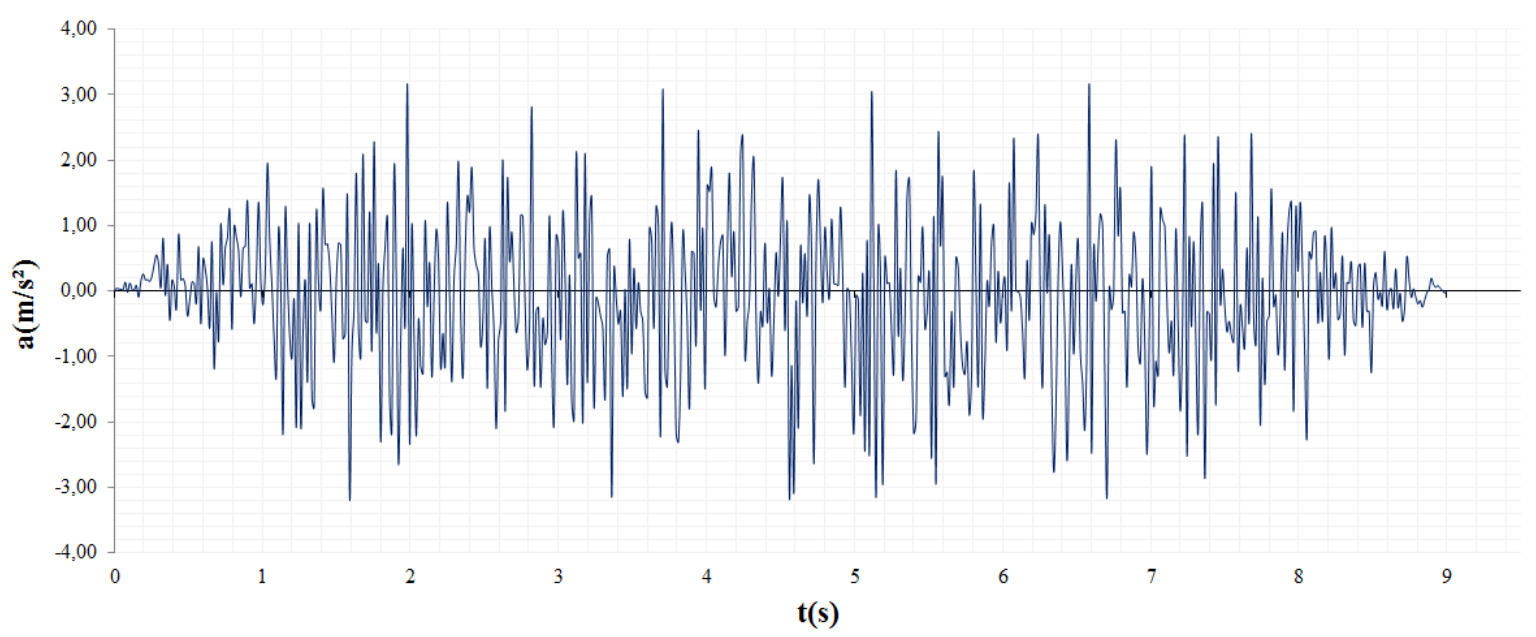

Fonte: Autor (2017)

No acelerograma gerado, é possível perceber que os critérios de ajustes produziram os resultados esperados. O acelerograma está ajustado no eixo zero, e a aceleração máxima obtida foi à esperada $a g=3,14 \mathrm{~m} / \mathrm{s}^{2}$. 
Na Figura 41 é apresentado o histórico de velocidades e na Figura 42 é apresentado o histórico de deslocamentos do acelerograma gerado.

Figura 41 - Histórico de Velocidades - Caso B

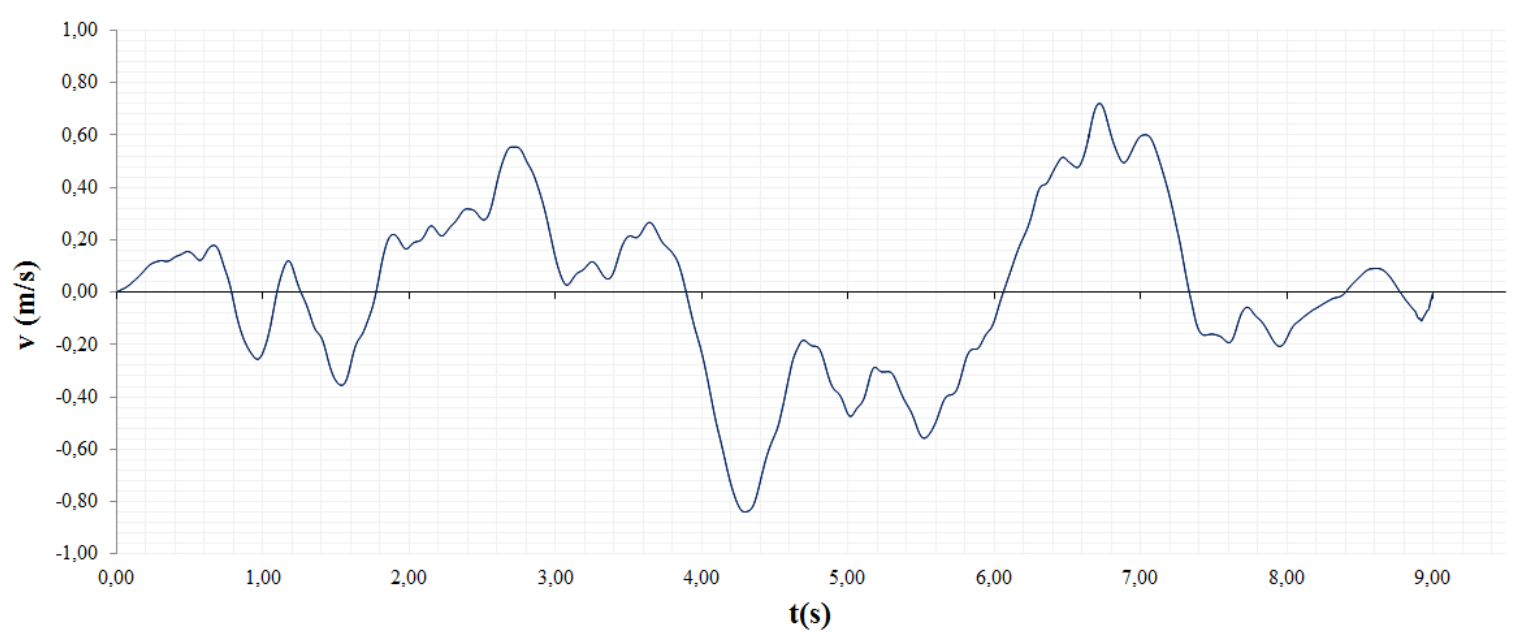

Fonte: Autor (2017)

Figura 42 - Histórico de Deslocamentos - Caso B

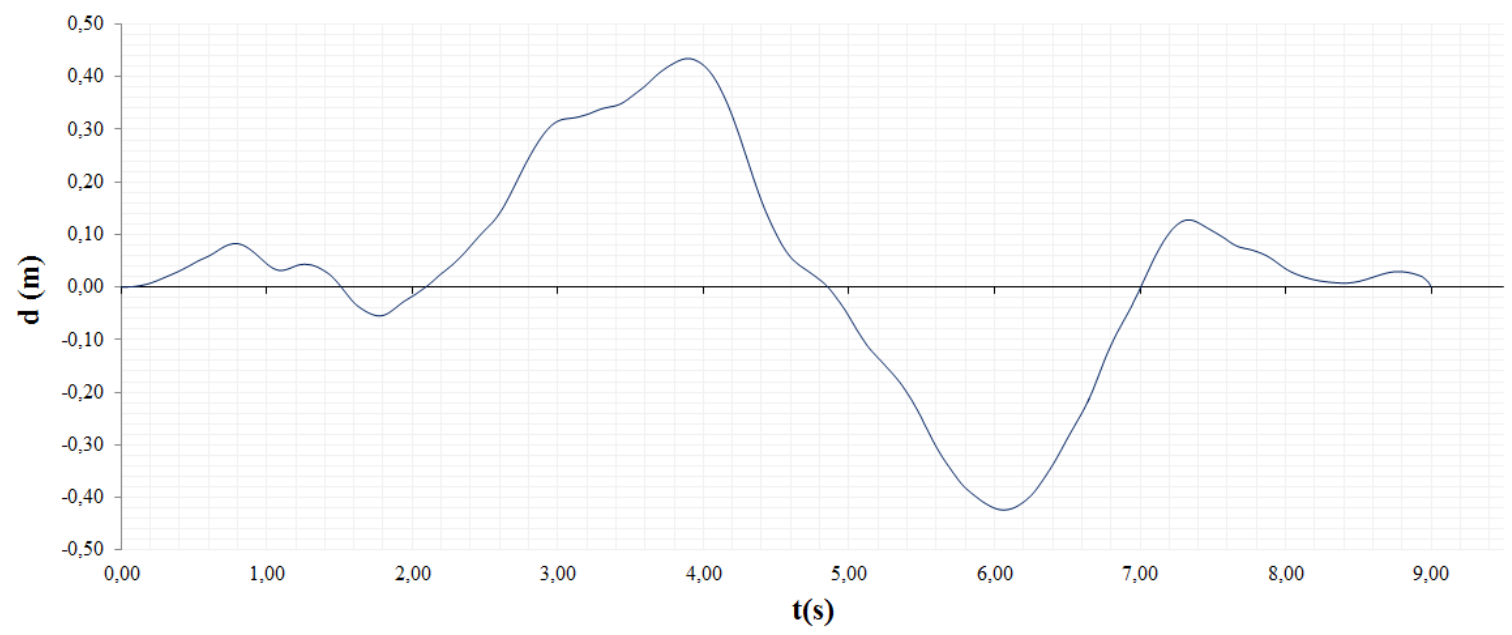

Fonte: Autor (2017)

Com o intuito de verificar a duração significativa $\left(D_{s}\right)$ entre $5 \%$ a $95 \%$ de toda a energia desenvolvida, foi calculada a intensidade de Arias em função do tempo e representada graficamente na Figura 43, representação conhecida como gráfico de Husid. Nele, pode-se perceber que a duração significativa está entre 1,5 e 7 segundos. Na Figura 44 é apresentada graficamente a função envoltória de intensidade resultante. 
Figura 43 - Gráfico de Husid - Caso B

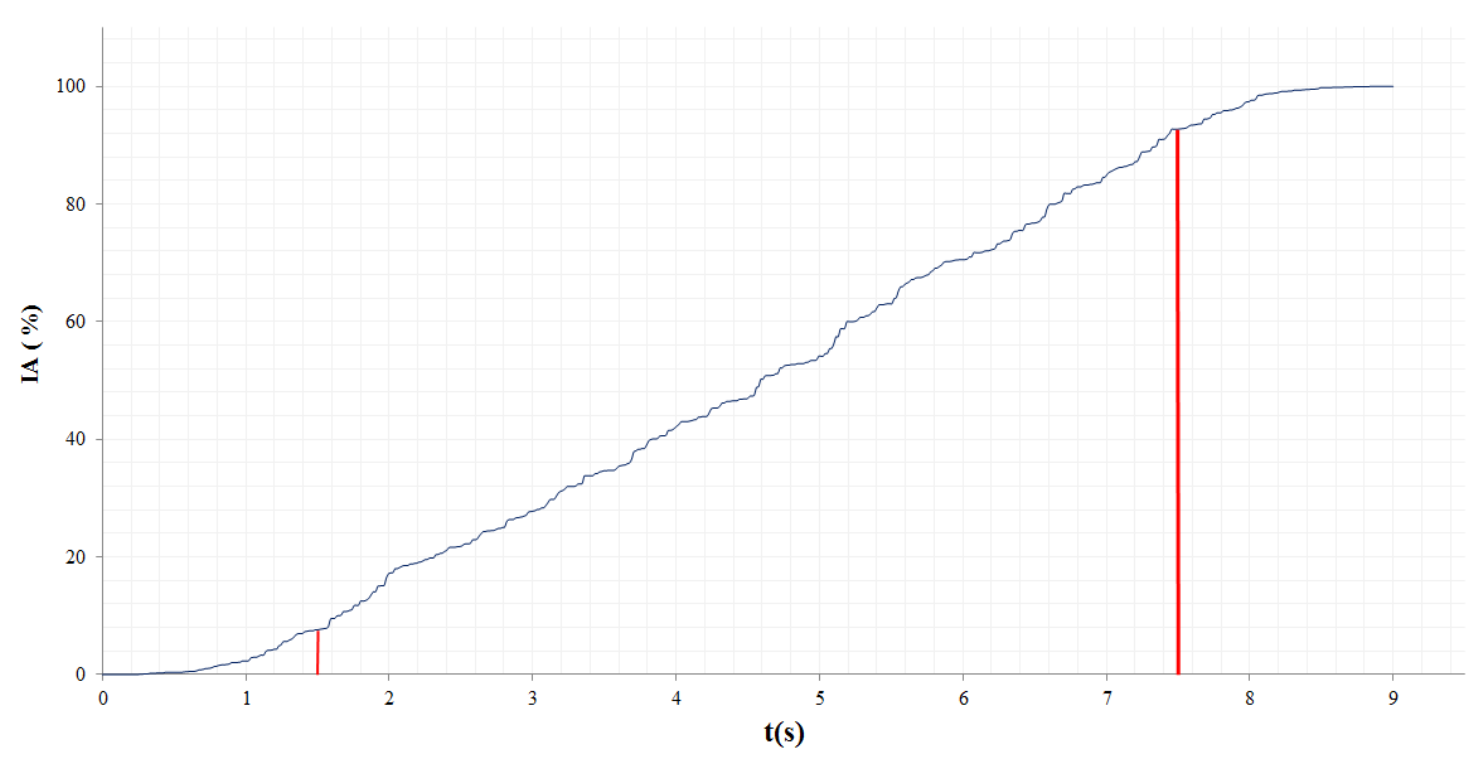

Fonte: Autor (2017)

Figura 44 - Função Envoltória de Intensidade - Caso B

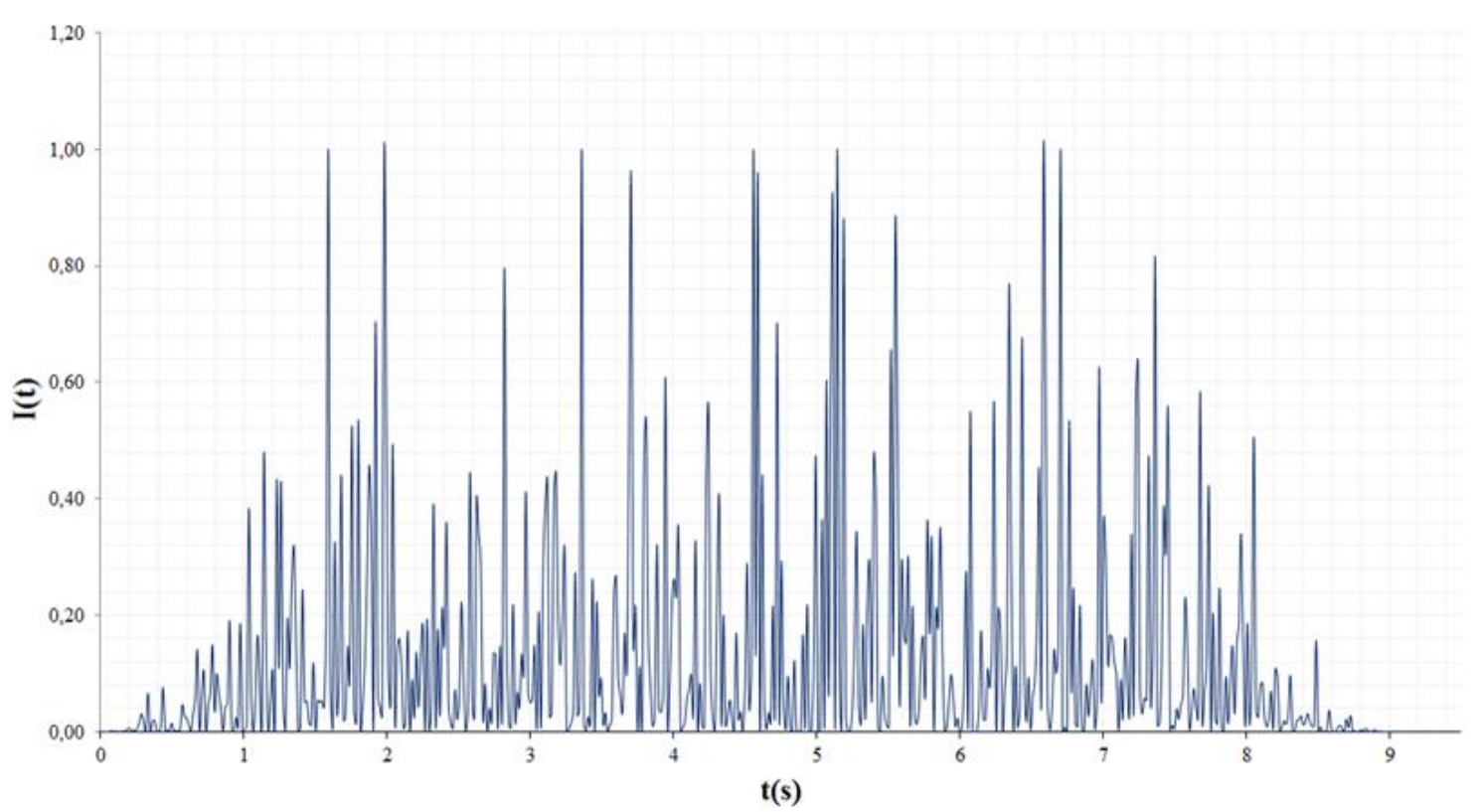

Fonte: Autor (2017)

Após definição de todos os parâmetros apresentados, resta verificar a compatibilidade do acelerograma artificial com o espectro de resposta normativo. Para tal, foi calculado espectros de respostas a partir do acelerograma artificial gerado e comparado com os espectros de respostas de norma. Para o cálculo do espectro de acelerações foi buscado um erro médio de $5 \%$ ao espectro de norma, para isso, foi necessários 22 iterações. Os resultados são apresentados na Figura 45. 
Figura 45 - Espectros de Respostas - Caso B

(a) Espectro de Acelerações

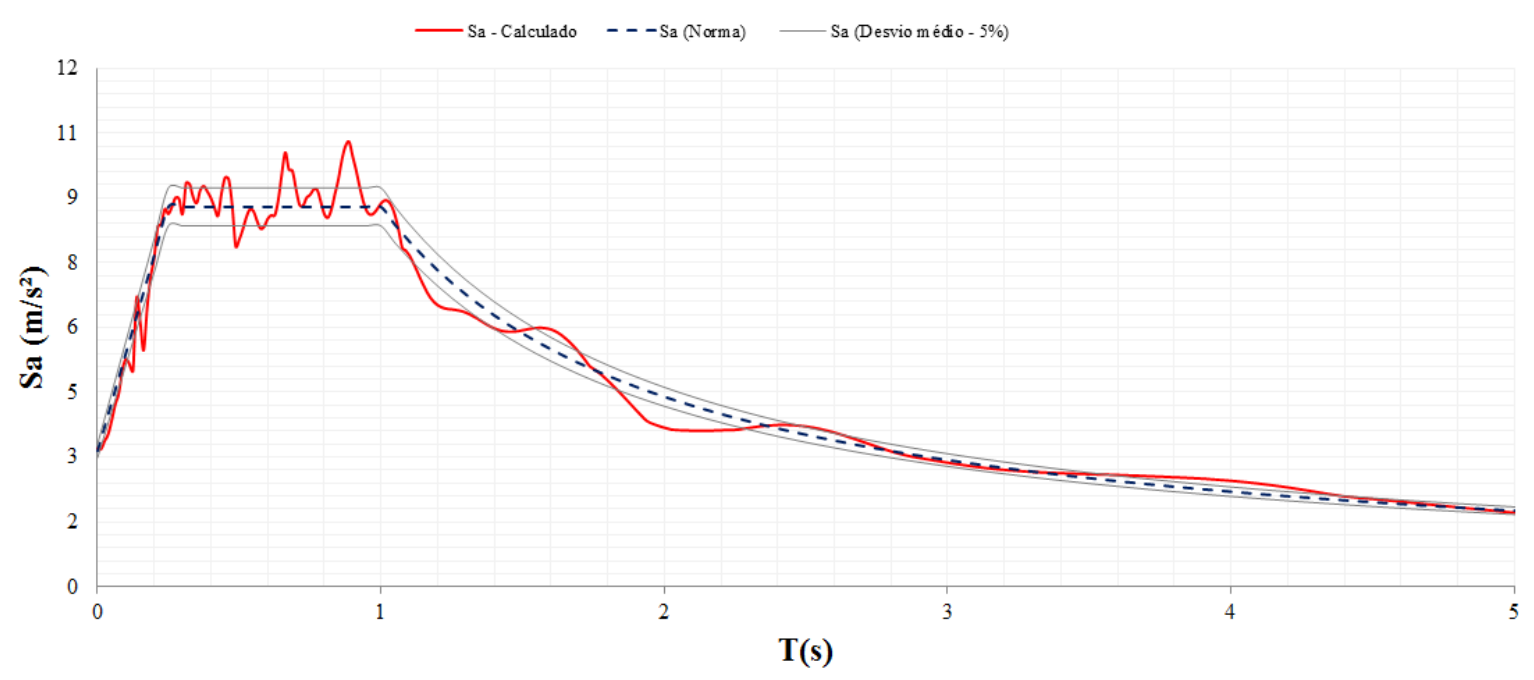

(b) Espectro de Velocidades

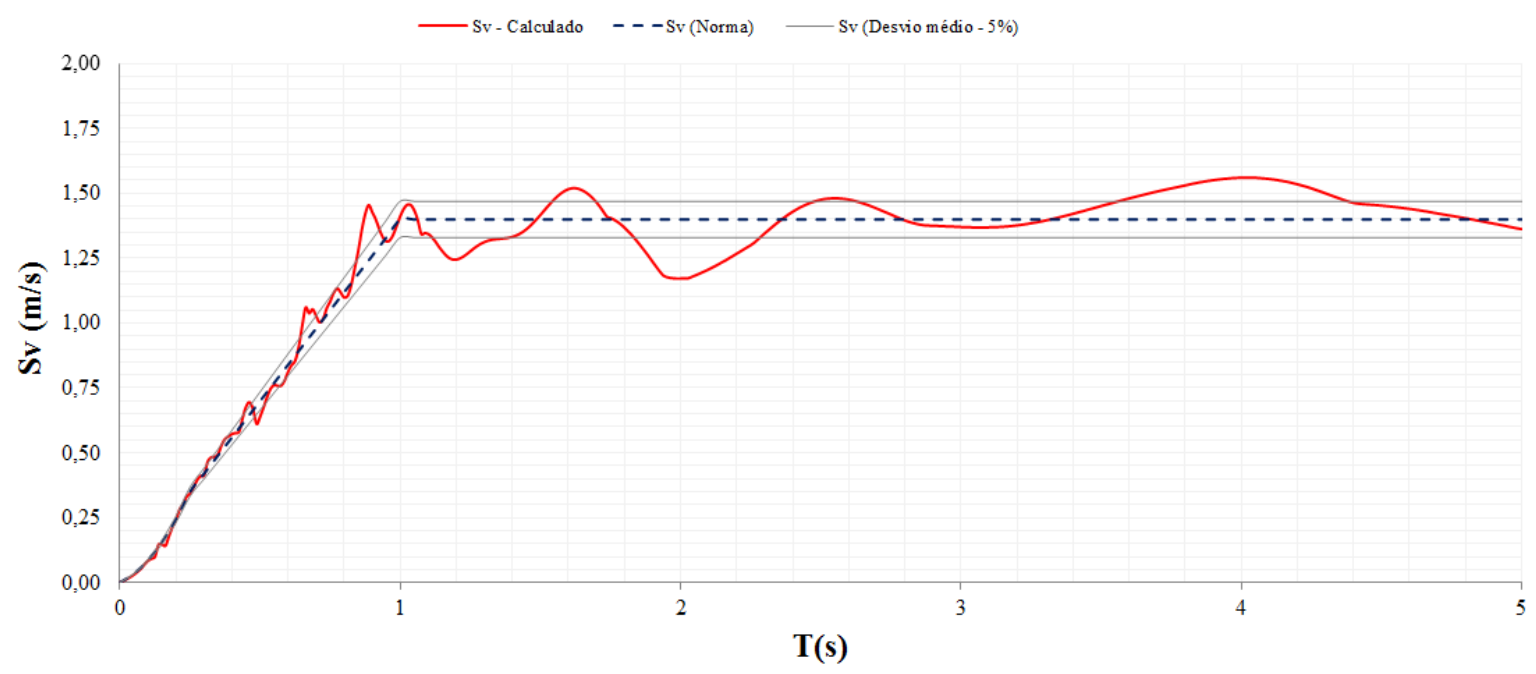

(c) Espectro de Deslocamentos

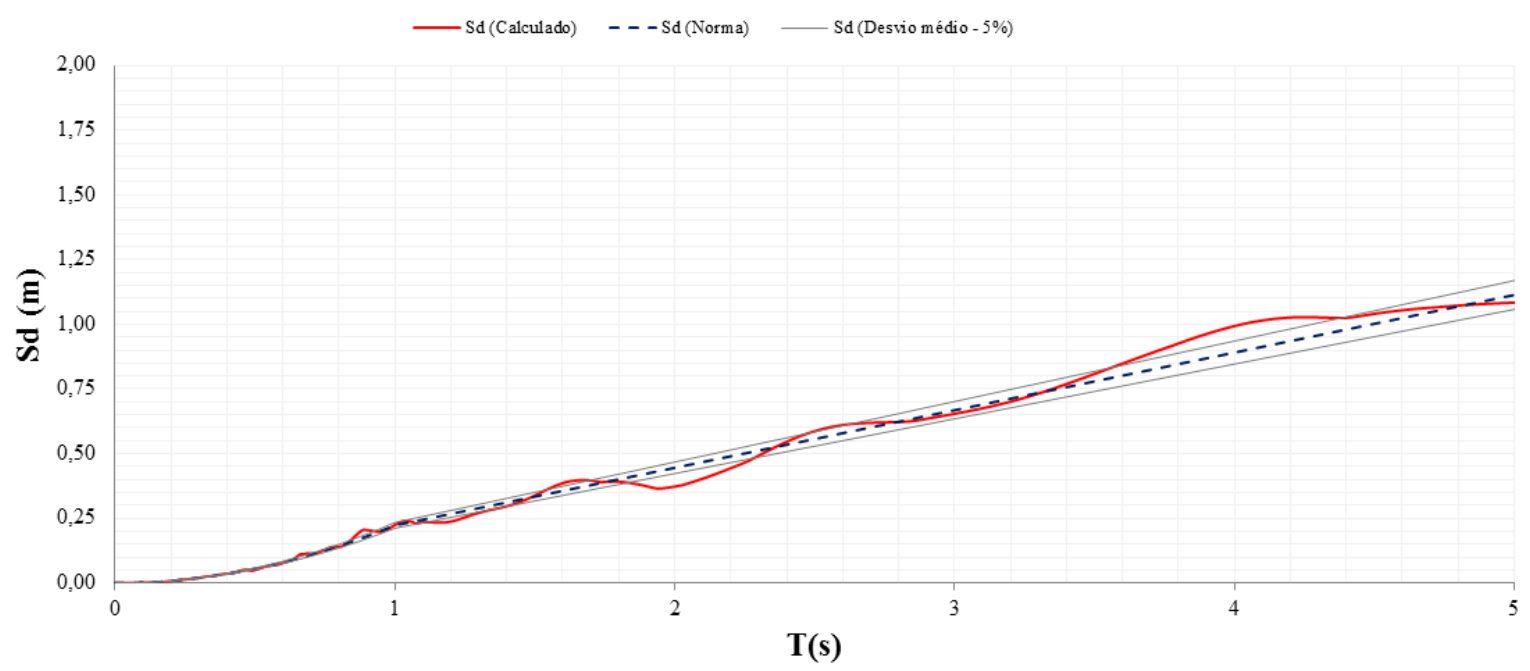

Fonte: Autor (2017) 
Como mencionado, as colunas são compostas de perfis metálico VS 150x15, sendo o módulo de resistência plástico do perfil, $Z=32 \mathrm{~cm}^{3}$. Através das Eqs.(5.20) e (5.21) pode-se definir a força restauradora, $R e=13675 \mathrm{~N}$.

Para a obtenção da resposta estrutural é adotado o método da integração numérica das equações de movimento passo - a - passo no tempo por diferenças finitas.

Quando se considera o comportamento elastoplástico do material, o histórico de resposta assume uma forma típica, como exibido na Figura 46 e Figura 47.

Figura 46 - Deslocamento no tempo com plastificação - Caso B

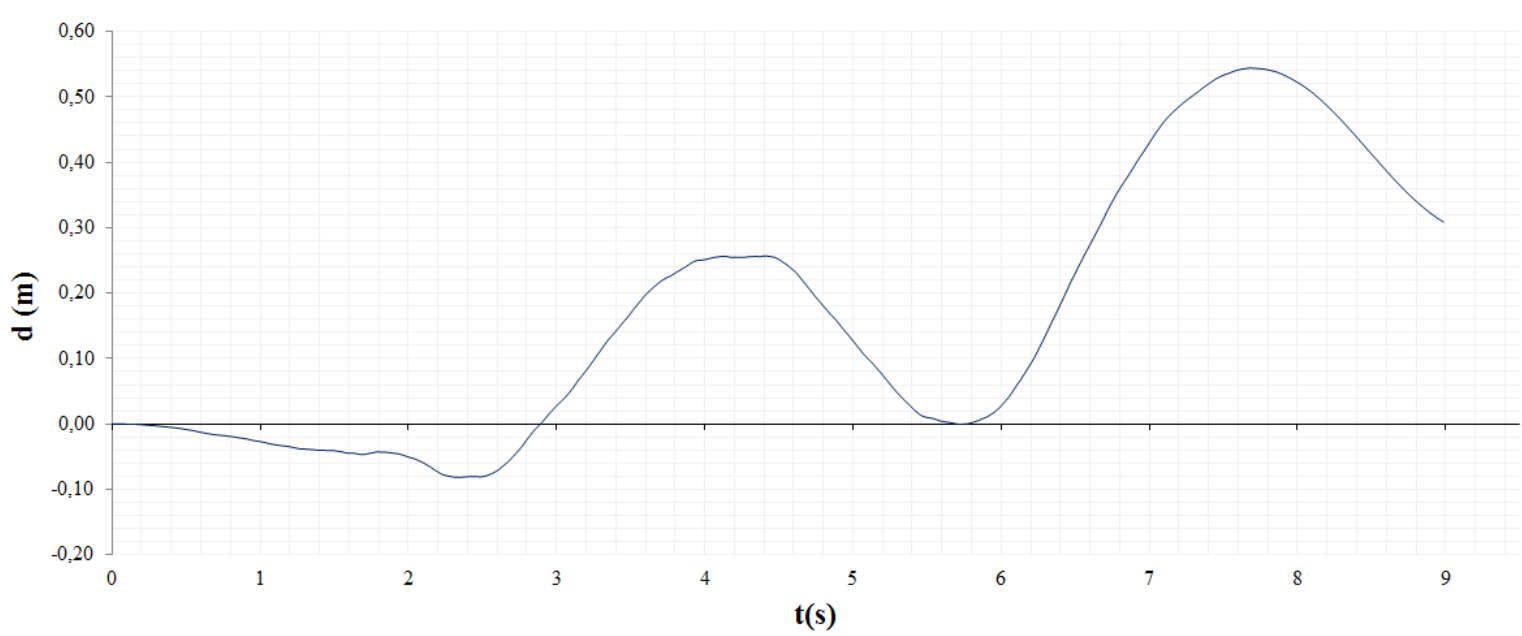

Fonte: Autor (2017)

Figura 47 - Força restauradora no tempo com plastificação - Caso B

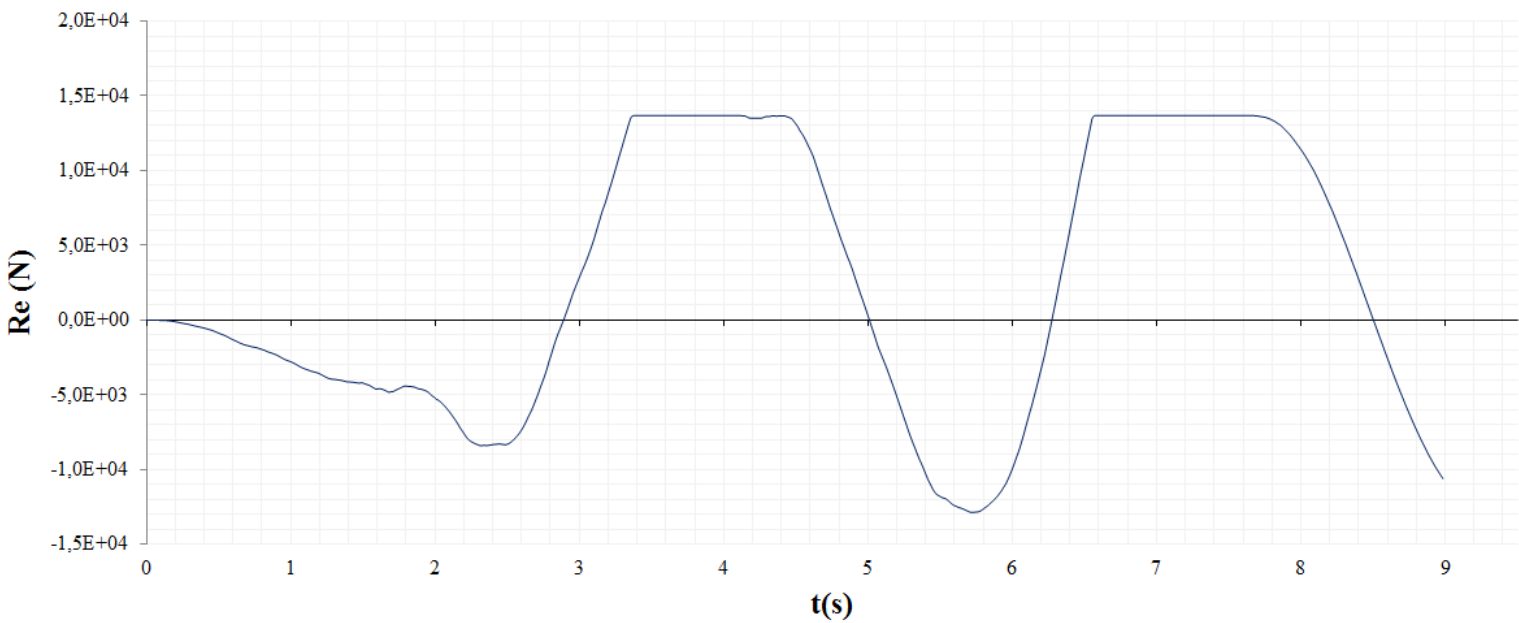

Fonte: Autor (2017) 
Admitindo-se que o material se comporta elasticamente para qualquer magnitude de carregamento, a resposta típica é similar à apresentada na Figura 48 e Figura 49.

Figura 48 - Deslocamento no tempo sem plastificação - Caso B

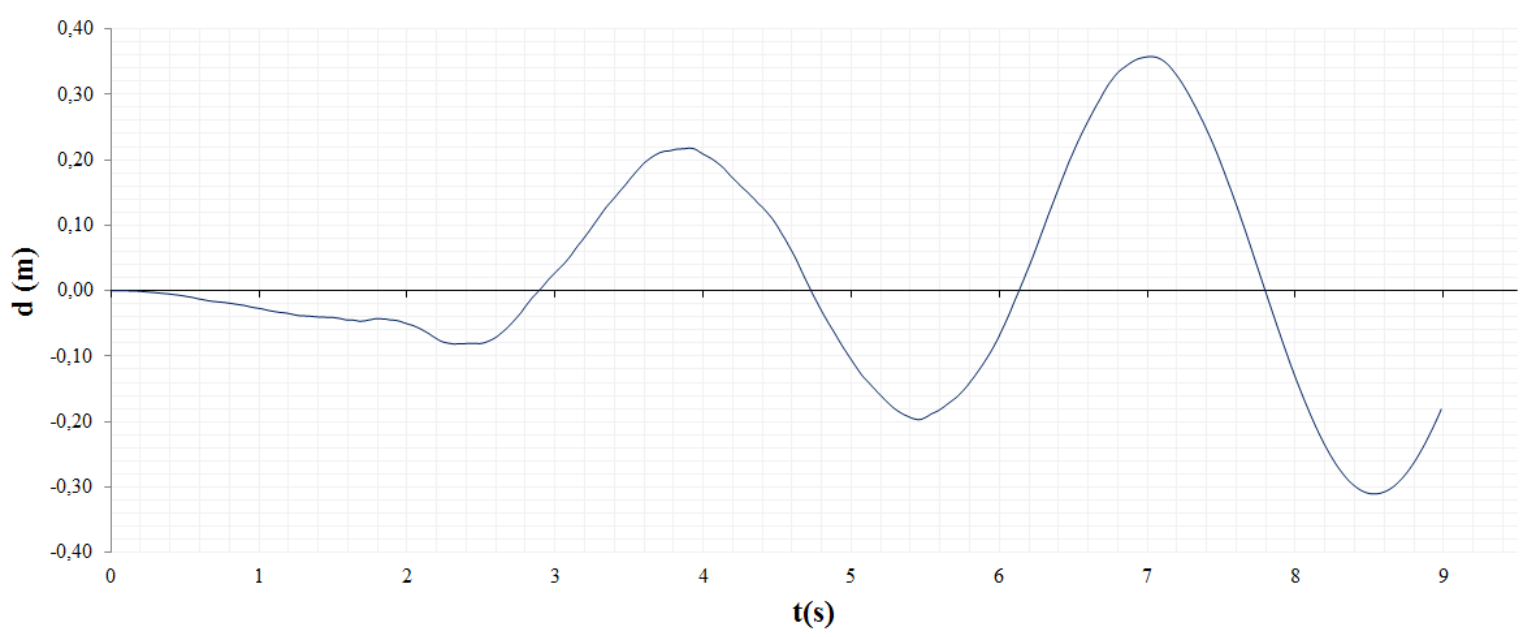

Fonte: Autor (2017)

Figura 49 - Força restauradora no tempo sem plastificação - Caso B

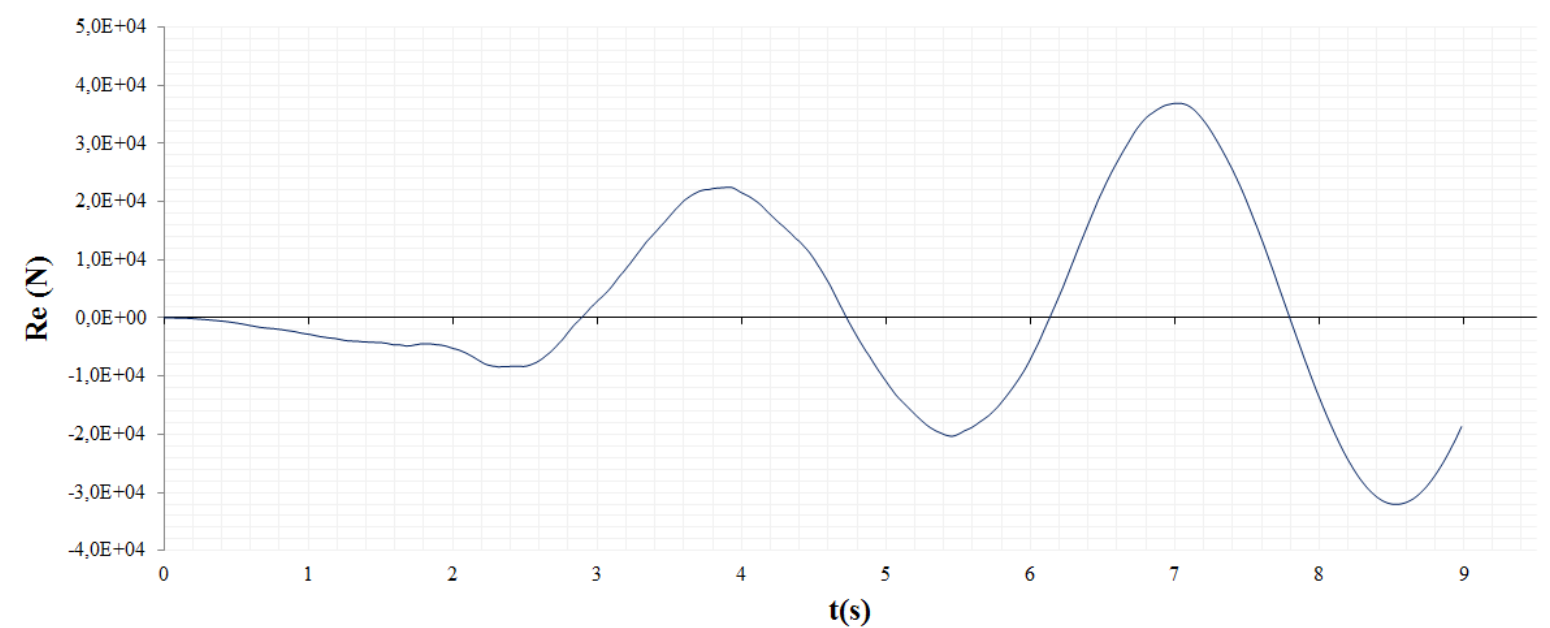

Fonte: Autor (2017)

Ao desprezar a plastificação, o deslocamento máximo é menor comparado ao se considerar a plastificação. Vale ressaltar que a Figura 48 e Figura 49 retratam uma situação completamente hipotética, dado que, para apresentar o histórico de resposta em questão, o material estrutural estaria sujeito a tensões superiores à tensão de escoamento $f y$. 


\section{Conclusões}

Este trabalho teve como objetivo desenvolver uma metodologia para a geração de acelerogramas sísmicos artificiais compatíveis com espectros de respostas elásticos indicados pelos códigos de construção de estruturas resistentes a sismo. Foram gerados dois acelerogramas sísmicos artificiais, sendo um compatível com um espectro de resposta elástico indicado pela norma Brasileira NBR 15421 (2006) e outro compatível com a norma Venezuelana COVENIN 1756 (2001) e verificado suas compatibilidades com as respectivas normas.

Os acelerogramas artificias gerados apresentaram resultados aceitáveis, não exigindo necessidades de correção quanto à linha de base. No entanto, os históricos de velocidades e deslocamentos apresentaram tal necessidade.

Contudo, os resultados mostraram que a metodologia proposta é satisfatória e que os acelerogramas artificiais gerados são compatíveis com a norma brasileira e venezuelana, estas por serem baseadas em outras normas faz com que a metodologia proposta seja compatível com diversas normas internacionais.

Este trabalho também teve como objetivo estudar a resposta das estruturas diante a ação sísmica, para isso, com o acelerograma artificial gerado compatível com a norma brasileira, foi aplicado à base de um edifício shear building de dez pavimentos e através de integração numérica por diferenças finitas passo-a-passo no domínio do tempo foi calculado o deslocamento do último pavimento deste edifício.

De forma semelhante, com o acelerograma artificial gerado compatível com a norma venezuelana, foi aplicado à base de um reservatório d'água sobre quatro pilares e estudado o seu comportamento elastoplástico perfeito. Com os resultados pode-se perceber a importância da consideração de um modelo elastoplástico frente a um modelo elástico, onde os deslocamentos máximos diferem mais de $50 \%$ respectivamente.

Quanto à continuação deste trabalho, recomenda-se o desenvolvimento de um programa para a geração de acelerogramas artificiais que contenha uma interface gráfica, possibilitando estudos das variações dos diversos parâmetros mencionados para a geração de acelerogramas artificias. Estudar a relação da geometria e ductilidade das estruturas em análises sísmica também é recomendado, por ser de grande importância no desenvolvimento de projetos estruturais, principalmente em modelos estruturais de maiores complexidades, como modelos em pórticos espaciais, modelos em cascas, dentre outros. 


\section{Referências}

ASCE 7-05 .2006. Minimum Design Loads for Buildings and Other Structures. American Society of Civil Engineers, 1801 Alexander Bell Drive, Reston, VA 20191, USA.

AKI, K. Seismic displacement near a fault. Journal Geophys. Res., Vol. 73, 6, p. 5359-5376, 1968.

ATC-40. 1996. Seismic evaluation and retrofit of concrete buildings. Applied Technology Council, Redwood City, CA.

ARIAS, A. A measure of earthquake intensity. Seismic design for nuclear power plants, Hansen, R., M.I.T Press, Cambridge, Massachusetts, p. 438-483, 1970.

ASSOCIAÇÃO BRASILEIRA DE NORMAS TÉCNICAS. NBR 15421: Projeto de estruturas resistentes a sismos - Procedimento. Rio de Janeiro, 2006.

BARBAT, A. et al. Definición de la acción sísmica, Centro internacional de Métodos Numéricos en Ingeniería, CIMNE, monografía IS-10, Barcelona, España, 1994.

BARBAT, H.; OLLER, S.; VIELMA, J, C.; Cálculo y diseño sismorresistente de edifícios. Aplicación de la norma NCSE-02, Centro internacional de Métodos Numéricos en Ingeniería, CIMNE, monografía IS-56, Barcelona, España, 2005.

BARONI, G.; IACON, F.; NAVARRA, G.; PALMERI, A. A novel analytical model of power spectral density function coherent with earthquake response spectra. IN: Papadrakakis, M., Papadopoulos, V. and Stefanou, G. (eds). Proceedings of UNCECOMP 2015: the 1st ECCOMAS Thematic Conference on Uncertainty Quantification in Computational Sciences and Engineering, 25th-27th May, Crete, Greece, 2015.

BERG, G.V.; HOUSNER, G, W. Integrade Velocity and displacement of strong earthquake ground motion. Seismological Society of America, 51, p. 175-189, 1961.

BERTERO, R.; VERRI, A.; LEHMANN, A.; MUSSAT, J.; Criterios para Construir el Espectro de Diseño Elastico y Seleccionar los Sismos de Diseño para un Sitio dado, EIPAC 2009, Mendonza, Argentina, 2009.

BIOT, M. A. A mechanical analyzer for the prediction of earthquake stresses, Bull. Seism. Soc. of Am. 31,151-171, 1941.

BISCH, P.; CARVALHO, E.; DEGEE, H. Eurocode 8: Seismic design of buildings. Worked examples. Luxembourg: Publications Office of the European Union, p. 515, 2012

BO LI;; BINH-LE LY.; XIE, W, C.; PANDEY, M, D.; Generating Spectrum-Compatible Time Histories Using Eigenfunctions. Bulletin of the Seismological Society of America. Vol. 107, No 3, pp. 1512-1525. June, 2017. 
BOMMER J.J., ELNASHAI A.S. and WEIR A.G. Compatible acceleration and displacement spectra for seismic design codes. Proceedings of the 12th World Conference on Earthquake Engineering, Auckland, New Zealand (Paper no. 0207), 2000.

BONETT, R.; PUJADES, L.; HURTADO, J. Generación de acelerograma artificiales compatibles con un espectro de respuesta. Aplicación a eventos recientes en Colombia y España. Revista Internacional de métodos Numéricos para Cálculo y Diseño en Ingeniería, v. 18, n. 2, p. 297-308, 2002.

BRASIL, R, M, L, R, F; BRITO, R, C. Seismic Analysis of a shear building model. Iberian Latin American Congress on Computational Methods in Engineering, Brasília, DF, Brazil, Nov. 2016.

BRASIL, R, M, L, R, F; DA SILVA, M, A. Introdução à dinâmica das estruturas. Edgar Blucher, $1^{\mathrm{a}}$ ed., 2013.

BRUNO, H; COTTON, F. Empirical determination of the ground shaking duration due to an earthquake using strong motion accelerograms for engineering application, paper $\mathrm{N}^{\mathrm{o}} 2254 / 4$, France, p. 11, 2000.

CACCIOLA, P.; COLAJANNI, P.; MUSCOLINO, G.. Combination of modal responses consistent with seismic input representation. Journal of Structural Engineering, [S.1.], v. 130, n. 1, p.47-55, jan, 2004.

CARR, A. SIMQKE: Artificial earthquake genearation - University of Canterbury, New Zealand, 1997.

CHOPRA, A. K., Structural dynamics: Theory and Applications to Earthquake Engineering. Prentice Hall, $4^{\text {th }}$ ed., 2011.

CLOUGH, R, W. PENZIEM, J. Dynamics of Structures - Computers \& Structures, New York, $1^{\text {th }}$ ed.,1975.

CORBANI, S., Análise dinâmica elasto-plástica de estruturas metálicas sujeitas a excitação aleatória de sismos. 64 f. Dissertação de Mestrado - Escola Politécnica - Universidade de São Paulo, São Paulo, 2006.

DANTAS, Raul Omar de Oliveira. Subsídios para o projeto de estruturas sismo resistentes. 2013. 226 p. Dissertação de Mestrado - Curso de Engenharia Civil, Universidade Federal do Rio Grande do Norte, Natal, 2013.

EUROCODE 8 (EC8). 2004. Design of structures for earthquake resistance, part 1: general rules, seismic actions and rules for buildings. EN 2004-1-1, CEN, Brussels, 2004.

FALCONI, R.A. Espectros Sísmicos de Riesgo Uniforme para Verificar Desempeño Estructural en Países Latinoamericanos. Anais do XVII Seminário Iberoamericano de Ingeniería Sísmica. Mendonza. Argentina, 2003.

FEMA-273. 1997. NEHRP Guidelines for the Seismic Rehabilitation of Buildings. Federal Emergency Management Agency, Washington, DC, USA, 1997. 
FUNDACIÓN VENEZOLANA DE INVESTIGACIONES SISMOLÓGICAS (FUNVISIS), Norma Venezolana COVENIN 1756:2001: Edificaciones Sismorresistentes. Caracas, 2001.

GUERREIRO, L. M. C. Acção sísmica - Engenharia sísmica de pontes. Texto didático, Mestrado em Engenharia de Estruturas, Instituto Superior Técnico. Lisboa. 2011. Disponível em: http://www.civil.ist.utl.pt/ luisg/. Acesso em: 10 mar. 2015, 00h35min.

GONZALEZ, M. R. Evaluación del riego sísmico en edificios mediante análisis estático no lineal: Aplicación a diversos escenarios sísmicos de Barcelona. Tese de Doutorado Universidad Politécnica de Cataluña, Barcelona, 2006.

HOU, S. Earthquake simulation models and their applications. M.I.T - Department of Civil Eng. Research Report R68-17, 1968.

HOUSNER, G. W. Calculation of the response of an oscillator to arbitrary ground motion, Bulletin of the Seismological Society of America. Vol.32, pp143-149, 1941.

HOUSNER, G. W.; MCCANN, D. The analysis of strong-motion earthquake records with electric analog computer, Bull. Seism. Soc. of Am: 39, 47-56, 1949.

HURTADO, J. E. Stochastic dynamics of hysteresis structures. Application to the seismic analysis of base isolated building. Tese de doutorado, UPC, Barcelona, pp. 206, 1998.

IRIKURA, K. Prediction of strong acceleration motions using empirical Green's function. Proceedings of the $7^{\text {th }}$ Japan Earthquake Engineering Symposium, p. 151-156, 1986.

JENNINGS, P. C; NIGAM, N. C. Calculation of Response Spectra from Strong-Motion Earthquake Records. Bulletin of the Seismological Society of America. Vol. 59, No 2, pp. 909-922. April, 1969.

KIUREGHIAN, A. A Structural response to stationary oscillation. Journal of Engineering Mechanics, 106(6), p.1195-1213, 1980.

KANAI, K. Semi-empirical formula for the seismic characteristic of the ground. Technical Report 35, Univ. Tokyo, Bull. Earthquake Res. Inst, 1957.

LAM, N. T. K; WILSON, J. L.; HUTCHINSON, G. L. Generation of synthetic earthquake accelerograms using seismological modelling: a review. Journal of Earthquake Engineering, Vol. 4, No. 3, p.321-354, 2000.

MOUTINHO, H. D. DA SILVA. Influência da duração dos registos sísmicos utilizados na análise do comportamento sísmico de estruturas. 95f. Dissertação de Mestrado - Universidade do Porto, Porto, Portugal, 2014.

NEWMARK, M, N.; HALL, J. W. Seismic design criteria for nuclear reactor facilities. Report no. 46, Building Practices for Disaster Mitigation, National Bureau of Standards, U.S. Department of Commerce, 1973.

NEWMARK, M, N.; HALL, J. W. Earthquake Spectra and Design - Earthquake Engineering Research Institute Monograph Series, v.3.Berkeley, California, 1982. 
ORRALA, F, H, W.; SANTOS, S, H.; SOUZA LIMA, S. Comparação de Resultados em Análise Sísmica -Métodos: Forças Horizontais Equivalentes, Espectro de Resposta e Histórico no Tempo. ABPE, v. 16 - n.2 - p.30-39- Jul./Dez, 2016.

PARISENTI, R. Estudo de análise dinâmica e métodos da NBR 15421 para projeto de edifícios submetidos a sismos. UFCS, Florianópolis, SC, 2011.

PEÑA, L, A, P. Análise dos efeitos provocados por abalos sísmicos em estruturas irregulares. Dissertação de mestrado. Universidade de Brasília, Brasília, DF, Abril, 2012.

RODRIGUES, R, M, R. Geração de acelerogramas sísmicos artificiais compatíveis com um espectro de resposta. Projeto de graduação-UFRJ-Escola Politécnica, Rio de Janeiro, 2012.

SHEIKH, M, N.; TSANG, H.; SABEGH, S.; ANBAZHAGAN, P. Evaluation of dumping modification factors for seismic response spectra. In S. Anderson (Eds.), Australian Earthquake Engineering Society Conference (pp. 1-13). Tasmania, 2013.

SORIANO, H, L. Introdução à dinâmica das estruturas. Rio de Janeiro: Elsevier, $1^{\text {a }}$ ed., 2014.

SANTOS, S. H. C., SOUZA LIMA, S. Estudos da Zonificação Sísmica Brasileira Integrada em um Contexto Sul-Americano. Anais das Jornadas Argentinas de Ingeniería Estructural. Buenos Aires, 2004.

SANTOS S. H. C.; SOUZA LIMA S. Subsídios para uma futura normalização brasileira para resistência anti-Sísmica das estruturas de concreto de edifícios - IBRACON, n.1, vol.1, 2005.

SANTOS, S. H. C.; SOUZA LIMA, S. Estimativa do Impacto no Projeto de Edificações da Proposta de Norma Brasileira de Sismos. Rio de Janeiro: Ibracon, 16p, 2006.

TAJIMI, H. A statiscal method of determining the maximum response of a building structure during an earthquake. Proc. $2^{\circ}$ WCEE, Vol.2, Tokyo e Kyoto, p. 781-798, 1960.

TRIFUNAC, M. D.; BRADY, A.G. A study on the duration of strong ground motion Bulletin Seismological Society of America, 65. P. 581-626, 1975.

UBC. 1997. Uniform Building Code. International Conference of Building Officials, Whittier, CA, 1994.

VANMARCKE, E,H. Properties of spectral moments with applications to random vibration, Journal of Engineering Mechanics, 98(2), pp. 425-446, 1972.

VANMARCKE, E, H. Structural response to earthquakes, C. Lominitz and E. Rosenblueth, eds., Seismic risk and engineering decisions, pp.287-337, Elsevier, New York, 1977.

VROCHIDOU, E.; ALVANITOPOULOS, P. F.; ANDREADIS, I.; ELENAS, A.; MALLOUSI, K. Synthesis of artificial spectrum-compatible seismic accelerograms. Department of Civil Engineering, Democritus University of Thrace, Xanthi, Greece, 2014. 